\title{
Genetic alterations affecting the genes encoding the enzymes of the kynurenine pathway and their association with human diseases
}

Fanni Boros ${ }^{\mathrm{a}}$, Zsuzsanna Bohár ${ }^{\mathrm{a}, \mathrm{b}}$, László Vécsei ${ }^{* a, b}$

aDepartment of Neurology, Albert Szent-Györgyi Clinical Center, Faculty of Medicine, University of Szeged, Szeged, Hungary

bMTA-SZTE Neuroscience Research Group, Szeged, Hungary

*Address correspondence to this author at the Department of Neurology, Albert SzentGyörgyi Medical Center, Faculty of Medicine, University of Szeged

P.O. Box: 427, H-6701, Szeged, Hungary

Tel/Fax: +36-62-545-351, +36-545-597

E-mail: vecsei.laszlo@med.u-szeged.hu 
Abstract: Tryptophan is metabolized primarily via the kynurenine pathway (KP), which involves several enzymes, including indoleamine 2,3-dioxygenase, tryptophan 2,3 dioxygenase (TDO), kynurenine aminotransferases (KATs), kynurenine monooxygenase (KMO) etc. The majority of metabolites are neuroactive: some of them, such as kynurenic acid, show neuroprotective effects, while others contribute to free radical production, leading to neurodegeneration. Imbalance of the pathway is assumed to contribute to the development of several neurodegenerative diseases, psychiatric disorders, migraine and multiple sclerosis.

Our aim was to summarize published data on genetic alterations of enzymes involved in the KP leading to disturbances of the pathway that can be related to different diseases.

To achieve this, a PubMed literature search was performed for publications on genetic alterations of the KP enzymes upto April 2017.

Several genetic alterations of the KP have been identified and have been proposed to be associated with diseases. Here we must emphasize that despite the large number of recognized genetic alterations, the number of firmly established causal relations with specific diseases is still small. The realization of this by those interested in the field is very important and finding such connections should be a major focus of related research.

Polymorphisms of the genes encoding the enzymes of the KP have been associated with autism, multiple sclerosis and schizophrenia, and were shown to affect the immune response of patients with bacterial meningitis, just to mention a few. 
To our knowledge, this is the first comprehensive review of the genetic alterations of the KP enzymes. We believe that the identification of genetic alterations underlying diseases has great value regarding both treatment and diagnostics in precision medicine, as this work can promote the understanding of pathological mechanisms, and might facilitate medicinal chemistry approaches to substitute missing components or correct the disturbed metabolite balance of KP.

Keywords: Tryptophan metabolism, kynurenines, metabolic enzymes, genetic alterations, polymorphism, metabolic disturbances 


\section{${ }^{1}$ Abbreviations}

$\mathrm{KP}$, kynurenine pathway; IDO, indoleamine 2,3-dioxygenase; TDO2, tryptophan 2,3 dioxygenase (gene); TDO, tryptophan 2,3 dioxygenase (enzyme); KAT, kynurenine aminotransferase; KMO, kynurenine monooxigenase; Trp, tryptophan; KYN, Lkynurenine; KYNA, kynurenic acid; 3-HK, 3-hydroxykynurenine; KYNU, kynureninase; AA, anthranilic acid; XA, xanthurenic acid; 3-HAA, 3-hydroxyanthranilate; ACMSD, aminocarboxymuconate-semialdehyde decarboxylase; QUIN, quinolinic acid; NAD+, nicotinamide-adenine-dinucleotide; GWAS, genome wide association studies; SNP, single nucleotide polymorphisms; LPS, lipopolysaccharides; TNF, tumor necrosis factor; IFN, interferon; MDD, major depressive disorder; CD, Crohn's disease; PDA, pancreatic ductal adenocarcinoma; TS, Tourette syndrome; ADHD, attention deficit hyperactivity disorder; GC, glucocorticoid; GRE, glucocorticoid responsive element; GR, glucocorticoid receptor; AADAT, aminoadipate aminotransferase; HD, Huntington's disease; AD, Alzheimer's disease; PD, Parkinson's disease; MS, multiple sclerosis; NMDS, N-methyl-D-aspartate; $\mathrm{BM}$, bacterial meningitis; MIP-1 $\alpha \mathrm{CCL} 3$, macrophage inflammatory protein 1-alpha; MIP1ßCCL4, macrophage inflammatory protein-1-beta; CSF, cerebrospinal fluid; HO-1, hemeoxygenase-1; NO-cGMP, nitric oxide - cyclic guanosine monophosphate; PFC, prefrontal cortex; PDS, postpartum depressive symptoms; 3-OHKYN, 3hydroxykynurenine; SHR, spontaneously hypertensive rat; 3-HAO, 3-hydroxyanthranilate 3,4-dioxygenase; COGA, Collaborative Study on the Genetics of Alcoholism; FCMTE, familial cortical myoclonic tremor and epilepsy; WGS, whole genome sequencing 


\section{Introduction}

\section{A general overview of the kynurenine pathway}

Most of the dietary tryptophan (Trp) not used for protein synthesis is metabolized via the kynurenine pathway (KP) [1]. The metabolites have a broad spectrum of biological actions, and have been connected to several diseases [2][3][4][5]. The KP is one branch of Trp metabolism; the other branch provides serotonin and melatonin (Fig. 1). The first step in the $\mathrm{KP}$ is the conversion of $\operatorname{Trp}$ to $\mathrm{N}$-formyl-L-kynurenine, by tryptophan 2,3-dioxygenase (TDO) or indoleamine 2,3-dioxygenase (IDO). Formamidase converts N-formyl-Lkynurenine to L-kynurenine (KYN), which can be further metabolized by three distinct pathways. Kynurenine aminotransferases (KATs) can convert KYN to kynurenic acid (KYNA), kynurenine 3-monooxygenase (KMO) can convert it to 3-hydroxykynurenine (3$\mathrm{HK}$ ), while kynureninase (KYNU) converts it to anthranilic acid (AA). 3-HK is either processed by KATs to xanthurenic acid (XA), or degraded to 3-hydroxyanthranilate (3HAA), which is metabolized by 3-hydroxyanthranilate 3,4-dioxygenase to form 2-amino-3carboxymuconate semialdehyde (ACMS). ACMS can be processed for either synthesis of 2-aminomuconate semialdehyde by aminocarboxymuconate-semialdehyde decarboxylase (ACMSD), or can form quinolinic acid (QUIN) by non-enzymatic cyclization. QUIN can be further metabolized for nicotinamide-adenine-dinucleotide (NAD+) synthesis, while 2aminomuconate semialdehyde can form picolinic acid or be subsequently processed to acetyl coenzyme A.

Intensive research is focused on the effects and alterations of the different KP metabolites and enzymes, however information regarding genetic alterations of this pathway is scarce. 
Our review aims to collect the data available on mutations and genetic alterations of the enzymes of the KP and reveal possible connections with various diseases. We will follow the metabolic route of Trp (Fig. 1) and collect the data available on the enzymes directly connected to the KP.

\section{Genetic alterations of the genes of kynurenine pathway enzymes and their association with diseases}

As a result of genome sequencing projects all genes encoding KP enzymes have been identified. Results of traditional human genetic analysis studies and targeted or non-targeted high throughput genome wide association (GWA) studies indicate that in seven genes which encode $\mathrm{KP}$ enzymes (IDO1/2, TDO2, KATII, KMO, KYNU, 3-HAO, ACMSD), alterations can be identified that might be causally linked to disease states. However, it has to be emphasized that the majority of the cases summarized here only indicate an association, and not a causal relationship, between the genetic alteration and the respective disease. Most of these alterations are single nucleotide polymorphisms (SNP) present in variable frequencies in different population groups. In some cases, the nucleotide changes are found within coding regions of KP genes and result in amino acid changes or early translational termination of the concerned protein product. Nucleotide alterations can also occur outside of exons. Polymorphisms affecting introns, promoters, enhancer and silencer regions can play a crucial role modulating gene expression both at the levels of transcription and translation. Single nucleotide changes in regulatory regions can result in elimination or formation of transcription factor binding sites and consequently these changes can alter the binding efficiency of DNA binding domains [6]. In a few cases nucleotide

alterations outside of exons affect gene function by changing intronic regions and thus modifying mRNA splicing and/or translation. It is worth noting that deletions or duplications have not been 
identified for any of the KP enzyme genes, which most probably reflects the essential functions this pathway performs.

Through the next sections we summarize data available on genetic alterations of genes of KP enzymes following the steps of the pathway. For each enzyme the description starts with a short introduction providing the enzyme function, protein size, gene designation, location, expression and/or other specifics.

\subsection{Indoleamine-2,3-dioxygenases}

IDO (EC 1.13.11.52) is the first enzyme of the KP. It catalyzes the conversion of Trp to Nformyl-L-kynurenine together with TDO. In humans, two IDO enzymes, IDO1 and IDO2 have been identified [7][8]. They are very similar in structure and function but are expressed in different patterns. IDO1 was first isolated from rabbit small intestine by Yamamoto and Hayaishi in 1967 [9].

It can be found ubiquitously in all tissues [10]. It is expressed in several types of immune cells, such as macrophages, monocytes, dendritic cells and microglia [11].It is a $45 \mathrm{kDa}$ protein of 403 amino acids. The gene encoding it is on the short arm of the 8th chromosome (8p11.21). Similarly, in mice it is also coded on chromosome 8, while in rats it localizes to chromosome 16. In humans, the transcribed region extends to 26516 nucleotides and consists of 10 exons. The expression of the gene is induced by lipopolysaccharides (LPS), cytokines, tumor necrosis factors (TNFs) and interferons (IFNs), especially IFN- $\gamma[12]$.

IDO1 is a heme enzyme located in the cytosol. It can convert various substrates, such as Ltryptophan, 5-hydroxy-tryptophan, serotonin and melatonin [13][14][15]. The crystal structure of the human enzyme was reported in 2006 by Sugimoto and colleagues [16]. 
The physiologic role of the IDO1 enzyme is to conduct immune activation in various states (Fig. 2). Upregulation of the enzyme leads to Trp depletion, which inhibits the proliferation of bacteria and other virulent agents. However, the mechanism of the decrease in Trp levels and the role that IDO plays in infectious states is controversial. Recently Badawy et al. argued that under specific conditions such as pregnancy Trp in fact is not depleted, rather its uptake by immune cells is increased greatly. Therefore IDO exerts its immune-regulating effect via the production of kynurenine metabolites [17].

Another mechanism by which IDO1 affects immune response is by inducing $\mathrm{T}$ cells to differentiate into $\mathrm{T}$ regulatory cells, thus blocking $\mathrm{T}$ cell responses [18]. This might explain the diverse expression of IDO1 throughout the human body. The gene is highly expressed in tissues that are highly exposed to antigens, such as mucosal surfaces of the lung and the intestinal system, lymph nodes and spleen. Antigen-presenting cells such as macrophages and dendritic cells also express IDO1. The anti-inflammatory effect of IDO1 activity contributes to maintain the immune homeostasis of different tissues. Thus it is conceivable that impairment in the activity of IDO1 can lead to the development of autoimmune diseases [19]. IDO1 could be involved in the process of immune editing, thus contributing to the immune escape of tumors [20]. Tumor derived factors have been reported to cause the differentation of dendritic cells with altered function. Immature dendritic cells in the tumor microenvironment show high expression of IDO1 [21]. The upregulation of IDO1 leads to a differentation shift towards regulatory $\mathrm{T}$ cells instead of effector T cells and natural killer cells, thus leading to immune tolerance [18]. High levels of IDO1 expression in placenta indicates the importance of the enzyme in the suppression of fetal rejection by suppressing the reactivity of maternal T cells [22]. 
Until the discovery of the second IDO enzyme, 'IDO' stood for what now is known as IDO1. By now a similar second enzyme has been recognized that is referred to as indoleamine 2,3dioxygenase-like protein, proto-indoleamine 2,3-dioxygenase, or most commonly indoleamine 2,3-dioxygenase-2, IDO-2 or IDO2.

IDO2 is structurally and functionally similar to IDO1, supporting the hypothesis that the two proteins are products of genes originated from duplication of a common ancestral IDO gene [23]. In all mammalian species two IDO genes (IDOI and 2) can be found. IDOI is thought to be specific to mammals, and the majority of lower vertebrate species possess only IDO2. However, IDOI has also been found in several fish and two turtle species This suggests that gene duplication occurred before the divergence of vertebrates, and IDOI was later lost in several lower vertebrate lineages [24]. This notion is further supported by the fact that in mammals IDOI and IDO2 are located next to each other - in case of humans on the short arm of chromosome 8 . Despite their similar structures [25], IDO2 is significantly bigger as it is 81778 nucleotides long and consists of 11 exons. The regulation of the two genes is in some way coordinated, which is supported by the observation that the expression of IDO2 was found to be significantly decreased in IDO1 knockout mice. An explanation for this finding could be the loss of IDO2 regulatory elements in consequence of removal of the IDOI gene region [7].

The product of the IDO2 gene is a 420 amino-acid protein, with a molecular weight of over 47 kDa. IDO2 and IDO1 proteins show $43 \%$ amino acid identity both in humans and mice [7]. Those residues which are critical for catalytic functions are conserved in the two proteins. In vitro studies suggest that IDO2 can convert the same substrates as IDO1 (L-tryptophan, D-tryptophan, 5-hydroxy-tryptamine, tryptamine and serotonin), however, the catabolic efficiency of IDO2 is much lower than that of IDO1 [26]. Interestingly, the enzymatic parameters of invertebrate IDOs' 
are similar to those of vertebrate IDO2. This suggests that the common ancestral IDO was similar to the present IDO2s in respect to their low catalytic efficiency [24]. In the distal heme pocket of IDO1 a Ser residue (distal-Ser, which corresponds to Ser167 of human IDO1) was found to be conserved in all IDO1 enzymes and also in a lizard (green anole, Anolis carolinensis) IDO2. In contrast with that in other IDO2 enzymes at this position a Thr (distal-Thr) residue is found [24]. Considering that IDO1 has a higher affinity to L-Trp than IDO2, and IDO2 of the green anole lizard shows similar enzymatic parameters to mammalian IDO1, this distal-Ser change seems to be crucial in the conversion of IDO1 from a low efficiency enzyme to a moderate efficiency one [24]. Besides the distal-Ser, another residue suspected to be - perhaps the most - critical residue for the high affinity for L-Trp is the distal-Tyr, which corresponds to Tyr126 in the human IDO1 [27].

IDO2 is expressed in the liver, kidney, epididymis and brain in mouse [7][28], and in the liver, kidney and specific tumors in humans [29].

\subsubsection{Diseases related to the genetic alterations of indoleamine 2,3-dioxygenase genes}

A large number of SNPs within the transcribed regions of IDO1 and IDO2 genes have been described. None of these are associated unequivocally with any disease, nonetheless linkage has been suggested between several SNPs and specific disease states (Fig. 1).

As IDO plays important roles in immune response, the effects of genetic changes in IDO genes were studied mostly in relation to diseases characterized by impaired immune function. It was suggested that in tumors elevated expression of IDO proteins can locally regulate the immune environment, enhancing immune tolerance and thus increasing the survival of cancer cells $[18][19][20][21]$. Similarly, moderation of immune functions can underlie the effects of IDO on 
allogenic fetal rejection [22][30][31][32]. Changes in IDO function have also been reported in neurodegenerative diseases [33].

One of the main inducers of IDO1 is IFN- $\alpha$, which is used in the treatment of patients suffering from chronic hepatitis C. Several earlier studies reported a decrease in blood Trp concentrations and increase of $\mathrm{KYN}$ in association with IFN- $\alpha$ induced depression, suggesting the role of IDO in the process [34][35].

In search of genetic variations that can be associated with the development of IFN- $\alpha$ provoked depressive symptoms, Galvão-de Almeida et al. investigated three SNPs of the IDO1 gene in 2011. However, none of the investigated polymorphisms (rs3824259, rs10089084, and rs35099072) were found to be associated with the disease [36]. The following year, Smith and colleagues investigated four SNPs (rs9657182, rs7820268, rs3739319 and rs6991530) of the gene with the same aim [11]. They found that one of the investigated SNPs had a significant effect on the evolution of depressive symptoms of IFN- $\alpha$ treated Caucasian patients with major depressive disorder (MDD) [11]. The SNP rs9657182 is a C/T nucleotide change in the promoter region of the gene. The nucleotide change has not been proven to alter any transcription binding site. Still, theoretically it could lead to altered gene function either alone, or via the effects of other polymorphism which may be associated with it [11].

In light of the normal physiological functions of the enzyme, the involvement of IDO1 in autoimmune diseases has been investigated. The induction of IDOI gene by pro-inflammatory stimuli results in Trp depletion and formation of KP metabolites, leading to the reduction of inflammation and the promotion of immune tolerance [37]. Consequently, impaired function of the enzyme might contribute to the development of autoimmune diseases. Guided by this notion the possible role of IDOI have been investigated in Crohn's disease (CD) and systemic sclerosis. 
Lee et al. [37] found that IDOI polymorphisms were rare among patients with CD. Out of the six investigated polymorphisms, they detected four in a group of clinically phenotyped CD patients (Table 1). Their results indicate that patients carrying specific IDO1 SNPs are more prone to extraintestinal manifestations, such as uveitis and arthritis. Their observation was that the presence of minor alleles was associated with a more severe disease course. Among carriers of the SNPs, a lower KYN level and KYN/Trp ratio could be detected as compared to the control group, leading to the assumption that the detected polymorphisms in CD patients result in impaired IDO1 function [37]. This study also included polymorphisms of the structurally and functionally similar IDO2 gene. It was found that although SNPs of the gene were common among a group of patients suffering from $\mathrm{CD}$, none of the investigated polymorphisms had effect on the severity of the disease [37].

IDO1 polymorphism can also be related to another autoimmune disease, systemic sclerosis. Tardito et al. investigated 5 SNPs of the IDOI gene, of which one (rs7820268, a C/T change in intron 5) was found to be present at a significantly higher frequency among systemic sclerosis patients compared to the non-patient group [38]. In the carriers of the minor allele a decrease in the CD8+ regulatory $\mathrm{T}$ cell suppressing capacity could be detected, suggesting an association between this gene variant and regulatory T cell function [38].

The involvement of IDO in immunological mechanisms gave ground to the notion that the enzyme could be involved in the suppression of fetal rejection. Published data on this issue are however controversial. An earlier study by Munn and collegues reported that inhibition of tryptophan catabolism via the implementation of the IDO - inhibitor 1-methyl-tryptophan resulted in fetal loss in a mice model. This is supposedly due to the lack of the $\mathrm{T}$ cell proliferation suppressing effect of cells catabolizing tryptophan. As 1-methyl-tryptophan is a known IDO 
inhibitor, it is likely that the above described fetal rejection was a consequence of maternal $\mathrm{T}$ cell proliferation due to the inhibition of IDO [22]. Interestingly, later Baban and colleagues found that IDO deficiency due to genetic manipulation did not affect pregnancy success in mice. They hypothesized that in IDO deficient mice IDO-independent mechanisms - such as the activation of another key enzyme of the KP, TDO - compensate for the lack of the enzyme. This notion was strengthened by the finding that assessment of the IDO inhibitor 1-methyl-tryptophan in IDO deficient animals did not cause changes in pregnancy outcomes on contrary to IDO - sufficient mice pregnancies [39]. Another interesting question that still needs to be elucidated is the question of the decrease in Trp level during pregnancy. Badawy and colleagues hypothesized that the decrease in the level of $\operatorname{Trp}$ is not due to the depletion of the amino acid but is the consequence of its augmented utilization by the cells of the immune system - similarly as in the case of infection. They claim that during pregnancy increased availability of maternal Trp is needed to fulfill the increased demand for protein synthesis by the fetus and the pregnant mother. Elevated maternal free plasma Trp is then utilized in the KP, ensuring the production of immunosuppressive kynurenine metabolites which support the maintenance of the balance of tolerance and immunity. Therefore immunosuppression is not achieved by Trp depletion itself, but by the increased utilization of the amino acid [17].

The findings of animal studies raised the question of the role of IDO during human pregnancy. One of the most serious and life-threatening conditions during human pregnancy is preeclampsia. Its etiology has not been fully understood so far, but several environmental and genetic factors have been proposed to contribute to its evolvement. The findings that in the placenta of pre-eclamptic women IDOI expression is reduced and a correlation can be observed between the severity of the illness and the activity of the enzyme [31][32] turned the attention to 
the KP. Taking this into consideration, Nishizawa et al. investigated the possible association of 19 SNPs of the IDO gene with pre-eclampsia [40]. However, none of the studied polymorphisms, each within the coding region of the gene, was found to be associated. The only genetic alteration that might be linked to the condition based upon this study was a four nucleotide deletion within the intronic region of the gene; however, it is unclear how this change affects expression of the gene, if at all [40]. 
Table 1. Genetic alterations affecting the enzymes of the kynurenine pathway

\begin{tabular}{|c|c|c|c|c|c|c|}
\hline Gene & rs number & $\begin{array}{c}\text { Base change/amino acid } \\
\text { change }\end{array}$ & $\begin{array}{c}\text { Localization in } \\
\text { the gene }\end{array}$ & $\begin{array}{l}\text { Change in } \\
\text { enzyme } \\
\text { function }\end{array}$ & Related disease & Reference \\
\hline \multirow{6}{*}{ IDOI } & rs9657182 & $\mathrm{C}>\mathrm{T}(\mathrm{fwd})$ & promoter region & & $\begin{array}{l}\text { IFN- } \alpha \text { induced } \\
\text { depressive symptoms } \\
\text { in patients with } \\
\text { Hepatitis C }\end{array}$ & {$[11]$} \\
\hline & rs35059413 & $\mathrm{C}>\mathrm{T}(\mathrm{rev}) / \mathrm{Ala} 4 \mathrm{Thr}$ & & \multirow{4}{*}{$\begin{array}{l}\text { diminishment in } \\
\text { enzyme activity }\end{array}$} & \multirow{4}{*}{$\begin{array}{l}\text { Severity of Crohn's } \\
\text { disease }\end{array}$} & \multirow{4}{*}[37]{} \\
\hline & rs35099072 & $\mathrm{C}>\mathrm{T}$ (rev)/Arg77His & & & & \\
\hline & & $\mathrm{C}>\mathrm{A}$ & exon 7 & & & \\
\hline & & 9 base pair deletion & exon 7 & & & \\
\hline & rs7820268 & $C>T(f w d)$ & intron 5 & $\begin{array}{l}\text { Treg suppression } \\
\text { is diminished }\end{array}$ & systemic sclerosis & {$[38]$} \\
\hline \multirow[b]{2}{*}{ IDO2 } & rs2929115 & $\mathrm{C}>\mathrm{T}$ (rev) & \multirow{2}{*}{$\begin{array}{l}\text { non-conserved } \\
\text { region between } \\
26 \mathrm{~kb} \text { and } 28 \mathrm{~kb} \\
\text { downstream } \\
\text { from the 3' end } \\
\end{array}$} & & \multirow[b]{2}{*}{$\begin{array}{l}\text { Citalopram } \\
\text { responsiveness in } \\
\text { major depressive } \\
\text { disorder }\end{array}$} & \multirow[b]{2}{*}[45]{} \\
\hline & rs2929116 & $\mathrm{G}>\mathrm{A}$ & & & & \\
\hline \multirow{5}{*}{ TDO2 } & & $\mathrm{G}>\mathrm{T}$ & \multirow{2}{*}{ intron 6} & & \multirow{2}{*}{ Tourette syndrome } & \multirow{2}{*}{ [49] } \\
\hline & & $\mathrm{G}>\mathrm{A}$ & & & & \\
\hline & rs3755910 & $A>C(f w d)$ & promoter region & & Autism & {$[67]$} \\
\hline & & $\begin{array}{l}\text { c.491dup/premature stop } \\
\text { codon }\end{array}$ & & $\begin{array}{l}\text { leads to a } \\
\text { truncated protein } \\
\text { (premature stop } \\
\text { codon) } \\
\end{array}$ & \multirow[t]{2}{*}{ Hyperserotoninemia } & \multirow[t]{2}{*}[68]{} \\
\hline & & $\mathrm{G}>\mathrm{C} /$ Met108Ile & & $\begin{array}{l}\text { accelerated } \\
\text { degradation of } \\
\text { the enzyme }\end{array}$ & & \\
\hline$A A D A T$ & rs 1480544 & $\mathrm{C}>\mathrm{T}(\mathrm{fwd})$ & $\begin{array}{l}\text { exonic splicing } \\
\text { silencer }\end{array}$ & $\begin{array}{l}\text { elevated enzyme } \\
\text { production }\end{array}$ & $\begin{array}{l}\text { Immune response in } \\
\text { bacterial meningitis }\end{array}$ & {$[78][81][80]$} \\
\hline \multirow{4}{*}{$K M O$} & rs 1053230 & $\begin{array}{l}\mathrm{A}>\mathrm{G}(\mathrm{rev}) ; \mathrm{C}>\mathrm{T}(\mathrm{fwd}) \\
/ \operatorname{Arg} 452 \mathrm{Cys}\end{array}$ & exon 15 & & $\begin{array}{l}\text { schizophrenia, bipolar } \\
\text { disorder, PDS }\end{array}$ & {$[93][94][96][97][86]$} \\
\hline & rs2275163 & $C>T(f w d)$ & intronic region & & schizophrenia & {$[93][90][94]$} \\
\hline & rs1053221 & $\mathrm{A}>\mathrm{G}(\mathrm{rev})$ & \multirow{2}{*}{ utr region } & & \multirow{2}{*}{ Sclerosis multiplex } & \multirow{2}{*}[99]{} \\
\hline & rs1053183 & $\mathrm{C}>\mathrm{T}$ (rev) & & & & \\
\hline \multirow{3}{*}{$K Y N U$} & rs606231307 & $\mathrm{A}>\mathrm{G}(\mathrm{fwd}) / \mathrm{Thr} 198 \mathrm{Ala}$ & exon 7 & & Xanthurenic aciduria & {$[103]$} \\
\hline & rs9013 & $\mathrm{A}>\mathrm{G}(\mathrm{fwd}) / \mathrm{Lys} 412 \mathrm{Glu}$ & & unknown & \multirow[b]{2}{*}{ Essential hypertension } & {$[106]$} \\
\hline & rs2304705 & $\mathrm{G}>\mathrm{A}(\mathrm{fwd}) / \operatorname{Arg} 188 \mathrm{Gln}$ & & $\begin{array}{l}\text { enzyme activity } \\
\text { reduced by } 50 \%\end{array}$ & & {$[107]$} \\
\hline \multirow{7}{*}{ HAAO } & rs375554 & $\mathrm{A}>\mathrm{G}(\mathrm{fwd})$ & & & \multirow{6}{*}{$\begin{array}{l}\text { Alcohol dependence } \\
\text { accompanied with } \\
\text { conduct disorder or } \\
\text { suicide attempts }\end{array}$} & \multirow{6}{*}[109]{} \\
\hline & rs13027051 & $\mathrm{C}>\mathrm{T}(\mathrm{fwd})$ & \multirow{5}{*}{ intronic region } & & & \\
\hline & rs2374442 & $A>G(f w d)$ & & & & \\
\hline & rs3816184 & $\mathrm{A}>\mathrm{G}(\mathrm{fwd})$ & & & & \\
\hline & rs3816182 & $A>C(f w d)$ & & & & \\
\hline & rs 737148 & $\mathrm{~A}>\mathrm{G}(\mathrm{rev})$ & & & & \\
\hline & rs3816183 & $\mathrm{C}>\mathrm{T} / \mathrm{Ile} 37 \mathrm{Val}$ & & & Hypospadiasis & {$[110]$} \\
\hline \multirow[t]{2}{*}{$A C M S D$} & & $\begin{array}{l}\mathrm{G}>\mathrm{A} / \text { premature stop } \\
\text { codon }\end{array}$ & & \begin{tabular}{|l|} 
leads to a \\
truncated protein \\
(premature stop \\
codon) \\
\end{tabular} & $\begin{array}{l}\text { Familial cortical } \\
\text { myoclonic tremor and } \\
\text { epilepsy }\end{array}$ & {$[113]$} \\
\hline & rs6710823 & $A>G(f w d)$ & & & Parkinson's disease & {$[115]$} \\
\hline
\end{tabular}

fwd/rev: allele reported to forward/reverse orientation to genome 
The controversial findings of animal experiments raised the question of the role of the enzyme in fetal rejection in humans. However, the examination of 10 SNPs among Iranian women suffering from recurrent spontaneous abortion revealed no linkage between the investigated polymorphisms and the disease [41].

Following the observation that IDO1 helps tumor cells to survive and proliferate by facilitating a local immunotolerant environment [20], Witkiewicz et al. investigated two polymorphisms of the functionally similar IDO2 gene in patients with pancreatic ductal adenocarcinomas (PDAs) [42]. The two polymorphisms they studied show high prevalence in the population and result in either complete or very severe decrease $(90 \%)$ in the catalytic activity of IDO2 [8]. Based on a relatively small patient cohort in which the frequencies of these polymorphisms were comparable to that of the control group, they did not find any link between IDO2 genotype and PDA [42]. In other words, these SNPs do not increase the risk of PDA development. On the other hand, their results show that the majority of investigated patients had at least one wild-type or functioning allele. This observation gives support to the argument that the IDO inhibitor D-1-methyltryptophan might be useful in treatment of PDA due to the inhibition of the anti-inflammatory effects of IDO [42]. However, this treatment should be preceded by genetic investigation of the patients to identify those with at least one active IDO2 allele. Furthermore, selectivity of the drug should also be taken into account. The question concerning the most potent IDO2 inhibitor remains to be answered. Several studies have found that $L-1$ - methyl-tryptophan, the levo stereosisomer of D-1-methyl-tryptophan has a more effective inhibitory effect of IDO2 [43] [44].

Besides the above discussed diseases, the relation of the IDO genes and a common psychiatric disorder has also been examined. Cutler et al. studied the potential role for IDO1 and IDO2 in MDD treatment outcome [45]. They found that two polymorphisms of the IDO2 gene have effect 
on the responsiveness to citalopram treatment in patients with MDD. The two polymorphisms (rs2929115 and rs2929116) should be considered as one marker, because they were found to be in very high linkage disequilibrium [45]. Both are in a non-conserved region between $26 \mathrm{~kb}$ and $28 \mathrm{~kb}$ downstream from the 3 ' end of IDO2. They are near to transcriptional binding sites and are surrounded by two histone modification sites, but the functional consequences of these polymorphisms have not been elucidated yet [46].

\subsection{Tryptophan 2,3-dioxygenase}

TDO enzyme (EC 1.13.11.11) is a $47 \mathrm{kDa}$ protein of 403 amino acids. The encoding gene, TDO2 is rather large, consisting of 65669 nucleotides and containing 12 exons. It is located on the long arm of chromosome 4 in humans, while it is located on chromosome 3 in mice and on chromosome 2 in rats.

TDO is a homotetrameric heme enzyme that catabolizes the conversion of L-Trp to N-formyl-Lkynurenine, which is a rate limiting step of the KP. Via this conversion the enzyme also modulates serotonin levels by reducing the amount of Trp available for synthesis of the neurotransmitter. TDO is found mainly in the liver, thus modulating the available quantity of Trp throughout the body. The expression of TDO is induced by glucocorticoid hormones and the enzyme is also regulated by the availability of its substrate, L-Trp [47].

As the serotoninergic system is involved in the modulation of mood, sleep, aggression and other states, TDO2 is a target of investigations in relation to psychiatric and neurological diseases characterized by changes in the circadian rhythm, behavior and the reward system.

\subsubsection{Diseases related to the genetic alterations of Tryptophan 2,3-dioxygenase gene}


A study by Comings et al. showed significant decrease in the Trp levels and in the serotonin/platelet ratio of patients with Tourette syndrome (TS) [48]. A decline in the serotonin/platelet ratio was also detected in the parents of the patients. Similar metabolic changes were reported among patients with attention deficit hyperactivity disorder (ADHD) and their parents. The similar findings suggest the existence of a link between TS and ADHD [48]. The observed alterations of serotonin level and the inheritance pattern of TS indicate the possible underlying genetic alteration: variants of the TDO2 gene are possible candidates contributing to these disorders. Mutations causing higher expression level, or leading to an enzyme that is more prone to induction can be a culprit behind the excessive $\mathrm{N}$-formyl-L-kynurenine formation, thus diverting Trp from serotonin synthesis [48].

Further studies by Comings et al. showed a significant association between two intronic TDO2 polymorphisms (a G to T and a $\mathrm{G}$ to A change) and TS (Fig. 1). One of these SNPs (the G to A change) was found to be significantly associated with altered platelet serotonin levels as well [49].

In a more recent study from the same laboratory [50] 20 genes were investigated in patients with ADHD. As this disorder is likely to be multigenic, caused by additive effects of several genes [51], the 20 studied genes were grouped into three sets. Those with activities related to dopaminergic neurotransmission formed one group (6 of the investigated genes), those related to the noradrenergic neurotransmission another group (7 of the genes) and the remaining 6 genes each involved in serotoninergic neurotransmission formed the third group. One SNP was investigated for each gene in the study. For TDO2, it was a $\mathrm{G}$ to A nucleotide change in the intronic region of the gene. According to the results noradrenergic genes were more likely to contribute to the ADHD phenotype than genes belonging to the other two groups [50]. 
Nonetheless this finding does not exclude the possibility that genetic alterations of the TDO2 gene affect the manifestation of ADHD.

The involvement of serotoninergic neurotransmission in the function of the reward system underpins the search for possible associations of specific changes in TDO2 with drug abuse. Previous findings show an increase in brain serotonin levels due to nicotine exposure, and an increase in the level of the neurotransmitter during withdrawal [52][53]. Clinical data also showed beneficial effects of the serotonin re-uptake inhibitor Fluoxetine during the decrease of nicotine intake of smokers. By applying the medication, weight gain, a common consequence of increased food intake frequently accompanying cessation of smoking, could be decreased [54]. Based on this notion, it is hypothesized that impairment in serotoninergic neurotransmission contributes to the mood and appetite disturbances associated with nicotine withdrawal and therefore might have a role in drug dependence [49].

In another study Comings et al. [49] investigated the association of drug dependence and two intronic polymorphisms of the TDO2 gene. Both of these SNPs are in intron 6 and potentially cause alteration in a binding site of the YY-1 transcription factor [6]. One SNP is a G to T change at position 666, the other is a $\mathrm{G}$ to A change at position 663 . Neither was, however, found to be associated with drug dependence [49].

Another unfortunately commonly used and abused drug in our society is alcohol. Changes in serotoninergic neurotransmission have been reported during acute ethanol administration. Shortly after alcohol intake, an induction of serotonin biosynthesis can be observed [55][56]. After 5-8 hours, this is followed by TDO stimulation, which causes a decrease in the serotonin level and simultaneously increases KYN production [56][57][58]. The gene activation is believed to be transcriptionally mediated by glucocorticoids (GC). The promoter region of the human TDO2 
gene contains four functional glucocorticoid responsive elements (GRE) [59], which can serve as target sites in this activation. Soichot et al. aimed to identify SNPs in the GREs of the TDO2 promoter region that cause alterations in the transcription regulatory effects of GCs. They investigated the effects of 12 SNPs of the TDO2 promoter region, three of which were in putative GREs. In in vitro experiments under basal conditions (without glucocorticoid receptor (GR) overexpression, or Dexamethasone exposure) the studied nucleotide changes did not cause significant differences in promoter activity. However, upon GR over-expression without, or combined with Dexamethasone exposure, a statistically significant difference in promoter activity could be observed [59]. The data suggest that these TDO2 polymorphisms exert their effects only during TDO2 gene activation. Since a similar pattern of gene activation changes has been observed also in the case of a polymorphism not located in a known GRE, this indicates the possibility of another, yet unexplored response element [59]. However, in contrast with results obtained in vitro, in vivo measurements did not reveal association between the polymorphisms and plasma KYN/Trp ratio, an indicator of TDO/IDO enzyme activity [59] (Table 2).

The findings regarding the effects of genetic alterations in the TDO2 promoter region serve as good examples to highlight the importance of SNPs localized outside coding regions and splicing sites. In this respect it should be emphasized that genetic alterations might have impact not only by changing protein structure and/or function. Polymorphisms affecting regulatory regions such as the promoter can lead to the elimination or the formation of transcription binding sites, thus altering the binding efficiency of DNA binding domains [6]. 
Table 2 .

Identified SNPs in the human TDO2 promoter region

\begin{tabular}{|ll|}
\hline rs number & base change \\
\hline rs3755908 & $1605 \mathrm{~T}>\mathrm{C}$ \\
\hline rs3775085 & $1532 \mathrm{~A}>\mathrm{C}$ \\
\hline rs17033763 & $1471 \mathrm{G}>\mathrm{A}$ \\
\hline Unknown & $1342 \mathrm{C}>\mathrm{A}$ \\
\hline rs3836580 & $1248 \quad 1247$ InsA \\
\hline rs10857287 & $1131 \mathrm{~A}>\mathrm{G}$ \\
\hline rs11935082 & 1059T $>\mathrm{C}$ \\
\hline rs60426490 & 935_933delGTT \\
\hline Unknown & 769T $>\mathrm{G}$ \\
\hline rs3775086 & 722T $>\mathrm{A}$ \\
\hline rs3755909 & 455C $>\mathrm{T}$ \\
\hline s3755910 & 311C $>\mathrm{A}$ \\
\hline
\end{tabular}

Besides ADHD, TS and drug dependence, impairment in serotoninergic neurotransmission has been reported in autism as well. In patients suffering from the disease impairments in serotonin synthesis in the brain have been detected [60][61], and more than a third of patients seems to have elevated platelet serotonin levels [62]. The involvement of serotoninergic neurotransmission in the disease is also supported by studies showing that Trp depletion exacerbates symptoms in patients with autistic disorder [63][64]. Family and twin studies suggest a genetically determined predisposition to autism [65][66]. In light of these data, genes involved in serotonin metabolism are potential disease-causing factors. Since investigation of genetic alterations of the serotonin transporter gene did not result in an unambiguous answer [49], TDO2 arose as a potential candidate. Nabi et al. studied the presence of five TDO2 polymorphisms in families with members diagnosed with autism using transmission disequilibrium test [67]. Four polymorphisms included in the study are located in the promoter region of the gene, while one is at the 3' slice region of exon 11 . For one of the investigated nucleotide changes affecting the promoter region (rs3755910, an A/C change) a significant difference was found in the transmission to autistic 
subjects. The more frequent $\mathrm{C}$ allele of the polymorphism was preferentially transmitted to family members with autistic disorders. This strongly suggests that though this SNP is not likely to be a risk factor in autism, it is in a strong linkage disequilibrium with another polymorphism associated with the disease that is so far unknown [67].

The role of TDO in Trp metabolism gives ground to the investigation of the enzyme not only in psychiatric disorders but in other Trp and serotonine related diseases. In a recent study Ferreira et al. reported a peculiar situation, in which a single patient was diagnosed with chronic hypertryptophanemia and hyperserotoninemia [68]. Sequencing of the TDO2 gene revealed the patient to be compound heterozygous for the c.491dup and c.324G $>$ C variant of the TDO2 gene. The variant c.491dup (paternally inherited in the patient) causes a premature stop codon leading to the formation of a truncated protein, which is $43 \%$ of the normal length of TDO [68]. The c.324G $>$ C gene variant (which was maternally inherited in this patient) leads to methionine to isoleucine change at the 108. amino acid of the protein. The expression level of the c.491dup variant mRNA was found to be similar to the wild type, as the transcription of the gene was not affected by this alteration. In vitro studies however showed that the truncated protein changed the catabolic activity of the enzyme [68].

The c.324G $>\mathrm{C}$ base change affects a specific site of the enzyme. Under normal conditions TDO has a short half-life which is regulated by the status of a non-catalytic Trp binding site. The enzyme activity and turnover depends on the occupancy of this binding site: when it is occupied it increases the catalytic activity, while when it is empty, it serves as a degradation signal [69]. The Met/lle change resulting from the $\mathrm{c} \cdot 324 \mathrm{G}>\mathrm{C}$ base change affects the formation of this noncatalytic Trp binding site. According to in vitro data the activity of the enzyme is not affected [68], however, as a result of the amino acid change the binding affinity of the enzyme to its 
substrate is significantly decreased, and consequently the degradation rate of the enzyme is increased [68]. Thus, the c.324G $>\mathrm{C}$ genetic alteration of the gene causes the accelerated degradation of the TDO enzyme [68]. In summary, according to Ferreira et al., the chronic hypertryptophanemia and hyperserotoninemia observed in this patient is a consequence of the combination of altered catabolic activity and accelerated degradation of TDO, both caused by single nucleotide genetic alteration of the TDO2 gene [68].

\subsection{Kynurenine formamidase}

Kynurenine formamidase/arylformamidase (EC 3.5.1.9) converts N-formyl-L-kynurenine to KYN. It is coded on chromosome 17, 10, 11 in humans, rats and mice, respectively ( $A F M I D$ gene). Little is known about this enzyme - it seems that it has two isoforms in humans, one a 301 AA and one a 303 AA form, and it is expressed in various tissues, but most abundant in liver and kidney [70]. To our knowledge, no specific alterations in the AFMID gene were directly correlated with any human disease.

\subsection{Kynurenine aminotransferases}

In human brain four KATs have been identified which catalyze KYNA synthesis (EC 2.6.1.7) [71]. These are glutamine transaminase K/cysteine conjugate beta-lyase 1 (KATI, EC 4.4.1.13), aminoadipate aminotransferase (KATII, EC 2.6.1.39), glutamine transaminase L/cysteine conjugate beta-lyase 2 (KATIII, EC 4.4.1.13), and glutamic-oxaloacetic transaminase 2/mitochondrial aspartate aminotransferase (KATIV EC 2.6.1.1) [71]. They are multifunctional enzymes with broad substrate specificity, and function as homodimers with pyridoxal 5'phosphate as cofactor [71]. Besides the irreversible transamination of KYN to KYNA, they can catalyze the conversion of 3-HK to XA. In human brain, the principal enzyme responsible for the formation of KYNA is KAT II [72][73], therefore we will focus on this enzyme below. 
The KATII enzyme is a $47 \mathrm{kDa}$ protein consisting of 425 amino acids. The aminoadipate aminotransferase (AADAT) gene encoding this protein is located on the long arm of chromosome 4 in humans. It spans 31478 nucleotides and contains 18 exons. The gene is located on chromosome 8 in mice and on chromosome 19 in rats.

In vitro studies show that KATII enzyme has very broad substrate specificity. Besides catalyzing the formation of KYNA from KYN, it catalyzes the transamination of $\alpha$-aminoadipate and several other amino acids [74].

Alterations in the level of KYNA have been reported in several neurological diseases, such as Huntington's disease (HD), Alzheimer's disease (AD) [75] Parkinson's disease (PD) [76] multiple sclerosis (MS) [77] and AIDS dementia. KYNA is a modulator of glutamatergic neurotransmission via its N-methyl-D-aspartate (NMDA) receptor antagonist effect and has neuroprotective features [74][75][76]. According to this, impairment in the synthesis of KYNA could thus contribute to the development of neurodegenerative diseases. Since KATII plays a crucial role in the formation of this neuroprotective agent, the enzyme has been mainly investigated in disorders related to neuronal damage.

\subsubsection{Diseases related to the genetic alterations of aminoadipate aminotransferase gene}

Predicated on previous studies reporting the involvement of the KP in inflammatory diseases, de Souza et al. [78] searched for genetic alterations affecting KP enzymes in patients with bacterial meningitis (BM) (Fig. 1). Two polymorphisms of the AADAT gene were included in the study: rs17852900, causing a $\mathrm{G}$ to $\mathrm{T}$ change, and rs1480544, a $\mathrm{C} / \mathrm{T}$ change. The rs 1480544 polymorphism affects a putative regulatory element, an exonic splicing silencer - consequently it is thought to affect mRNA and peptide synthesis [79]. This polymorphism was found to be significantly more frequent in patients with $\mathrm{BM}$ considering both allelic and genotypic 
frequencies. In patients homozygous for the minor allele (TT), a significant decrease was detected in the levels of tumor-necrosis factor alpha (TNF- $\alpha$ ), interleukin 1 beta (IL1- $\beta$ ), macrophage inflammatory protein 1-alpha (MIP-1 $\alpha$ CCL3), macrophage inflammatory protein-1beta (MIP-1ßCCL4) and in the number of cells counted in the collected cerebrospinal fluid (CSF), and an increase in immunoglobulin G (IgG) levels. These findings suggest that the rs 1480544 polymorphism causes impairment in the immune response against virulent agents. The $\mathrm{C} / \mathrm{T}$ change in the exonic splicing silencer region of the gene supposedly affects the expression of inflammatory markers such as TNF- $\alpha$, IL1- $\beta$, MIP1 $\alpha$ CCL3 and MIP1 $\beta C C L 4$, and causes impairment in the recruitment of leukocytes. The elevation of IgG levels in patients with TT genotype suggests the influence of KYNA on immunoglobulin production, the mechanism of which, however, is so far unknown [78].

In addition to de Souza's findings, Coutinho et al. found elevated KYNA levels in the CSF of patients with BM carrying the $\mathrm{T}$ allele of the rs1480544 polymorphism [80]. A tendency for increase in KYNA level was also noted among CT genotype patients suffering from acute BM. These results give support to the assumption that this particular SNP leads to an increase in the amount of $A A D A T$ mRNA and subsequently causes enhancement of KATII enzyme synthesis [80].

In 2015 Fontes et al. searched for possible combinations of genotypes that could have an effect on the course of BM [81]. Based on previous findings of de Souza et al., they examined the occurrence of the rs $1480544 \mathrm{C} / \mathrm{T}$ variant of the $A A D A T$ gene in combination with polymorphisms of genes previously reported to cause impairment in DNA repair mechanisms, such as Asn148Glu of Apurinic/Apyrimidinic Endodeoxyribonuclease (APEX1), Ser326Cys of 8Oxoguanine DNA Glycosylase $(O G G 1)$ and Val762Al of Poly(ADP-Ribose) Polymerase 1 
$(P A R P 1)$. Results of gene interaction analysis showed a statistically significant combined occurrence of these genetic alterations among BM patients, suggesting the possibility of synergism existing between different pathways involving these genes in the development and course of BM [81].

\subsection{Kynurenine 3-monooxygenase}

KMO (Kynurenine 3-monooxygenase, also known as Kynurenine 3-Hydroxylase) (EC 1.14.13.9) is a $55 \mathrm{kDa}$ molecular mass protein of more than 480 amino acids. In the KP it catalyzes the KYN to 3-HK conversion. It is a mitochondrial flavoprotein, utilizing $\mathrm{O}_{2}$ and NADPH for the catalyzed reaction [82]. Downstream of KMO in the pathway, 3-HAA and QUIN are synthesized. Elevated levels of 3-HK, which is an endogenous oxidative stress generator, have been reported in several neurodegenerative disorders [77][83]. In contrast to 3-HK, 3-HAA may be neuroprotective due to its hemeoxygenase-1 (HO-1) inducing effects in astrocytes. $\mathrm{HO}-1$ is an antioxidant enzyme with anti-inflammatory and cytoprotective features [84]. In the central nervous system QUIN acts as a neurotoxin, via activating NMDA receptors, thus creating an enormous calcium influx into astrocytes and neurons, causing cell damage [85]. QUIN has an effect on the appearance of depressive symptoms by inducing the nitric oxide - cyclic guanosine monophosphate (NO-cGMP) pathway, promoting oxidative stress and interfering with the translation of brain derived neurotrophic factor [86].

The $K M O$ gene in humans is localized on the long arm of chromosome 1. It is 63759 nucleotides long and consist of 17 exons. Kmo is coded on chromosome 13 in rat and on chromosome 1 in mice.

\subsubsection{Diseases related to the genetic alterations of kynurenine 3-monooxygenase gene}


Several studies have reported linkage between genetic loci on the long arm of chromosome 1 and psychiatric disorders with psychotic symptoms, such as bipolar disorder and schizophrenia (Fig.1) [87][88][89]. Since the $K M O$ gene is located at that locus, it became a candidate in the eye of researchers looking for a predisposing factor for the diseases mentioned above. Results obtained from postmortem tissue analysis of schizophrenic patients support this suspicion. A significant and correlated decrease in the expression of the KMO gene and the activity of the KMO enzyme was found in brain tissues obtained from schizophrenia patients compared to control patients [90]. Data concerning association between genetic alterations of the $K M O$ gene and schizophrenia are, however, inconclusive, as no linkage could be identified between the presence of any one of 15 studied polymorphic forms of the gene in Scandinavian patients [91].

Among Japanese patients the association of the rs2275163 (a C/T change) polymorphism with schizophrenia was found to be significant both by single marker comparisons and haplotype analysis. However, among a second, independent sample the significance of haplotype association could not be reproduced [92].

Results are similar regarding the rs2275163 polymorphism among Russian patients - no significant difference was found between the frequency of the minor allele in patients and in healthy controls [93]. However, this study revealed a significant intergroup difference concerning another SNP, rs 1053230.

The polymorphism is an $\mathrm{A} / \mathrm{G}$ base change in exon 15 of the $K M O$ gene, causing an arginine to cysteine change at the $452^{\text {nd }}$ amino acid of the enzyme (in fact the nucleotide change in the coding sequence is $\mathrm{C} / \mathrm{T}$, however the database records the SNP in reverse orientation). The frequency of the homozygous minor GG genotype of rs1053230 polymorphism was significantly higher among patients compared to the control group. Interestingly, though the minor allele (T) 
of the other studied SNP rs2275163 did not prove to be a risk factor alone, in combination with the GG genotype of rs1053230 it seemed to increase the risk of schizophrenia. The risk of schizophrenia among subjects with the GG genotype of the rs1053230 locus combined with at least one minor allele of the SNP rs2275163 (either in the form of a CT or TT genotype) was shown to be twice as high as in subjects with a different allele combination [93]. Though data concerning the association of polymorphism rs2275163 with the incidence of schizophrenia are equivocal, it is likely that is has an impact on the expression of the $K M O$ gene. In schizophrenic patients with at least one minor allele of the single nucleotide change rs2275163, a slightly higher $K M O$ mRNA level could be detected compared to those who had CC genotype [90].

Patients homozygous for the major allele of rs2275163 (CC genotype) were found to perform more poorly in neurocognitive tasks such as predictive pursuit and visuospatial working memory than members of the CT genotype subgroup [94][90]. However, when comparing patients with CC and TT genotypes, the difference was not significant [90]. It should be mentioned here that among healthy subjects with TT or CT genotypes inequality could also be observed in cognitive performance, though the difference was again not significant [94].

Effects upon cognitive functions were also reported for homozygous carriers of the SNP rs 1053230 major allele. Similarly to rs2275163, individuals of CC genotype regarding the SNP rs 1053230 reached lower composite scores compared to the CT or TT genotype [94].

Based on the fact that elevated KYNA levels have been reported in the CSF of schizophrenic patients and $\mathrm{KMO}$ is in charge of the formation of $3-\mathrm{HK}$, thus decreasing the amount of KYN available for KYNA synthesis, changes in KYNA levels can serve as an indirect indicator of KMO activity [95]. Andreassen et al. found that both in control and schizophrenic patients the 
presence of the T allele of the SNP rs1053230 (indicated in forward orientation) was associated with a $45 \%$ increase of KYNA level in the CSF [96].

Besides schizophrenia, KMO has been investigated in bipolar disorder and depression as well. A decrease in $K M O$ gene expression was detected in the prefrontal cortex (PFC) of bipolar disorder patients with psychotic features compared to patients without psychotic features [97]. This observation is in accord with results of postmortem brain tissue analysis of schizophrenic patients. However, in contrast with results of studies carried out among schizophrenic patients, the $\mathrm{C}$ allele of the rs1053230 (forward) polymorphism was found to be more common among bipolar disorder patients with psychotic features. The major allele was also associated with higher KYNA level in the CSF of bipolar patients, accompanied with a reduction in KMO activity. HapMap3 project data analysis revealed that this allele is also associated with a reduction in the $K M O$ expression detected in lymphoblastoid cell lines. The link between the $\mathrm{C}$ allele of the rs 1053230 SNP and $K M O$ gene expression can also be observed in epileptic patients [97].

The same polymorphism of $K M O$ (rs 1053230) was also found to be significantly associated with postpartum depressive symptoms (PDS) in Chinese women. AG genotype women with PDS were found to have significantly higher serum $3-\mathrm{HK}$ concentration and $3-\mathrm{HK} / \mathrm{KYN}$ ratio compared to those with the GG genotype. These findings suggest the possibility of the rs1053230 SNP causing higher KMO activity [86].

\section{Alongside psychiatric disorders, genetic alterations of the $K M O$ gene have also been investigated in diseases involving neurodegeneration, such as PD and MS.}

Török et al. investigated 4 polymorphisms of the $K M O$ gene in search for a genetic link between the KP and PD. Two of the examined SNPs (rs2275163 and rs1053230) have been associated with psychiatric disorders in other studies (see above). Both (rs2050518 and rs6661244) are 
localized in intronic regions of the gene; the former one of them is an A to $\mathrm{T}$ change (rs 2050518), the latter is a C to T. Neither of these polymorphisms was found to be associated with PD in the population studied [98].

In search for genetic alterations contributing to MS, a focused GWA study was carried out targeting chromosome 1q43. Two polymorphisms, rs1053221 (A/G) and rs $1053183(\mathrm{C} / \mathrm{T})$ located in the $K M O$ gene were found to be in significant association with the disease [99].

\subsection{Kynureninase/L-Kynurenine Hydrolase}

In humans, KYNU (EC 3.7.1.3) catalyses the 3-HK/3-HAA conversion. It is expressed in several tissues, such as bone marrow and organs of the immune system, kidney and urinary bladder, lung, brain, but most abundantly in the liver. It is a large protein composed of 465 amino acids, with a molecular weight over $52 \mathrm{kDa}$. It functions as a homodimer requiring PLP as a cofactor [100]. The gene is almost 307000 nucleotides long. It is located on the long arm of chromosome 2 at the 22.2 position and contains 21 exons in humans. In mice it localizes to chromosome 2, while in rats to chromosome 3 .

\subsubsection{Diseases related to the genetic alterations of kynureninase gene}

In 2007 Christensen et al. reported a family with xanthurenic aciduria (also known as hydroxykynureninuria). The diagnosis was based on detection of large quantities of urinary excretion of XA, 3-hydroxykynurenine (3-OHKYN) and $\mathrm{KYN}$ in one child and one of his siblings (sibling 1). Slightly increased urinary excretion of 3-OHKYN of the mother, father and another sibling (sibling 4) was also detected, each observation suggesting the deficiency of KYNU. Analysis of the KYNU gene showed that both the proband and sibling 4 were homozygous for a minor allele of the rs606231307 polymorphism of the gene (Fig. 1), whereas 
the parents and sibling 1 carried one minor and one major allele. The SNP is an A/G change in the 7 exon of the gene, and causes a threonine to alanine amino acid change at the 198 position. The alteration can cause impairment in KYNU function, thus leading to the metabolic changes listed above. Impairment in the enzymatic function of the KYNU enzyme has already been hypothesized to be the underlying cause of xanthurenic aciduria [101][102]; however, this was the first case establishing an association at molecular genetic level [103].

The involvement of the KP in blood pressure regulation has been confirmed in animal experiments. A $40 \mathrm{Hgmm}$ decrease of mean arterial blood pressure could be reached in spontaneously hypertensive (SHR) rats - widely used as models for the investigation of human hypertension - by injecting KYNA into the rostral ventrolateral medulla of the animals, an area with a key role in regulating arterial blood pressure [104]. Mizutani et al. hypothesized that high blood pressure in SHR rats might be due to malfunction of one of the enzymes related to KYNA metabolism. Therefore, they investigated the Kynu gene of the SHR strain, and found an A to G change at the 1291 position in exon 16, resulting in an isoleucine to valine switch in the enzyme. Another nucleotide change - a G to A substitution - was reported in intron 11 [105]. Comparison of the Kynu mRNA levels in the brainstem of SHR animals and animals of a non-hypertensive strain revealed a higher expression level in rats of the SHR strain. These findings - in concert with earlier results of Ito et al. - strongly suggest that the reported genetic alterations of the Kynu gene have an impact on enzyme function and participate in the development of hypertension [105].

The discovery of such drastic effects of KYNA in SHR rats, raised questions regarding the relationship between blood pressure regulation and the KP in humans. In 2005 Zhang et al. examined 16 polymorphisms of the $K Y N U$ gene among patients diagnosed with essential 
hypertension. An $\mathrm{A} / \mathrm{G}$ change polymorphism, causing a lysine to glutamic acid change at the 412 amino acid of the enzyme, was found to be significantly more frequent among hypertensive patients than in the control group, considering both allele- and genotype distribution [106].

In a more recent experiment of Zhang et al. a further polymorphism of the $K Y N U$ gene was found to be associated with essential hypertension. The SNP rs2304705 is a G to A base change, which leads to an Arg to Gln switch in the KYNU protein at the 188. amino acid position. The minor allele (GA and AA genotypes) was found to be significantly more frequent among patients than in the control group. The overwhelming majority of patients with GA genotype had hypertension in their family history $(96,97 \%)$, while this ratio was remarkably smaller $(50 \%)$ among the individuals of the control group. Those who carried the minor allele had significantly higher systolic and diastolic blood pressure, mean arterial pressure and serum creatinine levels compared to those who were homozygous to the major allele. Results of the genetic analysis of genotypediscordant sibling-pairs were in accordance with the findings presented above. Those who carried the minor allele had significantly higher systolic and diastolic blood pressure compared to those who were homozygous to the major allele (GG genotype). In vitro studies also revealed the link between the rs 2304705 polymorphism and reduced KYNU enzyme activity, with the finding that the Arg188Gln amino acid change diminished the enzyme activity by $50 \%$. Interestingly this association could not be detected in the case of the Lys412Glu polymorphism despite its association with essential hypertension (see above) [107].

\subsection{3-hydroxyanthranilate 3,4-dioxygenase}

The 3-hydroxyanthranilate 3,4-dioxygenase (3-HAO, EC 1.13.11.6) enzyme catalyzes the conversion of 3-HAA acid to acroleyl aminofumarate, which converts to QUIN through non- 
enzymatic cyclization. The gene of $3-\mathrm{HAO}$ is also known as $H A A O$. It is localized at 2p21, with a length of over 26000 bases, and it contains 11 exons.

The 286 amino acid enzyme has a molecular mass of $32 \mathrm{kDa}$. It is found in the cytosol as a monomer. 3-HAO can be found in several tissues throughout the body, among others in liver and kidney, and it is also expressed in low amounts in the central nervous system [108].

By the conversion of 3-HAA the enzyme decreases the amount of a neuroprotective metabolite while increases the amount of a product with neurotoxic properties. Therefore, not surprisingly, alterations of 3-HAO are found in diseases which are associated with the elevated levels of QUIN.2.7.1. Diseases related to the genetic alterations of 3-hydroxyanthranilate 3,4dioxygenase gene

Collaborative Study on the Genetics of Alcoholism (COGA) data have shown a linkage between the p14-q14.3 region of chromosome 2 and alcohol dependence combined with behavioral disorder or suicide attempts. Several of the genes found in this region have already been associated with the conditions mentioned above. One of these genes is $H A A O$. In a follow-up study of the COGA data, SNPs of the $H A A O$ gene were investigated with respect to their linkage to alcohol dependence accompanied by behavioral disorder or suicide attempts. Out of the 13 investigated polymorphisms, 6 (rs375554, rs13027051, rs2374442, rs3816184, rs3816182 and rs737148) were found to be significantly associated with the diseases (Fig.1) [109].

Another association of an $H A A O \mathrm{SNP}$ with a disease was identified by Geller et al. By GWA studies they found a significant association between the rs3816183 SNP of the HAAO gene and the occurrence of hypospadiasis. This disease is a birth defect, the development of which is caused by the contribution of both environmental and genetic risk factors have been identified [69]. The rs3816183 polymorphism of $H A A O$ is a $\mathrm{C}$ to $\mathrm{T}$ change that causes an isoleucine to 
valine change at the 37 amino acid position of the enzyme [110]. The mechanism by which this alteration results in the development of hypospadiasis remains to be elucidated.

\subsection{Aminocarboxymuconate semialdehyde decarboxylase}

The ACMSD (EC 4.1.1.45) is a $38 \mathrm{kDa}$ protein composed of 336 amino acids. The encoding gene is located on the long arm of chromosome 2. It is 63729 nucleotides long and comprises 13 exons in humans. In mice is coded on chromosome 1 while in rat on chromosome 13.

The enzyme can be found in the kidney, liver and brain. It plays a crucial role in the conversion of ACMS to 2-aminomuconate-semialdehyde. In the event of impaired ACMSD function, the reaction shifts towards production of QUIN, and through its neurotoxic properties may contribute to the development and progression of diseases such as $\mathrm{PD}, \mathrm{HD}, \mathrm{AD}$ and epileptic seizures $[13][111][112]$.

\subsubsection{Diseases related to the genetic alterations of aminocarboxymuconate semialdehyde decarboxylase gene}

Recently Martí-Massó et al. reported on a family suffering from familial cortical myoclonic tremor and epilepsy (FCMTE). Symptoms of the patients, such as epileptic seizures, tremor, gait disturbances and cognitive impairment - the latter ones symptoms often related to neurodegenerative diseases - turned the attention to the ACMSD gene [113]. Whole Genome Sequencing (WGS) revealed a mutation which results in a premature stop codon (Trp26Stop) (Fig. 1). Supported by findings of Fukuoka et al. [114], it is believed that this genetic alteration causes impairment in the enzymatic function. Due to decreased activity of the ACMSD enzyme, the pathway is shifted in the direction of QUIN formation. The excessive amount of QUIN can explain the symptoms of the patients, as elevated brain QUIN levels can lead to the development 
of epileptic seizures and promote the loss of neurons. This leads to the conclusion that the Trp26Stop mutation of the ACMSD gene can be a causative genetic alteration in FCMTE [113].

Findings of Martí-Massó et al., specifically the association of $A C M S D$ with the reported patients, support the hypothesis of the vulnerability of the nigrostriatal dopaminergic system to the alterations of this gene. This assumption raised after the meta-analysis of GWASs carried out in 2011 by the International Parkinson Disease Genomics Consortium. The aim of the study was to reveal so far unidentified genetic risks for PD. A polymorphism in the $A C M S D$ locus was found to have a significant impact on the risk of development of the neurodegenerative disease (Fig.1) [115].

\section{Conclusion}

The KP plays a pivotal role in the metabolism of Trp. Some of the enzymes of the pathway have multiple forms in different tissues of the human body.

In recent decades large amounts of data on the human genome have been accumulated. Results of traditional genetic analyses and targeted or non-targeted high throughput GWS revealed links between disease states and several variants of seven of the KP genes (IDO1/2, TDO2, KATII, $K M O, K Y N U, 3-H A O, A C M S D$ ) which result in expression of KP enzymes in somewhat altered forms. However, the majority of these findings represent associations linking genetic constitution to disease, and the alterations in the affected genes are not yet proven to be direct causes of the diseases.

Genetic alterations of the IDO enzymes were found to be associated mainly with autoimmune diseases such as CD and systemic sclerosis and disorders related to MDD. Association was found between $T D O 2$ gene polymorphisms, hypertryptophanaemia and psychiatric disorders. Similarly, 
based on its chromosomal localization, a significant association has been established between variants of the $K M O$ gene and such psychiatric disorders as schizophrenia, bipolar disorder and PDS. In relation to neurodegenerative diseases, a link between a KMO SNP and MS has been reported, however, the association of any $K M O$ genetic variant to PD so far has not been uncovered. Variants of other genes coding for further KP enzymes have been implicated as well in numerous malfunctions: alterations of the gene encoding KATII were found to be associated with modified inflammatory mechanism, the role of $K Y N U$ was shown in essential hypertension and xanthurenicaciduria. Variations of the $H A A O$ gene have been linked to alcohol dependence and - by an as yet unknown mechanism - to hypospadiasis. Finally, a mutation of the gene coding for the ACMSD enzyme was found in members of a family with FCMTE and polymorphism of this gene are also recognized as a risk factor in PD.

The genetic alterations leading to activity changes of the KP are mostly SNPs which are present in varying frequencies in different population groups. In some cases, the nucleotide change is found within the coding regions of KP gene and thus results in amino acid change or early translation termination. In a few known cases nucleotide alteration outside of an exon affects gene function either by modifying RNA splicing and/or translation, or by altering promoter structure, thereby affecting transcription intensity. In a particular case, a single nucleotide change of the TDO2 gene causes an amino acid change in a regulatory site of the protein, and leads to the accelerated degradation of the enzyme [68]. 
There are only a handful of cases where the disease-associated genetic alterations can clearly be linked to a change in enzyme activity (Table 3 ). The importance of studies aimed at linking enzyme activity changes to genetic changes can be hardly overemphasized and further approaches targeting this are clearly warranted. Clarifying linkages between changes of enzyme kinetics and genetic alterations can open new opportunities in the identification of potential therapeutic targets.

Table 3.

Genetic alterations of genes of KP enzymes that are suspected to be related to human diseases and cause changes in enzyme activity

\begin{tabular}{|c|c|c|c|}
\hline Gene & Polymorphism & Effect & Reference \\
\hline \multirow[t]{5}{*}{ IDOI } & rs35059413 & \multirow{4}{*}{$\begin{array}{l}\text { Crohn's disease patients with changes in the IDO1 gene } \\
\text { showed diminished IDO1 enzymatic activity compared } \\
\text { to healthy controls }\end{array}$} & \multirow[t]{4}{*}{ [37] } \\
\hline & rs35099072 & & \\
\hline & C/A change in exon 7 & & \\
\hline & 9 base pair deletion in exon 7 & & \\
\hline & rs7820268 & $\begin{array}{l}\text { Impaired Treg suppression in patients with systemic } \\
\text { sclerosis }\end{array}$ & {$[38]$} \\
\hline \multirow[t]{2}{*}{ TDO2 } & $\mathrm{G}>\mathrm{C} /$ Met108Ile & $\begin{array}{l}\text { Leads to a catalytically less efficient enzyme which is } \\
\text { more prone to degradation in patients suffering from } \\
\text { hyperserotoninaemia }\end{array}$ & \multirow[t]{2}{*}{ [68] } \\
\hline & $\begin{array}{l}\text { c. } 491 \text { dup/premature stop } \\
\text { codon }\end{array}$ & $\begin{array}{l}\text { Leads to the formation of truncated protein in patients } \\
\text { with hyperserotoninaemia }\end{array}$ & \\
\hline$A A D A T$ & rs1480544 & $\begin{array}{l}\text { Patients with bacterial meningitis carrying the } \\
\text { polymorphism had higher KYNA levels - this SNP } \\
\text { putatively causes elevated enzyme production }\end{array}$ & {$[80]$} \\
\hline$K Y N U$ & rs2304705 & $\begin{array}{l}\text { This mutation can predispose to essential hypertension } \\
\text { and was shown to cause a } 50 \% \text { decrease in the catalytic } \\
\text { efficiency in vitro }\end{array}$ & {$[107]$} \\
\hline$A C M S D$ & $\begin{array}{l}\text { G/A change leading to } \\
\text { premature stop codon }\end{array}$ & $\begin{array}{l}\text { Leads to the formation of truncated protein in patients } \\
\text { with Familial cortical myoclonic tremor and epilepsy }\end{array}$ & {$[113]$} \\
\hline
\end{tabular}

In addition to well-known effects of KP metabolites, which primarily consist of modulation of immune and inflammatory responses and neurodegeneration, there are several diseases in which enzymes or metabolites of the pathway are known to or suspected to play roles. Therefore, knowledge on the large number of genetic alterations resulting in minor allele variants of genes 
encoding KP enzymes may provide valuable help in prediction, diagnosis and/or prognostication of some of these diseases. Although these SNPs are believed to be associated only with disease, we believe that the further accumulation of knowledge on such changes will lead to the recognition of more and more genetic alterations with causal role as well. Moreover, the detection of SNPs affecting KP enzymes might also help to identify these genes and their products as potential therapeutic targets. A summary of our current knowledge of these genetic alterations can be useful for those developing approaches for precision medicine in respect of both the diagnosis of diseases and implementing the most suitable therapeutic methods.

\section{Conflict of interest}

The authors declare no conflict of interest.

\section{Acknowledgements and funding}

The current work was supported by GINOP 2.3.2-15-2016-00034 and Hungarian Brain Research Program - Grant No. KTIA_13_NAP-A-III/9.

Basic data of the enzymes and their genes was gathered from The Human Protein Atlas (http://www.proteinatlas.org), PubMed (http://www.ncbi.nlm.nih.gov/gene) and Gene Cards Human Genes Database (http://www.genecards.org). 


\section{References}

[1] J.E. Leklem, Quantitative aspects of tryptophan metabolism in humans and other species: a review., Am. J. Clin. Nutr. 24 (1971) 659-72.

[2] M.D. Lovelace, B. Varney, G. Sundaram, N.F. Franco, M.L. Ng, S. Pai, C.K. Lim, G.J. Guillemin, B.J. Brew, Current evidence for a role of the kynurenine pathway of tryptophan metabolism in multiple sclerosis, Front. Immunol. (2016). doi:10.3389/fimmu.2016.00246.

[3] C.K. Lim, F.J. Fernández-Gomez, N. Braidy, C. Estrada, C. Costa, S. Costa, A. Bessede, E. Fernandez-Villalba, A. Zinger, M.T. Herrero, G.J. Guillemin, Involvement of the kynurenine pathway in the pathogenesis of Parkinson's disease, Prog. Neurobiol. 155 (2017) 76-95. doi:10.1016/j.pneurobio.2015.12.009.

[4] S. Erhardt, L. Schwieler, S. Imbeault, G. Engberg, The kynurenine pathway in schizophrenia and bipolar disorder, Neuropharmacology. 112 (2017) 297-306. doi:10.1016/j.neuropharm.2016.05.020.

[5] P. Song, T. Ramprasath, H. Wang, M. Zou, Abnormal kynurenine pathway of tryptophan catabolism in cardiovascular diseases, Cell. Mol. Life Sci. (2017). doi:10.1007/s00018017-2504-2.

[6] J. V. Ponomarenko, G. V. Orlova, T.I. Merkulova, E. V. Gorshkova, O.N. Fokin, G. V. Vasiliev, A.S. Frolov, M.P. Ponomarenko, rSNP_Guide: An integrated database-tools system for studying SNPs and site-directed mutations in transcription factor binding sites, Hum. Mutat. 20 (2002) 239-248. doi:10.1002/humu.10116.

[7] H.J. Ball, A. Sanchez-Perez, S. Weiser, C.J.D. Austin, F. Astelbauer, J. Miu, J.A. McQuillan, R. Stocker, L.S. Jermiin, N.H. Hunt, Characterization of an indoleamine 2,3dioxygenase-like protein found in humans and mice, Gene. 396 (2007) 203-213. 
doi:10.1016/j.gene.2007.04.010.

[8] R. Metz, J.B. DuHadaway, U. Kamasani, L. Laury-Kleintop, A.J. Muller, G.C. Prendergast, Novel Tryptophan Catabolic Enzyme IDO2 Is the Preferred Biochemical Target of the Antitumor Indoleamine 2,3-Dioxygenase Inhibitory Compound D-1-MethylTryptophan, Cancer Res. 67 (2007) 7082-7087. doi:10.1158/0008-5472.CAN-07-1872.

[9] S. Yamamoto, O. Hayaishi, Tryptophan pyrrolase of rabbit intestine. D- and L-tryptophancleaving enzyme or enzymes., J. Biol. Chem. 242 (1967) 5260-6.

[10] L. Capece, M. Arrar, A.E. Roitberg, S. Yeh, M.A. Marti, D.A. Estrin, Substrate sterospecificity in tryptophan dioxygenase and indoleamine 2,3-dioxygenase, Proteins. 78 (2010) 2961-2972. doi:10.1002/prot.22819.Substrate.

[11] A.K. Smith, J. Simon, E. Gustafson, S. Noviello, J. Cubells, M. Epstein, D. Devlin, P. Qui, J. Albrecht, C. Brass, M. Sulkowski, J. McHutchinson, A.H. Miller, Association of a Polymorphism in the Indoleamine-2,3- Dioxygenase Gene and Interferon- $\alpha$-Induced Depression in Patients with Chronic Hepatitis C, Mol. Psychiatry. 17 (2012) 781-789. doi:10.1038/mp.2011.67.

[12] Y. Mándi, L. Vécsei, The kynurenine system and immunoregulation, J. Neural Transm. 119 (2012) 197-209. doi:10.1007/s00702-011-0681-y.

[13] R. Schwarcz, J. Bruno, P. Muchowski, H. Wu, Kynurenines in the mammalian brain: when Physiology Meets Pathology, Nat. Rev. Neurosci. 13 (2012) 465-477. doi:10.1038/nrn3257.KYNURENINES.

[14] S. Yamamoto, O. Hayaishi, Tryptophan Pyrrolase of Rabbit Intestine, J Biol Chem,. 242 (1967) 5260-5266. http://www.jbc.org/content/242/22/5260.abstract.

[15] T. Shizumu, S. Nomiyama, F. Hirata, O. Hayaishi, Indoleamine 2,3-Dioxygenase, J. Biol. 
Chem. 253 (1978) 4700-4706.

[16] H. Sugimoto, S. -i. Oda, T. Otsuki, T. Hino, T. Yoshida, Y. Shiro, Crystal structure of human indoleamine 2,3-dioxygenase: Catalytic mechanism of $\mathrm{O} 2$ incorporation by a heme-containing dioxygenase, Proc. Natl. Acad. Sci. 103 (2006) 2611-2616. doi:10.1073/pnas.0508996103.

[17] A.A.-B. Badawy, A.M.A. Namboodiri, J.R. Moffett, The end of the road for the tryptophan depletion concept in pregnancy and infection, Clin. Sci. 130 (2016) 1327-1333. doi:10.1042/CS20160153.

[18] B. Baban, P. Chandler, M. Sharma, J. Pihkala, P. Koni, D. Munn, A. Mellor, IDO activates regulatory T cells and blocks their conversion into TH17-like T cells, J. Immunol. 183 (2009) 2475-2483. doi:10.1038/jid.2014.371.

[19] D.H. Munn, A.L. Mellor, Indoleamine 2,3 dioxygenase and metabolic control of immune responses, Trends Immunol. 34 (2013) 137-143. doi:10.1016/j.it.2012.10.001.

[20] D.H. Munn, Indoleamine 2, 3-dioxygenase, tumor-induced tolerance and counterregulation, J. Clin. Invest. 117 (2007) 1147-1154. doi:10.1172/JCI31178.effects.

[21] D.S. Vinay, E.P. Ryan, G. Pawelec, W.H. Talib, J. Stagg, E. Elkord, T. Lichtor, W.K. Decker, R.L. Whelan, H.M.C.S. Kumara, E. Signori, K. Honoki, A.G. Georgakilas, A. Amin, W.G. Helferich, C.S. Boosani, G. Guha, M.R. Ciriolo, S. Chen, S.I. Mohammed, A.S. Azmi, W.N. Keith, A. Bilsland, D. Bhakta, D. Halicka, H. Fujii, K. Aquilano, S.S. Ashraf, S. Nowsheen, X. Yang, B.K. Choi, B.S. Kwon, Immune evasion in cancer: Mechanistic basis and therapeutic strategies, Semin. Cancer Biol. 35 (2015) S185-S198. doi:10.1016/j.semcancer.2015.03.004.

[22] D. Munn, M. Zhou, J. Attwood, I. Bondarev, S. Conway, B. Marshall, C. Brown, A. 
Mellor, Prevention of allogeneic fetal rejection by tryptophan catabolism., Science. 281 (1998) 1191-3. doi:10.1126/science.281.5380.1191.

[23] H.J. Yuasa, H.J. Ball, Indoleamine 2,3-dioxygenases with very low catalytic activity are well conserved across kingdoms: IDOs of Basidiomycota, Fungal Genet. Biol. 56 (2013) 98-106. doi:10.1016/j.fgb.2013.03.003.

[24] H.J. Yuasa, K. Mizuno, H.J. Ball, Low efficiency IDO2 enzymes are conserved in lower vertebrates, whereas higher efficiency IDO1 enzymes are dispensable, FEBS J. 282 (2015) 2735-2745. doi:10.1111/febs.13316.

[25] M.F. Murray, The human indoleamine 2,3-dioxygenase gene and related human genes., Curr. Drug Metab. 8 (2007) 197-200. doi:10.2174/138920007780362509.

[26] H.J. Ball, H.J. Yuasa, C.J.D. Austin, S. Weiser, N.H. Hunt, Indoleamine 2,3-dioxygenase2; a new enzyme in the kynurenine pathway, Int. J. Biochem. Cell Biol. 41 (2009) 467471. doi:10.1016/j.biocel.2008.01.005.

[27] H.J. Yuasa, High 1-Trp affinity of indoleamine 2,3-dioxygenase 1 is attributed to two residues located in the distal heme pocket, FEBS J. (2016) 3651-3661. doi:10.1111/febs.13834.

[28] M. Fukunaga, Y. Yamamoto, M. Kawasoe, Y. Arioka, Y. Murakami, M. Hoshi, K. Saito, Studies on tissue and cellular distribution of indoleamine 2,3-dioxygenase 2: the absence of IDO1 upregulates IDO2 expression in the epididymis., J. Histochem. Cytochem. 60 (2012) 854-60. doi:10.1369/0022155412458926.

[29] S. Löb, A. Königsrainer, D. Zieker, B.L.D.M. Brücher, H.G. Rammensee, G. Opelz, P. Terness, IDO1 and IDO2 are expressed in human tumors: Levo- but not dextro-1-methyl tryptophan inhibits tryptophan catabolism, Cancer Immunol. Immunother. 58 (2009) 153- 
157. doi:10.1007/s00262-008-0513-6.

[30] P. Sedlmayr, A. Blaschitz, R. Wintersteiger, M. Semlitsch, A. Hammer, C. MacKenzie, W. Walcher, O. Reich, O. Takikawa, G. Dohr, Localization of indoleamine 2,3-dioxygenase in human female reproductive organs and the placenta., Mol. Hum. Reprod. 8 (2002) 385391. doi:10.1093/molehr/8.4.385.

[31] Y. Kudo, C.A.R. Boyd, I.L. Sargent, C.W.G. Redman, Decreased tryptophan catabolism by placental indoleamine 2,3-dioxygenase in preeclampsia, Am. J. Obstet. Gynecol. 188 (2003) 719-726. doi:10.1067/mob.2003.156.

[32] H. Nishizawa, K. Hasegawa, M. Suzuki, S. Kamoshida, T. Kato, K. Saito, Y. Tsutsumi, H. Kurahashi, Y. Udagawa, The etiological role of allogeneic fetal rejection in pre-eclampsia, Am. J. Reprod. Immunol. 58 (2007) 11-20. doi:10.1111/j.1600-0897.2007.00484.x.

[33] I. Plangár, D. Zádori, P. Klivényi, J. Toldi, L. Vécsei, Targeting the kynurenine pathwayrelated alterations in alzheimer's disease: A future therapeutic strategy, J. Alzheimer's Dis. 24 (2011) 199-209. doi:10.3233/JAD-2011-110131.

[34] L. Capuron, G. Neurauter, D.L. Musselman, D.H. Lawson, C.B. Nemeroff, D. Fuchs, A.H. Miller, Interferon-alpha-induced changes in tryptophan metabolism: Relationship to depression and paroxetine treatment, Biol. Psychiatry. 54 (2003) 906-914. doi:10.1016/S0006-3223(03)00173-2.

[35] M.C. Wichers, G.H. Koek, G. Robaeys, R. Verkerk, S. Scharpé, M. Maes, IDO and interferon- $\alpha$-induced depressive symptoms: a shift in hypothesis from tryptophan depletion to neurotoxicity, Mol. Psychiatry. 10 (2005) 538-544. doi:10.1038/sj.mp.4001600.

[36] A. Galvão-de Almeida, L.C. Quarantini, A.S. Sampaio, A.C. Lyra, C.L. Parise, R. Paraná, I.R. de Oliveira, K.C. Koenen, Â. Miranda-Scippa, C. Guindalini, Lack of association of 
indoleamine 2,3-dioxygenase polymorphisms with interferon-alpha-related depression in hepatitis C, Brain. Behav. Immun. 25 (2011) 1491-1497. doi:10.1016/j.bbi.2011.06.001.

[37] A. Lee, N. Kanuri, Y. Zhang, G.S. Sayuk, E. Li, M.A. Ciorba, IDO1 and IDO2 nonsynonymous gene variants: Correlation with Crohn's disease risk and clinical phenotype, PLoS One. 9 (2014) 1-15. doi:10.1371/journal.pone.0115848.

[38] S. Tardito, S. Negrini, G. Conteduca, F. Ferrera, A. Parodi, F. Battaglia, F. Kalli, D. Fenoglio, M. Cutolo, G. Filaci, Indoleamine 2,3 dioxygenase gene polymorphisms correlate with CD8+ Treg impairment in systemic sclerosis, Hum. Immunol. 74 (2013) 166-169. doi:10.1016/j.humimm.2012.11.008.

[39] B. Baban, P. Chandler, D. McCool, B. Marshall, D.H. Munn, A.L. Mellor, Indoleamine 2,3-dioxygenase expression is restricted to fetal trophoblast giant cells during murine gestation and is maternal genome specific, J. Reprod. Immunol. 61 (2004) 67-77. doi:10.1016/j.jri.2003.11.003.

[40] H. Nishizawa, T. Kato, S. Ota, S. Nishiyama, K. Pryor-Koishi, M. Suzuki, M. Tsutsumi, H. Inagaki, H. Kurahashi, Y. Udagawa, Genetic Variation in the Indoleamine 2,3Dioxygenase Gene in Pre-eclampsia, Am. J. Reprod. Immunol. 64 (2010) 68-76. doi:10.1111/j.1600-0897.2010.00820.x.

[41] D. Amani, F. Ravangard, N. Niikawa, K. Yoshiura, M. Karimzadeh, A.S. Dehaghani, A. Ghaderi, Coding region polymorphisms in the indoleamine 2,3-dioxygenase (INDO) gene and recurrent spontaneous abortion, J. Reprod. Immunol. 88 (2011) 42-47. doi:10.1016/j.jri.2010.07.007.

[42] A.K. Witkiewicz, C.L. Costantino, R. Metz, A.J. Muller, G.C. Prendergast, C.J. Yeo, J.R. Brody, Genotyping and Expression Analysis of IDO2 in Human Pancreatic Cancer: A 
Novel, Active Target, J. Am. Coll. Surg. 208 (2009) 781-787.

doi:10.1016/j.jamcollsurg.2008.12.018.

[43] H.J. Yuasa, H.J. Ball, C.J.D. Austin, N.H. Hunt, 1-1-methyltryptophan is a more effective inhibitor of vertebrate IDO2 enzymes than 1-d-methyltryptophan, Comp. Biochem.

Physiol. - B Biochem. Mol. Biol. 157 (2010) 10-15. doi:10.1016/j.cbpb.2010.04.006.

[44] C.J.D. Austin, B.M. Mailu, G.J. Maghzal, A. Sanchez-Perez, S. Rahlfs, K. Zocher, H.J. Yuasa, J.W. Arthur, K. Becker, R. Stocker, N.H. Hunt, H.J. Ball, Biochemical characteristics and inhibitor selectivity of mouse indoleamine 2,3-dioxygenase-2, Amino Acids. 39 (2010) 565-578. doi:10.1007/s00726-010-0475-9.

[45] J.A. Cutler, A.J. Rush, F.J. McMahon, G. Laje, Common genetic variation in the indoleamine-2,3-dioxygenase genes and antidepressant treatment outcome in major depressive disorder, J. Psychopharmacol. 26 (2012) 360-367.

doi:10.1177/0269881111434622.

[46] S.E. Celniker, L.A.L. Dillon, M.B. Gerstein, K.C. Gunsalus, S. Henikoff, G.H. Karpen, M. Kellis, E.C. Lai, J.D. Lieb, D.M. MacAlpine, G. Micklem, F. Piano, M. Snyder, L. Stein, K.P. White, R.H. Waterston, Unlocking the secrets of the genome, Nature. 459 (2009) 927-930. doi:10.1038/459927a.

[47] D. Batabyal, S.R. Yeh, Human tryptophan dioxygenase: A comparison to indoleamine 2,3dioxygenase, J. Am. Chem. Soc. 129 (2007) 15690-15701. doi:10.1021/ja076186k.

[48] D. Comings, Blood serotonin and thyptophan in tourette syndrome, Am. J. Med. Genet. 36 (1990) 418-430. http://cat.inist.fr/?aModele=afficheN\&cpsidt=5520942.

[49] D.E. Comings, R. Gade, D. Muhleman, C. Chiu, S. Wu, M. To, M. Spence, G. Dietz, E. Winn-Deen, R.J. Rosenthal, H.R. Lesieur, L. Rugle, J. Sverd, L. Ferry, J.P. Johnson, J.P. 
MacMurray, Exon and intron variants in the human tryptophan 2,3-dioxygenase gene: potential association with Tourette syndrome, substance abuse and other disorders, Pharmacogenetics. 6 (1996) 307-318. http://www.ncbi.nlm.nih.gov/pubmed/8873217.

[50] D.E. Comings, R. Gade-Andavolu, N. Gonzalez, S. Wu, D. Muhleman, H. Blake, G. Dietz, G. Saucier, J. P MacMurray, Comparison of the role of dopamine, serotonin, and noradrenaline genes in ADHD, ODD and conduct disorder: multivariate regression analysis of 20 genes, Clin. Genet. 57 (2000) 178-196. doi:10.1034/j.13990004.2000.570304.x.

[51] J. Biederman, Attention-deficit/hyperactivity disorder: A selective overview, Biol. Psychiatry. 57 (2005) 1215-1220. doi:10.1016/j.biopsych.2004.10.020.

[52] S. Mihailescu, M. Palomero-Rivero, P. Meade-Huerta, A. Maza-Flores, R. Drucker-Colín, Effects of nicotine and mecamylamine on rat dorsal raphe neurons, Eur. J. Pharmacol. 360 (1998) 31-36. doi:10.1016/S0014-2999(98)00658-X.

[53] E.B. Ribeiro, R.L. Bettiker, M. Bogdanov, R.J. Wurtman, Effects of systemic nicotine on serotonin release in rat brain, Brain Res. 621 (1993) 311-318. doi:10.1016/00068993(93)90121-3.

[54] B. Hitsman, R. Pingitore, B. Spring, A. Mahableshwarkar, J. Mizes, K. Segraves, J.L. Kristeller, W. Xu, Antidepressant pharmacotherapy helps some cigarette smokers more than others., J. Consult. Clin. Psychol. 67 (1999) 547-554. doi:http://dx.doi.org/10.1037/0022-006X.67.4.547.

[55] A.A. Badawy, M. Evans, The role of free serum tryptophan in the biphasic effect of acute ethanol administration on the concentrations of rat brain tryptophan, 5-hydroxytryptamine and 5-hydroxyindol-3-ylacetic acid, Biochem. J. 160 (1976) 315-324. 
http://www.ncbi.nlm.nih.gov/pubmed/1008859.

[56] J. Morland, L. Stowell, H. Gjerde, Ethanol Increases Rat Liver Tryptophan Oxygenase : Evidence for Corticosterone Mediation, 2 (1985) 255-259.

[57] A. Badawy, C. Morgan, J. Lovett, D. Bradley, R. Thomas, Decrease in Circulating Tryptophan Availability to the Brain After Acute Ethanol Consumption by Normal Volunteers: Implications for Alcohol-Induced Aggressive Behaviour and Depression, Pharmacopsychiatry. 28 (1995) 93-97. doi:10.1055/s-2007-979626.

[58] D. LeMarquand, R.O. Pihl, C. Benkelfat, Serotonin and alcohol intake, abuse, and dependence: Findings of animal studies, Biol. Psychiatry. 36 (1994) 395-421. doi:10.1016/0006-3223(94)91215-7.

[59] M. Soichot, A. Vaast, J. Vignau, G.J. Guillemin, M. Lhermitte, F. Broly, D. Allorge, Characterization of functional polymorphisms and glucocorticoid-responsive elements in the promoter of TDO2, a candidate gene for ethanol-induced behavioural disorders, Alcohol Alcohol. 48 (2013) 415-425. doi:10.1093/alcalc/agt028.

[60] D.C. Chugani, O. Muzik, R. Rothermel, M. Behen, P. Chakraborty, T. Mangner, E.A. Da Silva, H.T. Chugani, Altered serotonin synthesis in the dentatothalamocortical pathway in autistic boys, Ann. Neurol. 42 (1997) 666-669. doi:10.1002/ana.410420420.

[61] D.C. Chugani, O. Muzik, M. Behen, R. Rothermel, J.J. Janisse, J. Lee, H.T. Chugani, Developmental changes in brain serotonin synthesis capacity in autistic and nonautistic children, Ann. Neurol. 45 (1999) 287-295. doi:10.1002/15318249(199903)45:3<287::AID-ANA3>3.0.CO;2-9.

[62] E.H. Cook, B.L. Leventhal, D.X. Freedman, Free serotonin in plasma: Autistic children and their first-degree relatives, Biol. Psychiatry. 24 (1988) 488-491. doi:10.1016/0006- 
$3223(88) 90192-8$.

[63] P.L. McDougle CJ, Naylor ST, Cohen DJ, Aghajanian GK, Heninger GR, Effects of Tryptophan Depletion in Drug-Free Adults With Autistic Disorder, Arch. Gen. Psychiatry. 53 (1996) 993-1000.

[64] S. Tordjman, L. Gutknecht, M. Carlier, E. Spitz, C. Antoine, F. Slama, V. Carsalade, D.J. Cohen, P. Ferrari, P.L. Roubertoux, G.M. Anderson, Role of the serotonin transporter gene in the behavioral expression of autism, Mol Psychiatry. 6 (2001) 434-439. doi:10.1038/sj.mp.4000873.

[65] A. Bailey, A. Le Couteur, I. Gottesman, P. Bolton, E. Simonoff, E. Yuzda, M. Rutter, Autism as a strongly genetic disorder: evidence from a British twin study, Psychol. Med. 25 (1995) 63. doi:10.1017/S0033291700028099.

[66] S. Folstein, M. Rutter, Infantile autism: a genetic study of 21 twin pairs., J. Child Psychol. Psychiatry. 18 (1977) 297-321. doi:10.1111/j.1469-7610.1977.tb00443.x.

[67] R. Nabi, F.J. Serajee, D.C. Chugani, H. Zhong, a H.M.M. Huq, Association of tryptophan 2,3 dioxygenase gene polymorphism with autism., Am. J. Med. Genet. B. Neuropsychiatr. Genet. 125B (2004) 63-68. doi:10.1002/ajmg.b.20147.

[68] P. Ferreira, I. Shin, I. Sosova, K. Dornevil, S. Jain, D. Dewey, F. Liu, A. Liu, Hypertryptophanemia due to tryptophan 2,3-dioxygenase deficiency, Mol. Genet. Metab. 120 (2017) 317-324. doi:10.1016/j.ymgme.2017.02.009.

[69] A. Lewis-Ballester, F. Forouhar, S.-M. Kim, S. Lew, Y. Wang, S. Karkashon, J. Seetharaman, D. Batabyal, B.-Y. Chiang, M. Hussain, M.A. Correia, S.-R. Yeh, L. Tong, Molecular basis for catalysis and substrate-mediated cellular stabilization of human tryptophan 2,3-dioxygenase, Sci. Rep. 6 (2016) 35169. doi:10.1038/srep35169. 
[70] V.N. Dobrovolsky, J.F. Bowyer, M.K. Pabarcus, R.H. Heflich, L.D. Williams, D.R. Doerge, B. Rn Arvidsson, J. Bergquist, J.E. Casida, Effect of arylformamidase (kynurenine formamidase) gene inactivation in mice on enzymatic activity, kynurenine pathway metabolites and phenotype, (2005). doi:10.1016/j.bbagen.2005.03.010.

[71] L.J. Han Q, Cai T, Tagle DA, Structure, expression and function of kynurenine aminotransferases in human and rodent brains, Cell. Mol. Life Sci. 67 (2010) 353-368. doi:10.1021/n1061786n.Core-Shell.

[72] Q. Han, T. Cai, D.A. Tagle, J. Li, Structure, expression, and function of kynurenine aminotransferases in human and rodent brains, Cell. Mol. Life Sci. (2010). doi:10.1007/s00018-009-0166-4.

[73] P. Guidetti, E. Okuno, R. Schwarcz, Characterization of rat brain kynurenine aminotransferases I and II, J. Neurosci. Res. 50 (1997) 457-465. doi:10.1002/(SICI)10974547(19971101)50:3<457::AID-JNR12>3.0.CO;2-3.

[74] L.J. Han Q, Cai T, Tagle DA, Robinson H, Substrate specificity and structure of human aminoadipate aminotransferase/kynurenine aminotransferase II, Biosci. Rep. 28 (2008) 205-15. doi:10.1016/j.humov.2008.02.015.Changes.

[75] D. Zádori, P. Klivényi, E. Vámos, F. Fülöp, J. Toldi, L. Vécsei, Kynurenines in chronic neurodegenerative disorders: Future therapeutic strategies, J. Neural Transm. 116 (2009) 1403-1409. doi:10.1007/s00702-009-0263-4.

[76] D. Zádori, P. Klivényi, J. Toldi, F. Fülöp, L. Vécsei, Kynurenines in Parkinson’s disease: therapeutic perspectives., J Neural Transm. 119 (2012) 275-83. doi:10.1007/s00702-011$0697-3$.

[77] J. Füvesi, C. Rajda, K. Bencsik, J. Toldi, L. Vécsei, The role of kynurenines in the 
pathomechanism of amyotrophic lateral sclerosis and multiple sclerosis: Therapeutic implications, J. Neural Transm. 119 (2012) 225-234. doi:10.1007/s00702-012-0765-3.

[78] F.R.S. de Souza, F.L. Fontes, T.A. da Silva, L.G. Coutinho, S.L. Leib, L.F. Agnez-Lima, Association of kynurenine aminotransferase II gene C401T polymorphism with immune response in patients with meningitis., BMC Med. Genet. 12 (2011) 51. doi:10.1186/14712350-12-51.

[79] J. Královičová, I. Vořechovský, Global control of aberrant splice-site activation by auxiliary splicing sequences: Evidence for a gradient in exon and intron definition, Nucleic Acids Res. 35 (2007) 6399-6413. doi:10.1093/nar/gkm680.

[80] L.G. Coutinho, S. Christen, C.L. Bellac, F.L. Fontes, F.R.S. de Souza, D. Grandgirard, S.L. Leib, L.F. Agnez-Lima, The kynurenine pathway is involved in bacterial meningitis, J. Neuroinflammation. 11 (2014) 169. doi:10.1186/s12974-014-0169-4.

[81] F.L. Fontes, L.F. de Araújo, L.G. Coutinho, S.L. Leib, L.F. Agnez-Lima, Genetic polymorphisms associated with the inflammatory response in bacterial meningitis., BMC Med. Genet. 16 (2015) 70. doi:10.1186/s12881-015-0218-6.

[82] H. Okamoto, O. Hayaishi, Flavin Adenine Dinucleotide Requirement For Kynurenine Hydroxylase Of Rat Liver Mitochondria, Biochem. Biophys. Res. Commun. 29 (1967).

[83] O. Shoki, N. Nobuyoshi, S. Hiroshi, K. Hiroshi, 3-Hydroxykynurenine, an Endogenous Oxidative Stress Generator, Causes Neuronal Cell Death with Apoptotic Features and Region Selectivity, J. Neurochem. 70 (1998) 299-307. doi:10.1046/j.14714159.1998.70010299.x.

[84] D. Krause, H.S. Suh, L. Tarassishin, Q.L. Cui, B.A. Durafourt, N. Choi, A. Bauman, M. Cosenza-Nashat, J.P. Antel, M.L. Zhao, S.C. Lee, The tryptophan metabolite 3- 
hydroxyanthranilic acid plays anti-inflammatory and neuroprotective roles during inflammation: Role of hemeoxygenase-1, Am. J. Pathol. 179 (2011) 1360-1372. doi:10.1016/j.ajpath.2011.05.048.

[85] R. Lugo-Huitrón, P.U. Muñiz, B. Pineda, J. Pedraza-Chaverrí, C. Ríos, V. Pérez-de la Cruz, Quinolinic acid: An endogenous neurotoxin with multiple targets, Oxid. Med. Cell. Longev. (2013). doi:10.1155/2013/104024.

[86] S.-Y. Wang, K.-M. Duan, X.-F. Tan, J.-Y. Yin, X.-Y. Mao, W. Zheng, C.-Y. Wang, M. Yang, C. Peng, H.-H. Zhou, Z.-Q. Liu, Genetic variants of the kynurenine-3monooxygenase and postpartum depressive symptoms after cesarean section in Chinese women, J. Affect. Disord. 215 (2017) 94-101. doi:10.1016/j.jad.2017.03.023.

[87] J. Ekelund, I. Hovatta, A. Parker, T. Paunio, T. Varilo, R. Martin, J. Suhonen, P. Ellonen, G. Chan, J.S. Sinsheimer, E. Sobel, H. Juvonen, R. Arajärvi, T. Partonen, J. Suvisaari, J. Lönnqvist, J. Meyer, L. Peltonen, Chromosome 1 loci in Finnish schizophrenia families, Hum. Mol. Genet. 10 (2001) 1611-1617. doi:10.1093/hmg/10.15.1611.

[88] D.H.R. Blackwood, A. Fordyce, M.T. Walker, D.M. St. Clair, D.J. Porteous, W.J. Muir, Schizophrenia and Affective Disorders-Cosegregation with a Translocation at Chromosome 1q42 That Directly Disrupts Brain-Expressed Genes: Clinical and P300 Findings in a Family, Am. J. Hum. Genet. 69 (2001) 428-433. doi:10.1086/321969.

[89] H.M.D. Gurling, G. Kalsi, J. Brynjolfson, T. Sigmundsson, R. Sherrington, B.S. Mankoo, T. Read, P. Murphy, E. Blaveri, A. McQuillin, H. Petursson, D. Curtis, Genomewide Genetic Linkage Analysis Confirms the Presence of Susceptibility Loci for Schizophrenia, on Chromosomes 1q32.2, 5q33.2, and 8p21-22 and Provides Support for Linkage to Schizophrenia, on Chromosomes 11q23.3-24 and 20q12.1-11.23, Am. J. Hum. Genet. 68 
(2001) 661-673. doi:10.1086/318788.

[90] I. Wonodi, O. Stine, K. Sathyasaikumar, R. Roberts, B. Mitchell, L. Hong, Y. Kajii, G.

Thaker, R. Schwarcz, Downregulated Kynurenine 3-Monooxygenase Gene Expression and Enzyme Activity in Schizophrenia and Genetic Association With Schizophrenia Endophenotypes, Arch. Gen. Psychiatry. 68 (2011) 665-674. doi:10.1001/archgenpsychiatry.2011.71.

[91] M. Holtze, P. Saetre, S. Erhardt, L. Schwieler, T. Werge, T. Hansen, J. Nielsen, S. Djurovic, I. Melle, O.A. Andreassen, H. Hall, L. Terenius, I. Agartz, G. Engberg, E.G. Jönsson, M. Schalling, Kynurenine 3-monooxygenase (KMO) polymorphisms in schizophrenia: An association study, Schizophr. Res. 127 (2011) 270-272. doi:10.1016/j.schres.2010.10.002.

[92] N. Aoyama, N. Takahashi, S. Saito, N. Maeno, R. Ishihara, X. Ji, H. Miura, M. Ikeda, T. Suzuki, T. Kitajima, Y. Yamanouchi, Y. Kinoshita, K. Yoshida, N. Iwata, T. Inada, N. Ozaki, Association study between kynurenine 3-monooxygenase gene and schizophrenia in the Japanese population, Genes, Brain Behav. 5 (2006) 364-368. doi:10.1111/j.1601183X.2006.00231.x.

[93] V.E. Golimbet, T. V. Lezheiko, M. V. Alfimova, L.I. Abramova, N. V. Kondrat'ev, Association of kynurenine-3-monooxygenase gene with schizophrenia, Russ. J. Genet. 50 (2014) 634-637. doi:10.1134/S1022795414060039.

[94] I. Wonodi, R.P. McMahon, N. Krishna, B.D. Mitchell, J. Liu, M. Glassman, L. Elliot Hong, J.M. Gold, Influence of kynurenine 3-monooxygenase (KMO) gene polymorphism on cognitive function in schizophrenia, Schizophr. Res. 160 (2014) 80-87. doi:10.1016/j.schres.2014.10.026. 
[95] F. Moroni, Tryptophan metabolism and brain function: Focus on kynurenine and other indole metabolites, Eur. J. Pharmacol. 375 (1999) 87-100. doi:10.1016/S00142999(99)00196-X.

[96] M. Holtze, P. Saetre, G. Engberg, L. Schwieler, T. Werge, O.A. Andreassen, H. Hall, L. Terenius, I. Agartz, E.G. Jönsson, M. Schalling, S. Erhardt, Kynurenine 3-monooxygenase polymorphisms: Relevance for kynurenic acid synthesis in patients with schizophrenia and healthy controls, J. Psychiatry Neurosci. 37 (2012) 53-57. doi:10.1503/jpn.100175.

[97] C. Lavebratt, S. Olsson, L. Backlund, L. Frisén, C. Sellgren, L. Priebe, P. Nikamo, L. Träskman-Bendz, S. Cichon, M.P. Vawter, U. Ösby, G. Engberg, M. Landén, S. Erhardt, M. Schalling, The KMO allele encoding Arg452 is associated with psychotic features in bipolar disorder type 1, and with increased CSF KYNA level and reduced KMO expression, Mol. Psychiatry. 19 (2014) 334-341. doi:10.1038/mp.2013.11.

[98] N. Török, R. Török, Z. Szolnoki, F. Somogyvári, P. Klivényi, L. Vécsei, The Genetic Link between Parkinson?s Disease and the Kynurenine Pathway Is Still Missing, Parkinsons. Dis. 2015 (2015) 1-7. doi:10.1155/2015/474135.

[99] J. McCauley, R. Zuvich, Y. Bradford, S. Kenealy, N. Schnetz-Boutaud, S. Gregory, S. Hauser, J. Oksenberg, D. Mortlock, M. Pericak-Vance, J. Haines, Follow-up examination of linkage and association to chromosome 1q43 in multiple sclerosis, Genes Immun. 10 (2009) 624-630. doi:10.1038/gene.2009.53.Follow-up.

[100] R.S. Phillips, Structure and mechanism of kynureninase., Arch. Biochem. Biophys. 544 (2014) 69-74. doi:10.1016/j.abb.2013.10.020.

[101] G. Komrower, R. Westall, Hydroxykynureninuria, Am. J. Dis. Child. 113 (1967) 77-80.

[102] O. Reddi, M. Reddy, K. Reddy, Familial Hydroxykynureninuria, Hum. Hered. 28 (1978) 
$238-240$.

[103] M. Christensen, M. Duno, A.M. Lund, F. Skovby, E. Christensen, Xanthurenic aciduria due to a mutation in KYNU encoding kynureninase, J. Inherit. Metab. Dis. 30 (2007) 248255. doi:10.1007/s10545-007-0396-2.

[104] S. Ito, K. Komatsu, K. Tsukamoto, A.F. Sved, Excitatory amino acids in the rostral ventrolateral medulla support blood pressure in spontaneously hypertensive rats, Hypertension. 35 (2000) 413-417. file://c/Users/Gustavo/Documents/1. Doutorado/5. Literatura/1. Artigos Hipertens?o/Ito (00) - Excitatory amino acids in the rostral ventrolateral medulla support blood pressure in spontaneously hypertensive rats.pdf.

[105] K. Mizutani, K. Sugimoto, T. Okuda, T. Katsuya, T. Miyata, T. Tanabe, J. Higaki, T. Ogihara, Y. Yamori, Y. Tsujita, N. Tago, N. Iwai, Kynureninase is a novel candidate gene for hypertension in spontaneously hypertensive rats., Hypertens. Res. 25 (2002) 135-40. doi:10.1291/hypres.25.135.

[106] Y. Zhang, K. Zhang, X. He, W. Yuan, G. Wang, S. Mao, P. Gao, W. Huang, D. Zhu, A polymorphism of kynureninase gene in a hypertensive candidate chromosomal region is associated with essential hypertension, Chinese J. Cardiol. 33 (2005) 588-591.

[107] Y. Zhang, J. Shen, X. He, K. Zhang, S. Wu, B. Xiao, X. Zhou, R. Phillips, P. Gao, X. Jeunemaitre, D. Zhu, A rare variant at the KYNU gene is associated with kynureninase activity and essential hypertension in the Han Chinese population, Circ. Cardiovasc. Genet. 4 (2011) 687-694. doi:10.1161/CIRCGENETICS.110.959064.

[108] H. Brkić, B. Kovačević, S. Tomić, Human 3-hydroxyanthranilate 3,4-dioxygenase (3HAO) dynamics and reaction, a multilevel computational study, Mol. Biosyst. 11 (2015) 898-907. doi:10.1039/c4mb00668b. 
[109] D.M. Dick, J. Meyers, F. Aliev, J.J. Nurnberger, J. Kramer, S. Kuperman, B. Porjesz, J. Tischfield, H.J. Edenberg, T. Foroud, M. Schuckit, A. Goate, V. Hesselbrock, L. Bierut, Evidence for Genes on Chromosome 2 Contributing to Alcohol Dependence With Conduct Disorder and Suicide Attempts, Am J Med Genet B Neuropsychiatr. 153B (2010) 11791188. doi:10.1002/ajmg.b.31089.Evidence.

[110] F. Geller, B. Feenstra, L. Carstensen, T.H. Pers, I.A.L.M. van Rooij, I.B. Körberg, S. Choudhry, J.M. Karjalainen, T.H. Schnack, M. V Hollegaard, W.F.J. Feitz, N. Roeleveld, D.M. Hougaard, J.N. Hirschhorn, L. Franke, L.S. Baskin, A. Nordenskjöld, L.F.M. van der Zanden, M. Melbye, Genome-wide association analyses identify variants in developmental genes associated with hypospadias, Nat. Genet. 46 (2014) 957-963. doi:10.1038/ng.3063.

[111] I.P. Lapin, Kynurenines and Seizures, Epilepsia. 22 (1981) 257-265. doi:10.1111/j.15281157.1981.tb04108.x.

[112] M. Amaral, T.F. Outeiro, N.S. Scrutton, F. Giorgini, The causative role and therapeutic potential of the kynurenine pathway in neurodegenerative disease, J. Mol. Med. 91 (2013) 705-713. doi:10.1007/s00109-013-1046-9.

[113] J.F. Martí-Massó, A. Bergareche, V. Makarov, J. Ruiz-Martinez, A. Gorostidi, A.L. De Munain, J.J. Poza, P. Striano, J.D. Buxbaum, C. Paisán-Ruiz, The ACMSD gene, involved in tryptophan metabolism, is mutated in a family with cortical myoclonus, epilepsy, and parkinsonism, J. Mol. Med. 91 (2013) 1399-1406. doi:10.1007/s00109-013-1075-4.

[114] S.I. Fukuoka, K. Ishiguro, K. Yanagihara, A. Tanabe, Y. Egashira, H. Sanada, K. Shibata, Identification and expression of a cDNA encoding human alpha-amino-betacarboxymuconate-epsilon-semialdehyde decarboxylase (ACMSD): A key enzyme for the tryptophan-niacine pathway and "quinolinate hypothesis," J. Biol. Chem. 277 (2002) 
35162-35167. doi:10.1074/jbc.M200819200.

[115] M.A. Nalls, V. Plagnol, D.G. Hernandez, M. Sharma, U.M. Sheerin, M. Saad, J. SimónSánchez, C. Schulte, S. Lesage, S. Sveinbjörnsdóttir, K. Stefánsson, M. Martinez, J. Hardy, P. Heutink, A. Brice, T. Gasser, A.B. Singleton, N.W. Wood, Imputation of sequence variants for identification of genetic risks for Parkinson's disease: A metaanalysis of genome-wide association studies, Lancet. 377 (2011) 641-649. doi:10.1016/S0140-6736(10)62345-8. 


\section{Figure legends}

Figure 1.

An overview of the KP. The metabolites are indicated with full name. The names of the enzymes are given in abbreviated forms. Diseases for which association of genetic alteration(s) resulting in malfunction of a particular enzyme has been investigated are listed with references. (Bold: association have been found)

Abbreviations: IDO1,2: Indoleamine-2,3-dioxygenase 1,2; TDO: Tryptophan 2,3-dioxygenase; KAT: Kynurenine aminotransferase; KMO: Kynurenine 3-monooxygenase / Kynurenine 3Hydroxylase; KYNU: Kynureninase/L-Kynurenine Hydrolase; 3-HAO: 3-hydroxyanthranilate 3,4-dioxygenase; ACMSD: Aminocarboxymuconate semialdehyde decarboxylase/Picolinate carboxylase; NAD+: Nicotinamide adenine dinucleotide

\section{Figure 2.}

The role of IDO1 in immune regulation

IDO1 expression can be enhanced by cytokines (IL-1, IL-2, IL-4, IL-13, TNF $\alpha$, TGF $\beta$, IFN $\alpha / \beta / \gamma$ ) and lipopolysaccharides (LPS). IDO1 induction leads to a decrease in tryptophan amount and the formation of kynurenine metabolites. By activating regulatory $\mathrm{T}$ cells, and via the inhibition of effector T cells and natural killer cells, IDO1 plays an important role in the maintenance of immune homeostasis, tumor immunity and in the suppression of fetal rejection and autoimmunity. 
Genetic alterations affecting the kynurenine pathway and their association with diseases

Fanni Boros ${ }^{\mathrm{a}}$, Zsuzsanna Bohár $^{\mathrm{a}, \mathrm{b}}$, László Vécsei ${ }^{* a, b}$

aDepartment of Neurology, Albert Szent-Györgyi Clinical Center, Faculty of Medicine, University of Szeged, Szeged, Hungary

bMTA-SZTE Neuroscience Research Group, Szeged, Hungary

*Address correspondence to this author at the Department of Neurology, Albert SzentGyörgyi Medical Center, Faculty of Medicine, University of Szeged

P.O. Box: 427, H-6701, Szeged, Hungary

Tel/Fax: +36-62-545-351, +36-545-597

E-mail: vecsei.laszlo@med.u-szeged.hu 


\begin{abstract}
Tryptophan is metabolized primarily via the kynurenine pathway (KP). The KP involves several enzymes, including indoleamine 2,3-dioxygenase, tryptophan 2,3 dioxygenase (TDO2), kynurenine aminotransferases (KATs), kynurenine monooxigenase (KMO) etc. The majority of metabolites are neuroactive, some of them such as kynurenic acid show neuroprotective effects, while others, for example 3-hydroxy-L-kynurenine and quinolinic acid contribute to free radical production, leading to neurodegeneration. Impaired balance of the pathway is assumed to participate in the development of several diseases such as Parkinson's disease, Huntington's disease, Alzheimer's disease, psychiatric disorders, migraine and multiple sclerosis.
\end{abstract}

The aim of this review is to summarize available literature data on genetic alterations of the $\mathrm{KP}$, leading to disturbances of the pathway that can be related to different diseases.

To achieve this goal, literature search was executed regarding the genetic alterations of enzymes related to the KP until April 2017 based on PubMed.

Several genetic alterations of the KP were found, and suggested to be associated with diseases. Polymorphisms of the TDO2 gene can be associated with autism; KATII polymorphisms affect the immune response of patients with bacterial meningitis, mutations of the KMO gene can be associated with multiple sclerosis and cognitive functions in schizophrenia, just to mention a few.

To our knowledge, this is the first comprehensive review of the genetic alterations of the KP enzymes. This work can promote the understanding of the mechanisms underlying the connected diseases, and might facilitate medicinal chemistry approaches to substitute missing components or correct the disturbed metabolite balance of KP. 
Keywords: Tryptophan metabolism, kynurenines, metabolic enzymes, genetic alterations, polymorphism, metabolic disturbances

\section{${ }^{1}$ Abbreviations}

KP, kynurenine pathway; IDO, indoleamine 2,3-dioxygenase; TDO2, tryptophan 2,3 dioxygenase; KAT, kynurenine aminotransferase; KMO, kynurenine monooxigenase; Trp, tryptophan; KYN, L-kynurenine; KYNA, kynurenic acid; 3-HK, 3-hydroxykynurenine; KYNU, kynureninase; AA, anthranilic acid; XA, xanthurenic acid; 3-HAA, 3hydroxyanthranilate; ACMSD, aminocarboxymuconate-semialdehyde decarboxylase; QUIN, quinolinic acid; NAD+, nicotinamide-adenine-dinucleotide; GWAS, genome wide association studies; SNP, single nucleotide polymorphisms; LPS, lipopolysaccharides; TNF, tumor necrosis factor; IFN, interferon; MDD, major depressive disorder; CD, Crohn's disease; PDA, pancreatic ductal adenocarcinoma; TS, Tourette syndrome; ADHD, attention deficit hyperactivity disorder; GC, glucocorticoid; GRE, glucocorticoid responsive element; GR, glucocorticoid receptor; AADAT, aminoadipate aminotransferase; HD, Huntington's disease; AD, Alzheimer's disease; PD, Parkinson's disease; MS, multiple sclerosis; NMDS, N-methyl-D-aspartate; BM, bacterial meningitis; MIP-1 $\alpha$ CCL3, macrophage inflammatory protein 1-alpha; MIP-1ßCCL4, macrophage inflammatory protein-1-beta; CSF, cerebrospinal fluid; HO-1, hemeoxygenase-1; NO-cGMP, nitric oxide - cyclic guanosine monophosphate; PFC, prefrontal cortex; PDS, postpartum depressive symptoms; 3OHKYN, 3-hydroxykynurenine; SHR, spontaneously hypertensive rat; 3-HAO, 3hydroxyanthranilate 3,4-dioxygenase; COGA, Collaborative Study on the Genetics of Alcoholism; FCMTE, familial cortical myoclonic tremor and epilepsy; WGS, whole genome sequencing 


\section{Introduction}

\section{A general overview of the kynurenine pathway}

Most of the dietary tryptophan (Trp) not used for protein synthesis is metabolized via the kynurenine pathway (KP) [1]. The produced metabolites have broad biological actions, and were connected to several diseases [2][3][4][5]. The KP is one branch of Trp metabolism, the other branch provides serotonin, and melatonin (Fig. 1). The first step in the KP is the conversion of Trp to N-formyl-L-kynurenine, by tryptophan 2,3-dioxygenase (TDO2) or indoleamine 2,3-dioxygenase (IDO). Formamidase converts N-formyl-L-kynurenine to Lkynurenine $(\mathrm{KYN})$, which can be further metabolized by three distinct pathways. Kynurenine aminotransferases (KATs) can convert KYN to kynurenic acid (KYNA), kynurenine 3-monooxygenase (KMO) can convert it to 3-hydroxykynurenine (3-HK), while kynureninase (KYNU) converts it to anthranilic acid (AA). 3-HK is either processed by KATs to xanthurenic acid (XA), or degraded to 3-hydroxyanthranilate (3-HAA), which is metabolized by 3-hydroxyanthranilate 3,4-dioxygenase to form 2-amino-3carboxymuconate semialdehyde (ACMS). ACMS can be processed for either synthesis of 2-aminomuconate semialdehyde by aminocarboxymuconate-semialdehyde decarboxylase (ACMSD), or can form quinolinic acid (QUIN) by non-enzymatic cyclization. QUIN can be further metabolized for nicotinamide-adenine-dinucleotide (NAD+) synthesis, while 2aminomuconate semialdehyde could form picolinic acid or be subsequently processed to acetyl coenzyme A.

Intensive research is focused on the effects and alterations of the different KP metabolites and enzymes, however the information regarding genetic alterations of this pathway are scarce. The present review aims to collect the data available on mutations and genetic 
alterations of the enzymes of the KP, and reveal the possible connections with various diseases. We will follow the metabolic route of Trp (Fig. 1) and will collect the data available on the enzymes strictly connected to the KP.

\section{Genetic alterations of the genes of kynurenine pathway enzymes and their association with diseases}

Due to genome sequencing projects, all genes encoding KP enzymes have been identified. Results of traditional human genetic analysis studies and targeted or non-targeted high throughput genome wide association (GWA) studies indicate that in seven genes (IDO1/2, TDO2, KATII, KMO, KYNU, 3-HAO, ACMSD) which encode KP enzymes, alterations can be identified that might be causally linked to disease states.

Most of these alterations are single nucleotide polymorphisms (SNP) present in variable frequencies in different population groups. In some cases, the nucleotide changes are found within coding regions of KP genes and result in amino acid changes or early translational termination of the concerned protein product. In a few cases nucleotide alterations outside of exons affect gene function either by changing intronic region and thus modifying mRNA splicing and/or translation, or by altering promoter structure and thus affecting transcription intensity. It is noteworthy that for none of the KP enzyme genes have been either deletion or duplication identified, which most probably reflects the essential functions this pathway performs.

Through the next sections we summarize data available on genetic alterations on genes of KP enzymes following the steps of the pathway. For each enzyme the description starts with a short introduction providing the enzyme function, protein size, gene designation, location, expression and/or other specifics. 


\subsection{Indoleamine-2,3-dioxygenases}

IDO (EC 1.13.11.52) is the first enzyme of the KP. It catalyzes the conversion of Trp to Nformyl-L-kynurenine together with TDO2. In human, two IDO enzymes, IDO1 and IDO2 have been identified [6][7]. They are very similar in structure and function, but are expressed in different patterns. IDO1 was first isolated from rabbit small intestine by Yamamoto and Hayaishi in 1967 [8].

IDO1 can be found ubiquitously in all tissues [9]. It is expressed in several immune cells, such as macrophages, monocytes, dendritic cells and microglia [10].

IDO1 is a $45 \mathrm{kDa}$ protein of 403 amino acids. The gene encoding it is on the short arm of the 8th chromosome ( $8 \mathrm{p} 11.21)$. Similarly, in mice it is also coded on chromosome 8 , while in rats it localizes to chromosome 16. In humans, the transcribed region extends to 26516 nucleotides and consists of 10 exons. The expression of the gene is induced by lipopolysaccharides (LPS), cytokines, tumor necrosis factors (TNFs) and interferons (IFNs), especially IFN- $\gamma$ [11].

IDO1 is a heme enzyme located in the cytosol. It can convert various substrates, such as Ltryptophan, 5-hydroxy-tryptophan, serotonin and melatonin [12]. The crystal structure of the human enzyme was reported in 2006 by Sugimoto and colleagues [13].

The physiologic role of the IDO1 enzyme is conducting immune activation in various states (Fig. 2). Upregulation of the enzyme leads to Trp depletion, by this manner the proliferation of bacteria and other virulent agents is inhibited. Another mechanism, by which IDO1 affects immune response, is inducing $\mathrm{T}$ cells to differentiate into $\mathrm{T}$ regulatory cells, this way blocking $\mathrm{T}$ cell responses [14]. This might explain the diverse expression of IDO1 throughout the human body. The gene is highly expressed in tissues that are highly exposed to antigens, such as mucosal 
surfaces of the lung and the intestinal system, lymph nodes and spleen. Antigen-presenting cells such as macrophages and dendritic cells also express IDO1. The anti-inflammatory effect of IDO1 activity contributes to maintain the immune-homeostasis of different tissues. Thus, it is conceivable, that impairment in the activity of IDO1 can lead to the development of autoimmune diseases [15]. IDO1 can be involved in the process of immune editing thus contributing to tumors escaping the immune system [16]. Tumor derived factors have been reported to cause the evolution of dendritic cells with altered function. Immature dendritic cells in the tumor microenvironment show high expression of IDO1 [17]. The upregulation of IDO1 leads to a shift in the direction of forming regulatory $\mathrm{T}$ cells instead of effector $\mathrm{T}$ cells and natural killer cells, thus leading to immune tolerance [14]. IDO1 high level expression in placenta implicates the importance of the enzyme in the suppression of fetal rejection, by suppressing the reactivity of maternal $\mathrm{T}$ cells $[18]$.

Until the discovery of the second IDO enzyme, 'IDO' stood for what now is known as IDO1. By now a similar second enzyme has been recognized that is referred to as indoleamine 2,3dioxygenase-like protein, proto-indoleamine 2,3-dioxygenase, or most commonly indoleamine 2,3-dioxygenase-2, IDO-2 or IDO2.

IDO2 is structurally and functionally similar to IDO1 supporting the hypothesis, that the two proteins are products of genes originated from duplication of an ancient proto-IDO gene [19]. The genes are located next to each other on the short arm of chromosome 8. Despite their similar structures [20], IDO2 is significantly bigger as it is 81778 nucleotides long and consists of 11 exons. The regulation of the two genes is in some way coordinated, which notion is supported by the observation that the expression of IDO2 was found significantly decreased in IDO1 knockout 
mice. An explanation for this finding could be the loss of IDO2 regulatory elements in consequence of removal of IDO1 gene region [6].

The product of IDO2 gene is a 420 amino-acid protein, with a molecular weight of over $47 \mathrm{kDa}$. IDO2 and IDO1 proteins show $43 \%$ amino acid identity both in humans and mice [6]. Those residues that are critical for catalytic functions are conserved in the two proteins. In vitro studies suggest, that IDO2 can convert the same substrates as IDO1 (L-tryptophan, D-tryptophan, 5hydroxy-tryptamine, tryptamine and serotonin), however, IDO2 catabolic efficiency is much lower than that of IDO1 [21]. IDO2 is expressed in the liver, kidney, epididymis and brain in mouse [6][22], and in the liver, kidney and specific tumors in humans [23].

\subsubsection{Diseases related to the genetic alterations of indoleamine 2,3-dioxygenase genes}

A large number of SNPs within the transcribed regions of IDO1 and IDO2 genes have been described. None of these are associated unequivocally with any disease, nonetheless linkage have been suggested between several SNPs and specific diseases states (Fig. 1).

As IDO plays important roles in immune response, the effects of genetic changes in IDO genes were studied mostly in relation to diseases characterized with impaired immune function. It was suggested that in tumors elevated expression of IDO proteins can locally regulate the immune environment, enhancing immune tolerance, this way increasing the survival of cancer cells $[14][15][16][17]$. Similarly, moderation of immune functions can underlay IDO enzymes demonstrated effects on allogenic fetal rejection [18][24][25][26]. Changes in IDO function have also been reported in neurodegenerative diseases [27].

One of the main inducers of IDO1 is IFN- $\alpha$ that is used in treatment of patients suffering from chronic hepatitis C. Several earlier studies reported a decrease in blood Trp concentrations and 
increase of KYN in association with IFN- $\alpha$ induced depression, suggesting the role of IDO in the process [28][29].

In 2011 Galvão-de Almeida et al. in search for genetic variations that can be associated to the development of IFN- $\alpha$ provoked depressive symptoms, investigated three SNPs of the IDO1 gene. However, none of the investigated polymorphisms (rs3824259, rs10089084, and rs35099072) were found to be associated to the disease [30]. The following year, Smith and colleagues investigated four SNPs (rs9657182, rs7820268, rs3739319 and rs6991530) of the gene with the same aim [10]. They found that one of the investigated SNPs has a significant effect on the evolution of depressive symptoms of IFN- $\alpha$ treated Caucasian patients with major depressive disorder (MDD) [10]. The SNP rs9657182 is a C/T nucleotide change in the promoter region of the gene. The nucleotide change has not been proven to alter any transcription binding site. Still, theoretically it could lead to altered gene function either alone, or via the effects of other polymorphism that could associate to it [10].

In light of the normal physiological functions of the enzyme involvement of IDO1 in autoimmune diseases have been investigated. The induction of IDO1 gene by pro-inflammatory stimuli results in Trp depletion and formation of KP metabolites, leading to inflammation reduction and promoting immune tolerance [31]. Consequently, impaired function of the enzyme might contribute to the development of autoimmune diseases.

Lee et al. [31] found, that IDO1 polymorphisms were rare among patients with Crohn's disease (CD). Out of the six investigated polymorphisms, they detected four in a group of clinically phenotyped CD patients (Table 1). Their results indicate that patients carrying specific IDO1 SNPs are more prone to extraintestinal manifestations, such as uveitis and arthritis. Their observation was that the presence of minor alleles was associated with a more severe disease 
course. As among the carriers of the SNPs a lower KYN level and KYN/Trp ratio could be detected as compared to the control, it can be assumed, that the detected polymorphisms in CD patients result in impaired IDO1 function [31]. This study included also polymorphisms of the structurally and functionally similar IDO2 gene. It was found, that though SNPs of the gene were common among a group of patients suffering from $\mathrm{CD}$, none of the investigated polymorphisms had effect on the severity of the disease [31].

IDO1 polymorphism can also be related to another autoimmune disease, systemic sclerosis. Tardito et al. investigated 5 SNPs of the IDO1 gene, of which one (rs 7820268, a C/T change in intron 5) was found to have a significantly higher frequency among systemic sclerosis patients compared to the non-patient group [32]. In the carriers of the minor allele a decrease in the CD8+ regulatory $\mathrm{T}$ cell suppressing capacity could be detected, suggesting the association between this gene variant and regulatory $\mathrm{T}$ cell function [32].

The role of IDO1 in the placenta for suppressing fetal rejection has been shown previously [18]. In the placenta of pre-eclamptic women IDO1 expression is reduced and a correlation can be observed between the severity of the illness and the activity of the enzyme [25][26]. Taking this into consideration, Nishizawa et al. investigated the possible association of 19 SNPs of the IDO gene with pre-eclampsia [33]. However, none of the studied polymorphisms, each within the coding region of the gene, was found to be associated. The only genetic alteration that might be linked to the disease based upon this study was a four-nucleotide deletion within the intronic region of the gene; however, it is unclear how does this change affect the gene expression, if it does at all [33]. 
Table 1. Genetic alterations affecting the enzymes of the kynurenine pathway

\begin{tabular}{|c|c|c|c|c|c|c|}
\hline Gene & rs number & $\begin{array}{c}\text { Base change/amino acid } \\
\text { change }\end{array}$ & $\begin{array}{c}\text { Localization in } \\
\text { the gene }\end{array}$ & $\begin{array}{l}\text { Change in } \\
\text { enzyme } \\
\text { function }\end{array}$ & Related disease & Reference \\
\hline \multirow{6}{*}{ IDO 1} & rs9657182 & $\mathrm{C}>\mathrm{T}(\mathrm{fwd})$ & promoter region & & $\begin{array}{l}\text { IFN- } \alpha \text { induced } \\
\text { depressive symptoms } \\
\text { in patients with } \\
\text { Hepatitis C }\end{array}$ & {$[10]$} \\
\hline & rs35059413 & $\mathrm{C}>\mathrm{T}(\mathrm{rev}) / \mathrm{Ala} 4 \mathrm{Thr}$ & & \multirow{4}{*}{$\begin{array}{l}\text { diminishment in } \\
\text { enzyme activity }\end{array}$} & \multirow{4}{*}{$\begin{array}{l}\text { Severity of Crohn's } \\
\text { disease }\end{array}$} & \multirow{4}{*}[31]{} \\
\hline & \begin{tabular}{|l|} 
rs35099072 \\
\end{tabular} & $\mathrm{C}>\mathrm{T}(\mathrm{rev}) / \mathrm{Arg} 77 \mathrm{His}$ & & & & \\
\hline & & $\mathrm{C}>\mathrm{A}$ & exon 7 & & & \\
\hline & & 9 base pair deletion & exon 7 & & & \\
\hline & rs7820268 & $\mathrm{C}>\mathrm{T}(\mathrm{fwd})$ & intron 5 & $\begin{array}{l}\text { Treg suppression } \\
\text { is diminished }\end{array}$ & systemic sclerosis & {$[32]$} \\
\hline \multirow[b]{2}{*}{ IDO2 } & rs2929115 & $\mathrm{C}>\mathrm{T}(\mathrm{rev})$ & \multirow{2}{*}{$\begin{array}{l}\text { non-conserved } \\
\text { region between } \\
26 \mathrm{~kb} \text { and } 28 \mathrm{~kb} \\
\text { downstream } \\
\text { from the } 3 \text { ' end } \\
\end{array}$} & & \multirow[b]{2}{*}{$\begin{array}{l}\text { Citalopram } \\
\text { responsiveness in } \\
\text { major depressive } \\
\text { disorder }\end{array}$} & \multirow[b]{2}{*}[36]{} \\
\hline & rs2929116 & $\mathrm{G}>\mathrm{A}$ & & & & \\
\hline \multirow{5}{*}{ TDO2 } & & $\mathrm{G}>\mathrm{T}$ & \multirow{2}{*}{ intron 6} & & \multirow{2}{*}{ Tourette syndrome } & \multirow{2}{*}[40]{} \\
\hline & & $\mathrm{G}>\mathrm{A}$ & & & & \\
\hline & rs3755910 & $A>C(f w d)$ & promoter region & & Autism & [59] \\
\hline & & $\begin{array}{l}\text { c.491dup/premature stop } \\
\text { codon }\end{array}$ & & $\begin{array}{l}\text { leads to a } \\
\text { truncated protein } \\
\text { (premature stop } \\
\text { codon) } \\
\end{array}$ & \multirow[t]{2}{*}{ Hyperserotoninemia } & \multirow[t]{2}{*}[60]{} \\
\hline & & $\mathrm{G}>\mathrm{C} /$ Met108Ile & & $\begin{array}{l}\text { accelerated } \\
\text { degradation of } \\
\text { the enzyme }\end{array}$ & & \\
\hline KAT II & rs 1480544 & $\mathrm{C}>\mathrm{T}(\mathrm{fwd})$ & $\begin{array}{l}\text { exonic splicing } \\
\text { silencer }\end{array}$ & $\begin{array}{l}\text { elevated enzyme } \\
\text { production }\end{array}$ & $\begin{array}{l}\text { Immune response in } \\
\text { bacterial meningitis }\end{array}$ & {$[71][74][73]$} \\
\hline \multirow{4}{*}{ KMO } & rs 1053230 & $\begin{array}{l}\mathrm{A}>\mathrm{G}(\mathrm{rev}) ; \mathrm{C}>\mathrm{T}(\mathrm{fwd}) \\
\text { /Arg452Cys }\end{array}$ & exon 15 & & $\begin{array}{l}\text { schizophrenia, bipolar } \\
\text { disorder, PDS }\end{array}$ & {$[86][87][89][90][79]$} \\
\hline & rs2275163 & $\mathrm{C}>\mathrm{T}(\mathrm{fwd})$ & intronic region & & schizophrenia & {$[86][83][87]$} \\
\hline & rs1053221 & $\mathrm{A}>\mathrm{G}(\mathrm{rev})$ & \multirow{2}{*}{ utr region } & & \multirow{2}{*}{ Sclerosis multiplex } & \multirow{2}{*}[92]{} \\
\hline & rs1053183 & $\mathrm{C}>\mathrm{T}$ (rev) & & & & \\
\hline \multirow{3}{*}{ KYNU } & rs606231307 & $\mathrm{A}>\mathrm{G}(\mathrm{fwd}) / \mathrm{Thr} 198 \mathrm{Ala}$ & exon 7 & & Xanthurenic aciduria & {$[96]$} \\
\hline & rs9013 & $\mathrm{A}>\mathrm{G}(\mathrm{fwd}) / \mathrm{Lys} 412 \mathrm{Glu}$ & & unknown & \multirow[b]{2}{*}{ Essential hypertension } & [99] \\
\hline & rs2304705 & $\mathrm{G}>\mathrm{A}(\mathrm{fwd}) / \operatorname{Arg} 188 \mathrm{Gln}$ & & $\begin{array}{l}\text { enzyme activity } \\
\text { reduced by } 50 \%\end{array}$ & & {$[100]$} \\
\hline \multirow{7}{*}{ HAAO } & rs375554 & $A>G(f w d)$ & & & \multirow{6}{*}{$\begin{array}{l}\text { Alcohol dependence } \\
\text { accompanied with } \\
\text { conduct disorder or } \\
\text { suicide attempts }\end{array}$} & \multirow{6}{*}[102]{} \\
\hline & rs13027051 & $\mathrm{C}>\mathrm{T}(\mathrm{fwd})$ & \multirow{5}{*}{ intronic region } & & & \\
\hline & rs2374442 & $A>G(f w d)$ & & & & \\
\hline & rs3816184 & $A>G(f w d)$ & & & & \\
\hline & rs3816182 & $A>C(f w d)$ & & & & \\
\hline & rs737148 & $\mathrm{A}>\mathrm{G}(\mathrm{rev})$ & & & & \\
\hline & rs3816183 & $\mathrm{C}>\mathrm{T} / \mathrm{Ile} 37 \mathrm{Val}$ & & & Hypospadiasis & [103] \\
\hline \multirow[t]{2}{*}{ ACMSD } & & $\begin{array}{l}\mathrm{G}>\mathrm{A} / \text { premature stop } \\
\text { codon }\end{array}$ & & $\begin{array}{l}\text { leads to a } \\
\text { truncated protein } \\
\text { (premature stop } \\
\text { codon) }\end{array}$ & $\begin{array}{l}\text { Familial cortical } \\
\text { myoclonic tremor and } \\
\text { epilepsy }\end{array}$ & [106] \\
\hline & rs6710823 & $A>G(f w d)$ & & & Parkinson's disease & {$[108]$} \\
\hline
\end{tabular}

fwd/rev: allele reported to forward/reverse orientation to genome 
The relation of IDO and the suppression of fetal rejection was also investigated by Amani et al [34]. The examination of 10 SNPs among Iranian women suffering from recurrent spontaneous abortion revealed no linkage between the investigated polymorphisms and the disease [34].

Following the observation, that IDO1 helps tumor cells to survive and proliferate by facilitating a local immunotolerant environment [16], Witkiewicz et al. investigated two polymorphisms of the functionally similar IDO2 gene in patients with pancreatic ductal adenocarcinomas (PDAs) [35]. The two polymorphisms they studied show high prevalence in the population and result in either complete- or a very severe decrease (90\%) in the catalytic activity of IDO2 [7]. Based on a relatively small patient cohort in which the frequencies of these polymorphisms were comparable to that of in the control group, they did not find any link between IDO2 genotype and PDA [35]. In other words, these SNPs do not increase the risk of PDA development. On the other hand, their results show, that the majority of the investigated patients had at least one wild-type or functioning allele. This observation gives support to the argument that the IDO inhibitor D-1methyl-tryptophan might be useful in treatment of PDA due to the inhibition of antiinflammatory effects of IDO [35]. However, this treatment should be preceded by genetic investigation of the patients in order to identify those with at least one active IDO2 allele. Furthermore, selectivity of the drug should also be taken into account.

Cutler et al. studied the potential role for IDO1 and IDO2 in MDD treatment outcome [36]. They found that two polymorphisms of the IDO2 gene have effect on the responsiveness to citalopram treatment in patients with MDD. The two polymorphisms (rs2929115 and rs2929116) should be considered as one marker, because they were found to be in very high linkage disequilibrium [36]. Both of them are located in a non-conserved region between $26 \mathrm{~kb}$ and $28 \mathrm{~kb}$ downstream from the 3' end of IDO2. They are near to transcriptional binding sites and are surrounded by two 
histone modification sites, but the functional consequences of these polymorphisms have not been elucidated yet [37].

\subsection{Tryptophan 2,3-dioxygenase}

TDO2 enzyme (EC 1.13.11.11) is a $47 \mathrm{kDa}$ protein of 403 amino acids. The TDO2 gene is rather big, it consists of 65669 nucleotides and contains 12 exons. It is located on the long arm of chromosome 4 in humans, while it is located on chromosome 3 in mice and on chromosome 2 in rats.

TDO2 is a homotetrameric heme enzyme that catabolizes the conversion of L-Trp to N-formyl-Lkynurenine which is a rate limiting step of the KP. By this conversion, the enzyme modulates the serotonin level as well with the reduction of the amount of Trp available for the synthesis of the neurotransmitter. TDO2 is found mainly in the liver, thus modulating the available quantity of Trp throughout in the body. The expression of TDO2 is induced by glucocorticoid hormones and the enzyme is also regulated by the availability of its substrate, L-Trp [38].

As the serotoninergic system is involved in the modulation of mood, sleep, aggression etc., TDO2 is a target of investigations in relation to psychiatric and neurological diseases characterized by changes in the circadian rhythm, behavior and the reward system.

\subsubsection{Diseases related to the genetic alterations of Tryptophan 2,3-dioxygenase gene}

A study of Comings et al. showed significant decrease in the Trp levels and in the serotonin/platelet ratio of patients with Tourette syndrome (TS) [39]. A decline in the serotonin/platelet ratio was also detected in the parents of the patients. Similar metabolic changes were reported among patients with attention deficit hyperactivity disorder (ADHD) and their parents. The similar findings suggest the existence of a link between TS and ADHD [39]. The 
observed alterations of serotonin level and the inheritance pattern of TS indicate the possible underlying genetic alteration: variants of the TDO2 gene are possible candidates contributing to these disorders. Mutations causing higher expression level, or leading to an enzyme that is more prone to induction can be a culprit behind the excessive $\mathrm{N}$-formyl-L-kynurenine formation, thus diverting Trp from serotonin synthesis [39].

Further studies by Comings et al. showed a significant association between two intronic TDO2 polymorphisms (an $\mathrm{G}$ to $\mathrm{T}$ and an $\mathrm{G}$ to A change) and TS (Fig. 1). One of these SNPs (the G to A change) was found to be in a significant association with changed platelet serotonin levels, as well [40].

In a more recent study from the same laboratory [41] 20 genes were investigated in patients with ADHD. As this disorder is likely to be multigenic, caused by as an additive effect of several genes [42], the 20 studied genes were grouped into three assemblies. Those which activities are related to dopaminergic neurotransmission formed one group (6 of the investigated genes), those related to the noradrenergic neurotransmission another group ( 7 of the genes) and the remaining 6 genes each involved in serotoninergic neurotransmission formed the third group. For each gene the investigation of one SNP was included in the study. For TDO2, it was a G to A nucleotide change in the intronic region of the gene. According to the results noradrenergic genes contributed more likely to the ADHD phenotype than genes belonging to the other two groups [41]. Nonetheless this finding does not exclude the possibility that genetic alterations of the TDO2 gene affect the manifestation of ADHD.

The involvement of the serotoninergic neurotransmission in the function of the reward system gives reason to search for whether specific changes in TDO2 might be associated with drug abuse. Previous findings show an increase in brain serotonin levels due to nicotine exposure, and 
an increase in the level of the neurotransmitter during withdrawal [43][44]. Clinical data also showed beneficial effects of the serotonin re-uptake inhibitor Fluoxetine during the decrease of nicotine intake of smokers. By applying the medication, weight gain, a common consequence of increased food intake frequently accompanying cessation of smoking, could be decreased [45]. Based on this notion, it is hypothesized, that impairment in serotoninergic neurotransmission contributes to the mood- and appetite disturbances during nicotine withdrawal and therefore might have a role in drug dependence [40].

In another study Comings et al. [40] investigated the association of drug dependence and two intronic polymorphisms of the TDO2 gene. Both of these SNPs are in intron 6 and potentially cause alteration in a binding site of the YY-1 transcription factor [46]. One SNP is a G to T change at position 666 , the other one is a $\mathrm{G}$ to A change at position 663 . None of them was, however, found to be in association with drug dependence [40].

Another, unfortunately commonly used and abused drug in our society is alcohol. Changes in the serotoninergic neurotransmission have been reported during acute ethanol administration. Shortly after alcohol intake, an induction of the serotonin biosynthesis can be observed [47][48]. After 58 hours, this is followed by TDO2 stimulation, that causes a decrease in the serotonin level and simultaneously increases kynurenine production [48][49][50]. The gene activation is believed to be transcriptional mediated by glucocorticoids (GC). The promoter region of the human TDO2 gene contains four functional glucocorticoid responsive elements (GRE) [51], which can serve as target sites in this activation. Soichot et al. aimed at identifying SNPs in the GREs of the TDO2 promoter region that cause alterations in the transcription regulatory effects of GCs. They investigated the effects of 12 SNPs of the TDO2 promoter region, three of which were in putative GREs. In in vitro experiments under basal conditions (without glucocorticoid receptor (GR) over- 
expression, or Dexamethasone exposure) the studied nucleotide changes did not cause significant differences in promoter activity. However, upon GR over-expression without, or combined with Dexamethasone exposure a statistically significant difference in promoter activity could be observed [51]. The data suggest, that these TDO2 polymorphisms exert their effects only during TDO2 gene activation. Since similar pattern of gene activation changes has been observed also in the case of a polymorphism not located in a known GRE, this indicates the possibility of another, yet unexplored response element [51]. However, in contrast with results obtained in vitro, in vivo measurements did not reveal association between the polymorphisms and plasma KYN/Trp ratio, an indicator of TDO2/IDO enzyme activity [51] (Table 2).

The findings regarding the effects of genetic alterations in the TDO2 promoter region serve as good examples to highlight the importance of SNPs localized outside coding regions and splicing sites. In this respect it should be emphasized, that genetic alterations might have impact not only by changing protein structure and/or function.

Table 2.

Identified SNPs in the human TDO2 promoter region

\begin{tabular}{|ll|}
\hline rs number & base change \\
\hline rs3755908 & $1605 \mathrm{~T}>\mathrm{C}$ \\
\hline rs3775085 & $1532 \mathrm{~A}>\mathrm{C}$ \\
\hline rs 17033763 & $1471 \mathrm{G}>\mathrm{A}$ \\
\hline Unknown & $1342 \mathrm{C}>\mathrm{A}$ \\
\hline rs3836580 & $1248 \_1247$ Ins $\mathrm{A}$ \\
\hline rs 10857287 & $1131 \mathrm{~A}>\mathrm{G}$ \\
\hline rs11935082 & $1059 \mathrm{~T}>\mathrm{C}$ \\
\hline rs60426490 & 935 933delGTT \\
\hline Unknown & $769 \mathrm{~T}>\mathrm{G}$ \\
\hline rs3775086 & $722 \mathrm{~T}>\mathrm{A}$ \\
\hline rs3755909 & $455 \mathrm{C}>\mathrm{T}$ \\
\hline s3755910 & $311 \mathrm{C}>\mathrm{A}$ \\
\hline
\end{tabular}


Polymorphisms affecting introns, promoters, enhancer- and silencer regions can play a crucial role modulating gene expression both at the levels of transcription and translation. Single nucleotide changes in regulatory regions can result in elimination or formation of transcription factor binding sites and consequently these changes can alter the binding efficiency of DNA binding domains [46].

Impairment in the serotoninergic neurotransmission has been reported in autism as well. In patients suffering from the disease impairments in serotonin synthesis in the brain have been detected [52][53], and more, than a third of the patients seems to have elevated platelet serotonin levels [54]. The involvement of serotoninergic neurotransmission in the disease is also supported by studies showing that Trp depletion exacerbates symptoms in patients with autistic disorder [55][56]. Family and twin studies suggest a genetically determined predisposition to autism [57][58]. In light of these data, genes involved in serotonin metabolism are potential disease causing factors. Since investigation of genetic alterations of the serotonin transporter gene did not result in an unambiguous answer [40], TDO2 arose as a potential candidate. Nabi et al. studied the presence of five TDO2 polymorphisms in families with members diagnosed with autism using transmission disequilibrium test [59]. Four polymorphisms included in the study are located in the promoter region of the gene, while one is at the 3' slice region of the 11 exon. For one of the investigated nucleotide changes affecting the promoter region (rs3755910, an $\mathrm{A} / \mathrm{C}$ change) a significant difference was found in the transmission to autistic subjects. The more frequent $\mathrm{C}$ allele of the polymorphism was preferentially transmitted to family members with autistic disorders. This strongly suggests, that though this SNP is not likely to be a risk factor in autism, it is in a strong linkage disequilibrium with another polymorphism associated with the disease, that is so far unknown [59]. (Table 3) 
Table 3.

Investigated SNPs by Nabi et al

\begin{tabular}{|lll|}
\hline rs number & base change & localization \\
\hline rs3755910 & $\mathrm{C} / \mathrm{A}$ & promoter \\
\hline rs3775085 & $\mathrm{A} / \mathrm{C}$ & promoter \\
\hline rs3755907 & $\mathrm{A} / \mathrm{G}$ & promoter \\
\hline rs3755908 & $\mathrm{C} / \mathrm{T}$ & promoter \\
\hline rs2292537 & $\mathrm{A} / \mathrm{G}$ & 11 exon 3' splice region \\
\hline
\end{tabular}

In a recent study Ferreira et al. reported a peculiar situation, in which a single patient was diagnosed with chronic hypertryptophanemia and hyperserotoninemia [60]. Sequencing of the TDO2 gene revealed the patient to be compound heterozygous for the c.491dup and c.324G $>\mathrm{C}$ variant of the TDO2 gene. The variant c.491dup (paternally inherited in the patient) causes a premature stop codon leading to the formation of a truncated protein, which is $43 \%$ of the normal length of TDO2 [60]. The c.324G $>$ C gene variant (which was maternally inherited in this patient) leads to methionine to isoleucine change at the 108. Amino acid of the protein. The expression level of the c.491dup variant mRNA was found similar to the wild- type, such as the transcription of the gene was not affected by this alteration. In vitro studies however showed, that the truncated protein changed the catabolic activity of the enzyme [60].

The c.324G $>$ C base change affects a specific site of the enzyme. Under normal condition TDO2 has a short half-life which is regulated by the status of a non-catalytic Trp binding site. The enzyme activity and turnover depends on the occupancy of this binding site, when it is occupied it increases the catalytic activity, while when it is empty, it serves as a degradation signal [61]. The Met/Ile change resulting from the $c .324 \mathrm{G}>\mathrm{C}$ base change affects the formation of this noncatalytic Trp binding site. According to in vitro data the activity of the enzyme is not affected 
[60], however, as a result of the amino acid change the binding affinity of the enzyme to its substrate is significantly decreased, and consequently the degradation rate of the enzyme is increased [60]. Thus, the c.324G $>\mathrm{C}$ genetic alteration of the gene causes the accelerated degradation of the TDO2 enzyme [60].

In summary, according to Ferreira et al., the chronic hypertryptophanemia and hyperserotoninemia observed in this patient is a consequence of the combination of altered catabolic activity and accelerated degradation of TDO2, both caused by single nucleotide genetic alteration of the TDO2 gene [60].

\subsection{Kynurenine formamidase}

Kynurenine formamidase/arylformamidase (EC 3.5.1.9) converts N-formyl-L-kynurenine to Lkynurenine. It is coded on chromosome 17, 10, 11 in humans, rats and mice, respectively (AFMID gene). Little is known about this enzyme, it seems that it has two isoforms in humans, one $301 \mathrm{AA}$ and one $303 \mathrm{AA}$ form, it is expressed in various tissues, but most abundant, in liver and kidney [62]. To our knowledge, no specific alterations in the AFMID gene were directly correlated to any human disease.

\subsection{Kynurenine aminotransferases}

In human brain four KATs have been identified to catalyze KYNA synthesis (EC 2.6.1.7) [63]. These are glutamine transaminase $\mathrm{K} /$ cysteine conjugate beta-lyase 1 (KATI, EC 4.4.1.13), aminoadipate aminotransferase (KATII, EC 2.6.1.39), glutamine transaminase L/cysteine conjugate beta-lyase 2 (KATIII, EC 4.4.1.13), and glutamic-oxaloacetic transaminase 2/mitochondrial aspartate aminotransferase (KATIV EC 2.6.1.1) [63]. They are multifunctional enzymes with broad substrate specificity, function as homodimers with pyridoxal 5'-phosphate as 
cofactor [63]. Besides the irreversible transamination of KYN to KYNA, they can catalyze the conversion of 3-HK to XA. In human brain, the principal enzyme responsible for the formation of KYNA is KAT II [64][65], therefore we will focus on this enzyme thereafter.

The KATII enzyme is a $47 \mathrm{kDa}$ protein, consisting of 425 amino acids. The aminoadipate aminotransferase (AADAT) gene encoding this protein is located on the long arm of chromosome 4 in humans. It spans 31478 nucleotides and contains 18 exons. The gene is located on chromosome 8 in mice and on chromosome 19 in rats.

In vitro studies show, that KATII enzyme has very broad substrate specificity. Besides catalyzing the formation of KYNA from L-formyl-N-kynurenine, it catalyzes the transamination of $\alpha$ aminoadipate, and several other amino acids [66].

Alterations in the level of KYNA have been reported in several neurological diseases, such as Huntington's disease (HD), Alzheimer's disease (AD) [67] Parkinson's disease (PD) [68] multiple sclerosis (MS) [69] and AIDS dementia. KYNA is a modulator of glutamatergic neurotransmission via its N-methyl-D-aspartate (NMDA) receptor antagonist effect and has neuroprotective features $[66][67][68]$. According to this, impairment in the synthesis of KYNA could contribute to the development of neurodegenerative diseases. Since KATII plays a crucial role in the formation of this neuroprotective agent, the enzyme has been mainly investigated in disorders related to neuronal damages [70].

\subsubsection{Diseases related to the genetic alterations of aminoadipate aminotransferase gene}

Predicated on previous studies reporting the involvement of the KP in inflammatory diseases de Souza et al. [71] searched for genetic alterations affecting KP enzymes in patients with bacterial meningitis (BM) (Fig. 1). Two polymorphisms of the AADAT gene were included in the study: 
rs 17852900 , causing a $G$ to $T$ change, and rs1480544, a $\mathrm{C} / \mathrm{T}$ change. The rs 1480544 polymorphism affects a putative regulatory element, an exonic splicing silencer, consequently it is thought to affect mRNA and peptide synthesis [72]. This polymorphism was found to be significantly more frequent in patients with $\mathrm{BM}$ considering both allelic and genotypic frequencies. In patients homozygous for the minor allele (TT), a significant decrease was detected in the levels of tumor-necrosis factor alpha (TNF- $\alpha$ ), interleukin 1 beta (IL1- $\beta$ ), macrophage inflammatory protein 1-alpha (MIP-1 $\alpha$ CCL3), macrophage inflammatory protein-1beta (MIP-1ßCCL4) and in the number of cells counted in the collected cerebrospinal fluid (CSF), and an increase in immunoglobulin $\mathrm{G}(\mathrm{IgG})$ levels. These findings suggest, that rs 1480544 polymorphism causes impairment in the immune response against virulent agents. The $\mathrm{C} / \mathrm{T}$ change in the exonic splicing silencer region of the gene supposedly affects the expression of inflammation markers such as TNF- $\alpha$, IL1- $\beta$, MIP1 $\alpha$ CCL3 and MIP1 $\beta C C L 4$, and causes impairment in the recruitment of leukocytes. The elevation of IgG levels in patients with TT genotype suggests the influence of KYNA on immunoglobulin production, however, by a so far unknown mechanism [71].

In addition to de Souza's findings, Coutinho et al. found elevated KYNA levels in CSF of patients with BM carrying the $\mathrm{T}$ allele of the rs1480544 polymorphism [73]. A tendency for increase in KYNA level could also be noted among CT genotype patients suffering from acute BM. These results give support to the assumption that this particular SNP leads to an increase in the amount of AADAT mRNA and subsequently causes enhancement of KATII enzyme synthesis [73].

In 2015 Fontes et al. searched for possible combinations of genotypes that could have an effect on the course of BM [74]. Based on previous findings of de Souza et al., they examined the 
occurrence of the rs1480544 $\mathrm{C} / \mathrm{T}$ variant of the AADAT gene in combination with polymorphisms of genes previously reported to cause impairment in DNA repair mechanisms, such as Asn148Glu of Apurinic/Apyrimidinic Endodeoxyribonuclease (APEX1), Ser326Cys of 8-Oxoguanine DNA Glycosylase (OGG1) and Val762Al of Poly(ADP-Ribose) Polymerase 1 (PARP1). Results of gene interaction analysis showed a statistically significant combined occurrence of these genetic alterations among BM patients, suggesting the possibility of synergism existing between different pathways involving these genes in the development and course of BM [74].

\subsection{Kynurenine 3-monooxygenase}

KMO (Kynurenine 3-monooxygenase, also known as Kynurenine 3-Hydroxylase) (EC 1.14.13.9) is a $55 \mathrm{kDa}$ molecular mass protein of more, than 480 amino acids. In the KP it catalyzes the KYN to 3-HK conversion. It is mitochondrial flavoprotein, utilizing O2 and NADPH for the catalyzed reaction [75]. Downstream of KMO in the pathway are synthetized 3-HAA and QUIN. Elevated levels of 3-HK, that is an endogenous oxidative stress generator, have been reported in several neurodegenerative disorders [69][76]. In contrast to 3-HK, 3-HAA may be neuroprotective due to its hemeoxygenase-1 (HO-1) inducing effects in astrocytes. HO-1 an antioxidant enzyme with anti-inflammatory and cytoprotective features [77]. In the central nervous system QUIN acts as a neurotoxin, via activating NMDA receptors, thus creating an enormous calcium influx into astrocytes and neurons causing cells damage [78]. QUIN has an effect on the appearance of depressive symptoms by inducing the nitric oxide - cyclic guanosine monophosphate (NO-cGMP) pathway, promoting oxidative stress and interfering the translation of brain derived neurotrophic factor [79]. 
The KMO gene in humans is localized on the long arm of chromosome 1. It is 63759 nucleotides long and consist of 17 exons. KMO is coded on chromosome 13 in rat and on chromosome 1 in mice.

\subsubsection{Diseases related to the genetic alterations of kynurenine 3-monooxygenase gene}

Several studies have reported linkage between genetic loci on the long arm of chromosome 1 and psychiatric disorders with psychotic symptoms, such as bipolar disorder and schizophrenia (Fig.1) $[80][81][82]$. Since the KMO gene is located in that locus, it became a candidate in the eye of researchers looking for a predisposing factor for the diseases mentioned above. Results obtained from postmortem tissue analysis of schizophrenic patients support this suspicion. A significant and correlated decrease in the expression of KMO gene and the activity of the KMO enzyme was found in brain tissues obtained from schizophrenia patients compared to control patients [83]. Data concerning association between genetic alterations of the KMO gene and schizophrenia are however, inconclusive, as no linkage could be identified between the presence of any one of 15 studied polymorphic forms of the gene and among Scandinavian patients [84] (Table 4).

Table 4.

15 studied polymorphic forms of the gene investigated among Scandinavian patients with schizophrenia by Holtze et al.

\begin{tabular}{|ll|}
\hline rs number & base change \\
\hline rs10926508 & $\mathrm{A} / \mathrm{G}$ \\
\hline $\mathrm{rs} 2992642$ & $\mathrm{~A} / \mathrm{C}$ \\
\hline $\mathrm{rs} 3014572$ & $\mathrm{~T} / \mathrm{C}$ \\
\hline $\mathrm{rs} 2050513$ & $\mathrm{C} / \mathrm{A}$ \\
\hline $\mathrm{rs} 3014569$ & $\mathrm{~T} / \mathrm{C}$ \\
\hline $\mathrm{rs} 10926513$ & $\mathrm{~A} / \mathrm{T}$ \\
\hline $\mathrm{rs} 6661244$ & $\mathrm{C} / \mathrm{T}$ \\
\hline $\mathrm{rs} 6689793$ & $\mathrm{G} / \mathrm{C}$ \\
\hline $\mathrm{rs} 3007737$ & $\mathrm{C} / \mathrm{T}$ \\
\hline $\mathrm{rs} 2065799$ & $\mathrm{C} / \mathrm{T}$ \\
\hline $\mathrm{rs} 3765806$ & $\mathrm{C} / \mathrm{G}$ \\
\hline $\mathrm{rs} 12139441$ & $\mathrm{~A} / \mathrm{G}$ \\
\hline $\mathrm{rs} 4660103$ & $\mathrm{G} / \mathrm{A}$ \\
\hline $\mathrm{rs} 850678$ & $\mathrm{~A} / \mathrm{T}$ \\
\hline $\mathrm{rs} 1053230$ & $\mathrm{C} / \mathrm{T}$ \\
\hline
\end{tabular}


Among Japanese patients the rs2275163 (a C/T change) polymorphism association with schizophrenia was found to be significant both by single-marker comparisons and haplotype analysis. However, among a second, independent sample the significance of haplotype association could not be reproduced [85].

Results are similar regarding the rs2275163 polymorphism among Russian patients - no significant difference was found between the frequency of the minor allele of patients and that of healthy controls [86]. However, this study revealed a significant intergroup difference concerning another SNP, rs1053230.

The polymorphism is an $\mathrm{A} / \mathrm{G}$ base change in exon 15 of the KMO gene, causing an arginine to cysteine change at the $452^{\text {nd }}$ amino acid of the enzyme (in fact the nucleotide change in the coding sequence is $\mathrm{C} / \mathrm{T}$, however the database records the SNP in reverse orientation). The frequency of the homozygous minor GG, genotype of rs1053230 polymorphism was significantly higher among patients compared to the control group. Interestingly, though the minor allele (T) of the other studied SNP rs2275163 did not prove to be a risk factor alone, in combination with the GG genotype of rs1053230 it seemed to increase the risk of schizophrenia. The risk of schizophrenia among subjects with the GG genotype of the rs1053230 locus combined with at least one minor allele of the SNP rs2275163 (either in the form of a CT or TT genotype) was shown to be twice as big as in subjects with a different allele combination [86]. Though data concerning the association of polymorphism rs2275163 with the incidence of schizophrenia are unequivocal, it is likely that is has an impact on the expression of KMO gene. In schizophrenic patients with at least one minor allele of the single nucleotide change rs2275163, a slightly higher KMO mRNA level could be detected compared to those who had CC genotype [83]. 
Patients homozygous to the major allele of rs2275163 (CC genotype) were found to perform poorer in neurocognitive tasks such as predictive pursuit and visuospatial working memory than members of the CT genotype subgroup [87][83]. However, when comparing patients with CC and TT genotypes, the difference was not significant [83]. It should be mentioned here, that among healthy subjects with TT or CT genotypes inequality could also be observed in cognitive performance though the difference was again not significant [87].

Effects upon cognitive functions were also reported for homozygous carriers SNP rs 1053230 major allele. Similarly to rs2275163, individuals of CC genotype regarding the SNP rs 1053230 reached lower composite scores compared to with CT or TT genotype [87].

Elevated KYNA levels have been reported in the CSF of schizophrenic patients. As KMO is in charge of the formation of 3-HK, thus decreasing the amount of KYN available for KYNA synthesis, changes in KYNA levels can serve as an indirect indicator of KMO activity [88]. Andreassen et al. found, that both in control- and schizophrenic patients the presence of the $\mathrm{T}$ allele of the SNP rs1053230 (indicated in forward orientation) was associated with a $45 \%$ increase of KYNA level in the CSF [89].

A decrease in the KMO gene expression was detected in the prefrontal cortex (PFC) of bipolar disorder patients with psychotic features compared to patients without psychotic features [90]. This observation is in accord with results of postmortem brain tissue analysis of schizophrenic patients. However, in contrast with results of studies carried out among schizophrenic patients, the $\mathrm{C}$ allele of the rs1053230 (forward) polymorphism was found to be more common among bipolar disorder patients with psychotic features. The major allele was also associated with higher KYNA level in the CSF of bipolar patients accompanied with a reduction in KMO activity. HapMap3 project data analysis revealed, that this allele is also associated with a reduction in the 
KMO expression detected in lymphoblastoid cell lines. The link between the $\mathrm{C}$ allele of the rs 1053230 SNP and KMO gene expression can be observed also in epileptic patients [90].

Polymorphism rs1053230 of KMO was found to be significantly associated with postpartum depressive symptoms (PDS) in Chinese women. AG genotype women with PDS were found to have significantly higher serum $3-\mathrm{HK}$ concentration and $3-\mathrm{HK} / \mathrm{KYN}$ ratio compared to those with the GG genotype. These findings suggest the possibility of the rs1053230 SNP causing higher KMO activity [79].

Genetic alterations of the KMO gene have been investigated besides psychiatric disorders also in diseases involving neurodegeneration such as PD and MS.

Török et al. investigated 4 polymorphisms of the KMO gene in search for a genetic link between the KP and PD. Two of the examined SNPs (rs2275163, and rs1053230) have been associated with psychiatric disorders by other studies (see above). Both of the other two polymorphisms (rs2050518 and rs6661244) are localized in intronic regions of the gene, the former one of them is an A to T change (rs 2050518), the latter one is a C to T. Neither of these polymorphisms was found to be associated with PD in the population studied [91].

In search for genetic alterations contributing to MS, a focused GWA study was carried out targeting chromosome 1q43. Two polymorphisms, rs1053221 (A/G) and rs1053183 (C/T) located in the KMO gene were found to be in significant association with MS [92].

\subsection{Kynureninase/L-Kynurenine Hydrolase}

In human, KYNU (EC 3.7.1.3) catalyses the 3-HK/3-HAA conversion. It is expressed in several tissues of the body, such as bone marrow and organs of the immune system, kidney and urinary bladder, lung, brain, but most abundantly in the liver. It is a large protein, built up of 465 amino 
acids, with a molecular weight over $52 \mathrm{kDa}$. It functions as a homodimer requiring PLP as a cofactor [93]. The gene is almost 307000 nucleotides. It is located on the long arm of chromosome 2 at 22.2 position, and contains 21 exons in man. In mice it localizes to chromosome 2, while in rats to chromosome 3.

\subsubsection{Diseases related to the genetic alterations of kynureninase gene}

In 2007 Christensen et al. reported a family with xanthurenic aciduria (also known as hydroxykynureninuria). The diagnosis detected massive urinary excretion of XA, 3hydroxykynurenine (3-OHKYN) and KYN in one child and one of his siblings (sibling 1). Slightly increased urinary excretion of 3-OHKYN of the mother, father and another sibling (sibling 4) each observation suggesting the deficiency of KYNU. Analysis of the KYNU gene showed, that both the proband and sibling 4 were homozygous for a minor allele of the rs606231307 polymorphism of the gene (Fig. 1), whereas the parents and sibling 1 carried one minor, and one major allele. The SNP is an A/G change in the 7 exon of the gene, and causes a threonine to alanine amino acid change at the 198 position. The alteration can cause impairment in KYNU function, thus leading to the metabolic changes listed above. Impairment in the enzymatic function of the KYNU enzyme has already been hypothesized to be the underlying cause of xanthurenic aciduria [94][95], however, this was the first case establishing an association at molecular genetic level [96].

The involvement of the KP in blood pressure regulation has been confirmed in animal experiments. A $40 \mathrm{Hgmm}$ decrease of mean arterial blood pressure could be reached in spontaneously hypertensive (SHR) rats - widely used as models for the investigation of human hypertension - by injecting KYNA into the rostral ventrolateral medulla of the animals, an area with key role in regulating arterial blood pressure [97]. Mizutani et al. hypothesized that high 
blood pressure in SHR rats might be due to malfunction of one of the enzymes related to KYNA metabolism. Therefore, they investigated the KYNU gene of the SHR strain, and found an A to G change in 1291 position in exon 16, resulting in an isoleucine to valine switch in the enzyme. Another nucleotide change - a G to A substitution - was reported in the 11 intron [98]. Comparison of the KYNU mRNA levels in the brainstem of SHR animals and animals of a nonhypertensive strain revealed a higher expression level in rats of the SHR strain. These findings in concert with earlier results of Ito et al. - strongly suggest, that the reported genetic alterations of the KYNU gene have an impact on the enzyme function and participate in the development of hypertension [98].

Discovering such drastic effects of KYNA in SHR rats, raised questions regarding the relationship between blood pressure regulation and the KP in human. In 2005 Zhang et al. examined 16 polymorphisms of the KYNU gene among patients diagnosed with essential hypertension. An $\mathrm{A} / \mathrm{G}$ change polymorphism, causing a lysine to glutamic acid change at the 412 amino acid of the enzyme, was found to be significantly more frequent among hypertensive patients than in the control group, considering both allele- and genotype distribution [99].

In a more recent experiment of Zhang et al. a further polymorphism of the KYNU gene was found to be in association with essential hypertension. The SNP rs2304705 is a G to A base change, which leads to an Arg to Gln switch in the KYNU protein at the 188. Amino acid position. The minor allele (GA and AA genotypes) was found to be significantly more frequent among patients than in the control group. The overwhelming majority of the patients with GA genotype had hypertension in their family history $(96,97 \%)$, while this ratio was remarkably smaller $(50 \%)$ among the individuals of the control group. Those, who carried the minor allele, had significantly higher systolic and diastolic blood pressure, mean arterial pressure and serum 
creatinine level compared to those, who were homozygous to the major allele. Results of the genetic analysis of genotype-discordant sibling-pairs were in accordance with the findings presented above. Those, who carried the minor allele had significantly higher systolic and diastolic blood pressure compared to those, who were homozygous to the major allele (GG genotype). In vitro studies also revealed the link between the rs2304705 polymorphism and reduced KYNU enzyme activity, finding the Arg188Gln amino acid change to diminish the enzyme activity by $50 \%$. Interestingly this association could not be detected in the case of the Lys412Glu polymorphism despite its association with essential hypertension (see above) [100].

\subsection{3-hydroxyanthranilate 3,4-dioxygenase}

The 3-hydroxyanthranilate 3,4-dioxygenase (3-HAO, EC 1.13.11.6) enzyme catalyzes the conversion of 3-HAA acid to QUIN. The gene of 3-HAO is also known as HAAO. It is localized at 2 p21, with a length over 26000 bases and it contains 11 exons.

The 286 amino acid enzyme has a molecular mass of $32 \mathrm{kDa}$. It is found in the cytosol as a monomer. 3-HAO can be found in several tissues throughout the body, among others in liver and kidney, and it is also expressed in low amounts in the central nervous system [101].

By converting 3-HAA to QUIN the enzyme decreases the amount of a neuroprotective metabolite while increases the amount of a product with neurotoxic properties. Therefore, not surprisingly, alterations of 3-HAO are found in diseases which are associated with the elevated levels of QUIN.2.7.1. Diseases related to the genetic alterations of 3-hydroxyanthranilate 3,4dioxygenase gene

Collaborative Study on the Genetics of Alcoholism (COGA) data have shown a linkage between the p14-q14.3 region of chromosome 2 and alcohol dependence combined with conduct disorder 
or suicide attempts. Several of the genes found in this region have already been associated with the conditions mentioned above. One of these genes is HAAO. In a follow-up study of the COGA data SNPs of the HAAO gene were investigated in respect of their linkage to alcohol dependence accompanied with conduct disorder or suicide attempts. Out of the 13 investigated polymorphisms 6 (rs375554, rs13027051, rs2374442, rs3816184, rs3816182 and rs737148) were found to be significantly associated with the diseases (Fig.1) [102].

Another association of an HAAO SNP with a disease was associated by Geller et al. By GWA studies they found a significant association between the rs3816183 SNP of the HAAO gene and the occurrence of hypospadiasis. This disease is a birth defect, for the development of which the contribution of both environmental and genetic risk factors have been identified [61]. The rs3816183 polymorphism of HAAO is a $\mathrm{C}$ to $\mathrm{T}$ change that causes an isoleucine to valine change at the 37 amino acid position of the enzyme [103]. Presently it is unknown that through what mechanism this alteration results in the development of hypospadiasis.

\subsection{Aminocarboxymuconate semialdehyde decarboxylase}

The ACMSD (EC 4.1.1.45) is a $38 \mathrm{kDa}$ protein built from 336 amino acids. The encoding gene is located on the long arm of chromosome 2. It is 63729 nucleotides and comprises 13 exons in humans. In mice is coded on chromosome 1 while in rat on chromosome 13.

The enzyme can be found in the kidney, liver and brain. It plays a crucial role in the conversion of ACMS to 2-aminomuconate-semialdehyde. In case of impaired ACMSD function, the reaction shifts in the direction of production of QUIN, and through its neurotoxic properties may contributes to the development and progression of diseases such as $\mathrm{PD}, \mathrm{HD}, \mathrm{AD}$ and epileptic seizures [12][104][105]. 


\subsubsection{Diseases related to the genetic alterations of aminocarboxymuconate semialdehyde decarboxylase gene}

Recently Martí-Massó et al. reported on a family suffering from familial cortical myoclonic tremor and epilepsy (FCMTE). Symptoms of the patients, such as epileptic seizures, tremor, gait disturbances and cognitive impairment - the latter ones are symptoms often related to neurodegenerative diseases - turned the attention to the ACMSD gene [106]. Whole Genome Sequencing (WGS) revealed a mutation, which results in a premature stop codon (Trp26Stop)

(Fig. 1). Supported by findings of Fukuoka et al. [107], it is believed, that this genetic alteration causes impairment in the enzymatic function. Due to decreased activity of the ACMSD enzyme, the pathway is shifted in the direction of QUIN formation. The excessive amount of QUIN can explain the symptoms of the patients, as elevated brain QUIN level can lead to the formation of epileptic seizures and promote the loss of neurons. This leads to the conclusion that Trp26Stop mutation of the ACMSD gene can be a causative genetic alteration in FCMTE [106].

Findings of Martí-Massó et al., specifically the association of ACMSD with the reported patients, support the hypothesis of the vulnerability of the nigrostriatal dopaminergic system to the alterations of this gene. Such assumption raised after the meta-analysis of GWASs carried out in 2011 by the International Parkinson Disease Genomics Consortium. The aim of the study was to reveal so far unidentified genetic risks for PD. A polymorphism in the ACMSD locus was found to have a significant impact on the risk of the development of the neurodegenerative disease (Fig.1) [108].

\section{Conclusion}


The KP plays a pivotal role in the metabolism of Trp. Some of the enzymes of the pathway have multiple forms in different tissues of the human body.

In the last decades massive amount of data on the human genome has been accumulated. Results of traditional genetic analyses and targeted or non-targeted high throughput GWS revealed causal links between disease states and several variants of seven of the KP genes (IDO1/2, TDO2, KATII, KMO, KYNU, 3-HAO, ACMSD) that result in expression of KP enzymes in somewhat altered forms.

Genetic alterations of the IDO enzymes were found to be associated mainly with such autoimmune diseases as $\mathrm{CD}$ and systemic sclerosis and disorders related to MDD. Association was found between TDO2 gene polymorphisms and hypertryptophanaemia and psychiatric disorders. Similarly, based on its chromosomal localization a significant association have been established between variants of the KMO gene and such psychiatric disorders as schizophrenia, bipolar disorder and PDS. In relation of neurodegenerative diseases link between a KMO SNP and MS has been reported, however, the association of any KMO genetic variant to PD so far has not been uncovered. Variants of other genes coding for further KP enzymes have been implicated as well in numerous malfunctions: KATII alterations were found to be associated with modified inflammatory mechanism. The role of KYNU was shown in in essential hypertension and xanthurenicaciduria. Variations of the HAAO gene have been linked to alcohol dependence and by a so far unknown mechanism - to hypospadiasis. Finally, a mutation of the gene coding for the ACMSD enzyme was found in members of a family with FCMTE and polymorphism of this gene are also recognized as a risk factor in PD.

The genetic alterations leading to activity changes of the KP are mostly SNPs, that are present in variable frequencies in different population groups. In some cases, the nucleotide change is found 
within the coding regions of KP gene and thus results in amino acid change or early translation termination. In a few known cases nucleotide alteration outside of exon affects gene function either by modifying RNA splicing and/or translation, or by altering promoter structure thereby affecting transcription intensity. In a particular case, a single nucleotide change of the TDO2 gene causes an amino acid change in a regulatory site of the protein, and leads to the accelerated degradation of the enzyme [60].

In addition to well-known effects of KP metabolites, which are primarily modulation of immune and inflammatory responses and neurodegeneration, there are several diseases in which enzymes or metabolites of the pathway are known or suspected to play roles. Therefore, knowledge on the large number of genetic alterations resulting in minor allele variants of genes encoding KP enzymes may provide valuable help in prediction, diagnosis and/or prognosis of some of these diseases. Moreover, the detection of SNPs affecting KP enzymes might as well help to identify these genes and their products of as potential therapeutic targets.

\section{Conflict of interest}

The authors declare no conflict of interest.

\section{Acknowledgements and funding}

The current work was supported by GINOP 2.3.2-15-2016-00034 and Hungarian Brain Research Program - Grant No. KTIA_13_NAP-A-III/9. 
Basic data of the enzymes and their genes was gathered from The Human Protein Atlas (http://www.proteinatlas.org), PubMed (http://www.ncbi.nlm.nih.gov/gene) and Gene Cards Human Genes Database (http://www.genecards.org). 


\section{References}

[1] J.E. Leklem, Quantitative aspects of tryptophan metabolism in humans and other species: a review., Am. J. Clin. Nutr. 24 (1971) 659-72.

[2] M.D. Lovelace, B. Varney, G. Sundaram, N.F. Franco, M.L. Ng, S. Pai, C.K. Lim, G.J. Guillemin, B.J. Brew, Current evidence for a role of the kynurenine pathway of tryptophan metabolism in multiple sclerosis, Front. Immunol. (2016). doi:10.3389/fimmu.2016.00246.

[3] C.K. Lim, F.J. Fernández-Gomez, N. Braidy, C. Estrada, C. Costa, S. Costa, A. Bessede, E. Fernandez-Villalba, A. Zinger, M.T. Herrero, G.J. Guillemin, Involvement of the kynurenine pathway in the pathogenesis of Parkinson's disease, Prog. Neurobiol. 155 (2017) 76-95. doi:10.1016/j.pneurobio.2015.12.009.

[4] S. Erhardt, L. Schwieler, S. Imbeault, G. Engberg, The kynurenine pathway in schizophrenia and bipolar disorder, Neuropharmacology. 112 (2017) 297-306. doi:10.1016/j.neuropharm.2016.05.020.

[5] P. Song, T. Ramprasath, H. Wang, M. Zou, Abnormal kynurenine pathway of tryptophan catabolism in cardiovascular diseases, Cell. Mol. Life Sci. (2017). doi:10.1007/s00018017-2504-2.

[6] H.J. Ball, A. Sanchez-Perez, S. Weiser, C.J.D. Austin, F. Astelbauer, J. Miu, J.A. McQuillan, R. Stocker, L.S. Jermiin, N.H. Hunt, Characterization of an indoleamine 2,3dioxygenase-like protein found in humans and mice, Gene. 396 (2007) 203-213. doi:10.1016/j.gene.2007.04.010.

[7] R. Metz, J.B. DuHadaway, U. Kamasani, L. Laury-Kleintop, A.J. Muller, G.C. Prendergast, Novel Tryptophan Catabolic Enzyme IDO2 Is the Preferred Biochemical Target of the Antitumor Indoleamine 2,3-Dioxygenase Inhibitory Compound D-1-Methyl- 
Tryptophan, Cancer Res. 67 (2007) 7082-7087. doi:10.1158/0008-5472.CAN-07-1872.

[8] S. Yamamoto, O. Hayaishi, Tryptophan pyrrolase of rabbit intestine. D- and L-tryptophancleaving enzyme or enzymes., J. Biol. Chem. 242 (1967) 5260-6.

[9] L. Capece, M. Arrar, A.E. Roitberg, S. Yeh, M.A. Marti, D.A. Estrin, Substrate sterospecificity in tryptophan dioxygenase and indoleamine 2,3-dioxygenase, Proteins. 78 (2010) 2961-2972. doi:10.1002/prot.22819.Substrate.

[10] A.K. Smith, J. Simon, E. Gustafson, S. Noviello, J. Cubells, M. Epstein, D. Devlin, P. Qui, J. Albrecht, C. Brass, M. Sulkowski, J. McHutchinson, A.H. Miller, Association of a Polymorphism in the Indoleamine-2,3- Dioxygenase Gene and Interferon- $\alpha$-Induced Depression in Patients with Chronic Hepatitis C, Mol. Psychiatry. 17 (2012) 781-789. doi:10.1038/mp.2011.67.

[11] Y. Mándi, L. Vécsei, The kynurenine system and immunoregulation, J. Neural Transm. 119 (2012) 197-209. doi:10.1007/s00702-011-0681-y.

[12] R. Schwarcz, J. Bruno, P. Muchowski, H. Wu, Kynurenines in the mammalian brain: when Physiology Meets Pathology, Nat. Rev. Neurosci. 13 (2012) 465-477. doi:10.1038/nrn3257.KYNURENINES.

[13] H. Sugimoto, S. -i. Oda, T. Otsuki, T. Hino, T. Yoshida, Y. Shiro, Crystal structure of human indoleamine 2,3-dioxygenase: Catalytic mechanism of $\mathrm{O} 2$ incorporation by a heme-containing dioxygenase, Proc. Natl. Acad. Sci. 103 (2006) 2611-2616. doi:10.1073/pnas.0508996103.

[14] B. Baban, P. Chandler, M. Sharma, J. Pihkala, P. Koni, D. Munn, A. Mellor, IDO activates regulatory T cells and blocks their conversion into TH17-like T cells, J. Immunol. 183 (2009) 2475-2483. doi:10.1038/jid.2014.371.

[15] D.H. Munn, A.L. Mellor, Indoleamine 2,3 dioxygenase and metabolic control of immune 
responses, Trends Immunol. 34 (2013) 137-143. doi:10.1016/j.it.2012.10.001.

[16] D.H. Munn, Indoleamine 2, 3-dioxygenase, tumor-induced tolerance and counterregulation, J. Clin. Invest. 117 (2007) 1147-1154. doi:10.1172/JCI31178.effects.

[17] D.S. Vinay, E.P. Ryan, G. Pawelec, W.H. Talib, J. Stagg, E. Elkord, T. Lichtor, W.K. Decker, R.L. Whelan, H.M.C.S. Kumara, E. Signori, K. Honoki, A.G. Georgakilas, A. Amin, W.G. Helferich, C.S. Boosani, G. Guha, M.R. Ciriolo, S. Chen, S.I. Mohammed, A.S. Azmi, W.N. Keith, A. Bilsland, D. Bhakta, D. Halicka, H. Fujii, K. Aquilano, S.S. Ashraf, S. Nowsheen, X. Yang, B.K. Choi, B.S. Kwon, Immune evasion in cancer: Mechanistic basis and therapeutic strategies, Semin. Cancer Biol. 35 (2015) S185-S198. doi:10.1016/j.semcancer.2015.03.004.

[18] D. Munn, M. Zhou, J. Attwood, I. Bondarev, S. Conway, B. Marshall, C. Brown, A. Mellor, Prevention of allogeneic fetal rejection by tryptophan catabolism., Science. 281 (1998) 1191-3. doi:10.1126/science.281.5380.1191.

[19] H.J. Yuasa, H.J. Ball, Indoleamine 2,3-dioxygenases with very low catalytic activity are well conserved across kingdoms: IDOs of Basidiomycota, Fungal Genet. Biol. 56 (2013) 98-106. doi:10.1016/j.fgb.2013.03.003.

[20] M.F. Murray, The human indoleamine 2,3-dioxygenase gene and related human genes., Curr. Drug Metab. 8 (2007) 197-200. doi:10.2174/138920007780362509.

[21] H.J. Ball, H.J. Yuasa, C.J.D. Austin, S. Weiser, N.H. Hunt, Indoleamine 2,3-dioxygenase2; a new enzyme in the kynurenine pathway, Int. J. Biochem. Cell Biol. 41 (2009) 467471. doi:10.1016/j.biocel.2008.01.005.

[22] M. Fukunaga, Y. Yamamoto, M. Kawasoe, Y. Arioka, Y. Murakami, M. Hoshi, K. Saito, Studies on tissue and cellular distribution of indoleamine 2,3-dioxygenase 2: the absence of IDO1 upregulates IDO2 expression in the epididymis., J. Histochem. Cytochem. 60 
(2012) 854-60. doi:10.1369/0022155412458926.

[23] S. Löb, A. Königsrainer, D. Zieker, B.L.D.M. Brücher, H.G. Rammensee, G. Opelz, P. Terness, IDO1 and IDO2 are expressed in human tumors: Levo- but not dextro-1-methyl tryptophan inhibits tryptophan catabolism, Cancer Immunol. Immunother. 58 (2009) 153157. doi:10.1007/s00262-008-0513-6.

[24] P. Sedlmayr, A. Blaschitz, R. Wintersteiger, M. Semlitsch, A. Hammer, C. MacKenzie, W. Walcher, O. Reich, O. Takikawa, G. Dohr, Localization of indoleamine 2,3-dioxygenase in human female reproductive organs and the placenta., Mol. Hum. Reprod. 8 (2002) 385391. doi:10.1093/molehr/8.4.385.

[25] Y. Kudo, C.A.R. Boyd, I.L. Sargent, C.W.G. Redman, Decreased tryptophan catabolism by placental indoleamine 2,3-dioxygenase in preeclampsia, Am. J. Obstet. Gynecol. 188 (2003) 719-726. doi:10.1067/mob.2003.156.

[26] H. Nishizawa, K. Hasegawa, M. Suzuki, S. Kamoshida, T. Kato, K. Saito, Y. Tsutsumi, H. Kurahashi, Y. Udagawa, The etiological role of allogeneic fetal rejection in pre-eclampsia, Am. J. Reprod. Immunol. 58 (2007) 11-20. doi:10.1111/j.1600-0897.2007.00484.x.

[27] I. Plangár, D. Zádori, P. Klivényi, J. Toldi, L. Vécsei, Targeting the kynurenine pathwayrelated alterations in alzheimer's disease: A future therapeutic strategy, J. Alzheimer's Dis. 24 (2011) 199-209. doi:10.3233/JAD-2011-110131.

[28] L. Capuron, G. Neurauter, D.L. Musselman, D.H. Lawson, C.B. Nemeroff, D. Fuchs, A.H. Miller, Interferon-alpha-induced changes in tryptophan metabolism: Relationship to depression and paroxetine treatment, Biol. Psychiatry. 54 (2003) 906-914. doi:10.1016/S0006-3223(03)00173-2.

[29] M.C. Wichers, G.H. Koek, G. Robaeys, R. Verkerk, S. Scharpé, M. Maes, IDO and interferon- $\alpha$-induced depressive symptoms: a shift in hypothesis from tryptophan depletion 
to neurotoxicity, Mol. Psychiatry. 10 (2005) 538-544. doi:10.1038/sj.mp.4001600.

[30] A. Galvão-de Almeida, L.C. Quarantini, A.S. Sampaio, A.C. Lyra, C.L. Parise, R. Paraná, I.R. de Oliveira, K.C. Koenen, Â. Miranda-Scippa, C. Guindalini, Lack of association of indoleamine 2,3-dioxygenase polymorphisms with interferon-alpha-related depression in hepatitis C, Brain. Behav. Immun. 25 (2011) 1491-1497. doi:10.1016/j.bbi.2011.06.001.

[31] A. Lee, N. Kanuri, Y. Zhang, G.S. Sayuk, E. Li, M.A. Ciorba, IDO1 and IDO2 nonsynonymous gene variants: Correlation with Crohn's disease risk and clinical phenotype, PLoS One. 9 (2014) 1-15. doi:10.1371/journal.pone.0115848.

[32] S. Tardito, S. Negrini, G. Conteduca, F. Ferrera, A. Parodi, F. Battaglia, F. Kalli, D. Fenoglio, M. Cutolo, G. Filaci, Indoleamine 2,3 dioxygenase gene polymorphisms correlate with CD8+ Treg impairment in systemic sclerosis, Hum. Immunol. 74 (2013) 166-169. doi:10.1016/j.humimm.2012.11.008.

[33] H. Nishizawa, T. Kato, S. Ota, S. Nishiyama, K. Pryor-Koishi, M. Suzuki, M. Tsutsumi, H. Inagaki, H. Kurahashi, Y. Udagawa, Genetic Variation in the Indoleamine 2,3Dioxygenase Gene in Pre-eclampsia, Am. J. Reprod. Immunol. 64 (2010) 68-76. doi:10.1111/j.1600-0897.2010.00820.x.

[34] D. Amani, F. Ravangard, N. Niikawa, K. Yoshiura, M. Karimzadeh, A.S. Dehaghani, A. Ghaderi, Coding region polymorphisms in the indoleamine 2,3-dioxygenase (INDO) gene and recurrent spontaneous abortion, J. Reprod. Immunol. 88 (2011) 42-47. doi:10.1016/j.jri.2010.07.007.

[35] A.K. Witkiewicz, C.L. Costantino, R. Metz, A.J. Muller, G.C. Prendergast, C.J. Yeo, J.R. Brody, Genotyping and Expression Analysis of IDO2 in Human Pancreatic Cancer: A Novel, Active Target, J. Am. Coll. Surg. 208 (2009) 781-787. doi:10.1016/j.jamcollsurg.2008.12.018. 
[36] J.A. Cutler, A.J. Rush, F.J. McMahon, G. Laje, Common genetic variation in the indoleamine-2,3-dioxygenase genes and antidepressant treatment outcome in major depressive disorder, J. Psychopharmacol. 26 (2012) 360-367. doi:10.1177/0269881111434622.

[37] S.E. Celniker, L.A.L. Dillon, M.B. Gerstein, K.C. Gunsalus, S. Henikoff, G.H. Karpen, M. Kellis, E.C. Lai, J.D. Lieb, D.M. MacAlpine, G. Micklem, F. Piano, M. Snyder, L. Stein, K.P. White, R.H. Waterston, Unlocking the secrets of the genome, Nature. 459 (2009) 927-930. doi:10.1038/459927a.

[38] D. Batabyal, S.R. Yeh, Human tryptophan dioxygenase: A comparison to indoleamine 2,3dioxygenase, J. Am. Chem. Soc. 129 (2007) 15690-15701. doi:10.1021/ja076186k.

[39] D. Comings, Blood serotonin and thyptophan in tourette syndrome, Am. J. Med. Genet. 36 (1990) 418-430. http://cat.inist.fr/?aModele=afficheN\&cpsidt=5520942.

[40] D.E. Comings, R. Gade, D. Muhleman, C. Chiu, S. Wu, M. To, M. Spence, G. Dietz, E. Winn-Deen, R.J. Rosenthal, H.R. Lesieur, L. Rugle, J. Sverd, L. Ferry, J.P. Johnson, J.P. MacMurray, Exon and intron variants in the human tryptophan 2,3-dioxygenase gene: potential association with Tourette syndrome, substance abuse and other disorders, Pharmacogenetics. 6 (1996) 307-318. http://www.ncbi.nlm.nih.gov/pubmed/8873217.

[41] D.E. Comings, R. Gade-Andavolu, N. Gonzalez, S. Wu, D. Muhleman, H. Blake, G. Dietz, G. Saucier, J. P MacMurray, Comparison of the role of dopamine, serotonin, and noradrenaline genes in ADHD, ODD and conduct disorder: multivariate regression analysis of 20 genes, Clin. Genet. 57 (2000) 178-196. doi:10.1034/j.13990004.2000.570304.x.

[42] J. Biederman, Attention-deficit/hyperactivity disorder: A selective overview, Biol. Psychiatry. 57 (2005) 1215-1220. doi:10.1016/j.biopsych.2004.10.020. 
[43] S. Mihailescu, M. Palomero-Rivero, P. Meade-Huerta, A. Maza-Flores, R. Drucker-Colín, Effects of nicotine and mecamylamine on rat dorsal raphe neurons, Eur. J. Pharmacol. 360 (1998) 31-36. doi:10.1016/S0014-2999(98)00658-X.

[44] E.B. Ribeiro, R.L. Bettiker, M. Bogdanov, R.J. Wurtman, Effects of systemic nicotine on serotonin release in rat brain, Brain Res. 621 (1993) 311-318. doi:10.1016/00068993(93)90121-3.

[45] B. Hitsman, R. Pingitore, B. Spring, A. Mahableshwarkar, J. Mizes, K. Segraves, J.L. Kristeller, W. Xu, Antidepressant pharmacotherapy helps some cigarette smokers more than others., J. Consult. Clin. Psychol. 67 (1999) 547-554. doi:http://dx.doi.org/10.1037/0022-006X.67.4.547.

[46] J. V. Ponomarenko, G. V. Orlova, T.I. Merkulova, E. V. Gorshkova, O.N. Fokin, G. V. Vasiliev, A.S. Frolov, M.P. Ponomarenko, rSNP_Guide: An integrated database-tools system for studying SNPs and site-directed mutations in transcription factor binding sites, Hum. Mutat. 20 (2002) 239-248. doi:10.1002/humu.10116.

[47] A.A. Badawy, M. Evans, The role of free serum tryptophan in the biphasic effect of acute ethanol administration on the concentrations of rat brain tryptophan, 5-hydroxytryptamine and 5-hydroxyindol-3-ylacetic acid, Biochem. J. 160 (1976) 315-324. http://www.ncbi.nlm.nih.gov/pubmed/1008859.

[48] J. Morland, L. Stowell, H. Gjerde, Ethanol Increases Rat Liver Tryptophan Oxygenase : Evidence for Corticosterone Mediation, 2 (1985) 255-259.

[49] A. Badawy, C. Morgan, J. Lovett, D. Bradley, R. Thomas, Decrease in Circulating Tryptophan Availability to the Brain After Acute Ethanol Consumption by Normal Volunteers: Implications for Alcohol-Induced Aggressive Behaviour and Depression, Pharmacopsychiatry. 28 (1995) 93-97. doi:10.1055/s-2007-979626. 
[50] D. LeMarquand, R.O. Pihl, C. Benkelfat, Serotonin and alcohol intake, abuse, and dependence: Findings of animal studies, Biol. Psychiatry. 36 (1994) 395-421. doi:10.1016/0006-3223(94)91215-7.

[51] M. Soichot, A. Vaast, J. Vignau, G.J. Guillemin, M. Lhermitte, F. Broly, D. Allorge, Characterization of functional polymorphisms and glucocorticoid-responsive elements in the promoter of TDO2, a candidate gene for ethanol-induced behavioural disorders, Alcohol Alcohol. 48 (2013) 415-425. doi:10.1093/alcalc/agt028.

[52] D.C. Chugani, O. Muzik, R. Rothermel, M. Behen, P. Chakraborty, T. Mangner, E.A. Da Silva, H.T. Chugani, Altered serotonin synthesis in the dentatothalamocortical pathway in autistic boys, Ann. Neurol. 42 (1997) 666-669. doi:10.1002/ana.410420420.

[53] D.C. Chugani, O. Muzik, M. Behen, R. Rothermel, J.J. Janisse, J. Lee, H.T. Chugani, Developmental changes in brain serotonin synthesis capacity in autistic and nonautistic children, Ann. Neurol. 45 (1999) 287-295. doi:10.1002/15318249(199903)45:3<287::AID-ANA3>3.0.CO;2-9.

[54] E.H. Cook, B.L. Leventhal, D.X. Freedman, Free serotonin in plasma: Autistic children and their first-degree relatives, Biol. Psychiatry. 24 (1988) 488-491. doi:10.1016/0006$3223(88) 90192-8$.

[55] P.L. McDougle CJ, Naylor ST, Cohen DJ, Aghajanian GK, Heninger GR, Effects of Tryptophan Depletion in Drug-Free Adults With Autistic Disorder, Arch. Gen. Psychiatry. 53 (1996) 993-1000.

[56] S. Tordjman, L. Gutknecht, M. Carlier, E. Spitz, C. Antoine, F. Slama, V. Carsalade, D.J. Cohen, P. Ferrari, P.L. Roubertoux, G.M. Anderson, Role of the serotonin transporter gene in the behavioral expression of autism, Mol Psychiatry. 6 (2001) 434-439. doi:10.1038/sj.mp.4000873. 
[57] A. Bailey, A. Le Couteur, I. Gottesman, P. Bolton, E. Simonoff, E. Yuzda, M. Rutter, Autism as a strongly genetic disorder: evidence from a British twin study, Psychol. Med. 25 (1995) 63. doi:10.1017/S0033291700028099.

[58] S. Folstein, M. Rutter, Infantile autism: a genetic study of 21 twin pairs., J. Child Psychol. Psychiatry. 18 (1977) 297-321. doi:10.1111/j.1469-7610.1977.tb00443.x.

[59] R. Nabi, F.J. Serajee, D.C. Chugani, H. Zhong, a H.M.M. Huq, Association of tryptophan 2,3 dioxygenase gene polymorphism with autism., Am. J. Med. Genet. B. Neuropsychiatr. Genet. 125B (2004) 63-68. doi:10.1002/ajmg.b.20147.

[60] P. Ferreira, I. Shin, I. Sosova, K. Dornevil, S. Jain, D. Dewey, F. Liu, A. Liu, Hypertryptophanemia due to tryptophan 2,3-dioxygenase deficiency, Mol. Genet. Metab. 120 (2017) 317-324. doi:10.1016/j.ymgme.2017.02.009.

[61] A. Lewis-Ballester, F. Forouhar, S.-M. Kim, S. Lew, Y. Wang, S. Karkashon, J. Seetharaman, D. Batabyal, B.-Y. Chiang, M. Hussain, M.A. Correia, S.-R. Yeh, L. Tong, Molecular basis for catalysis and substrate-mediated cellular stabilization of human tryptophan 2,3-dioxygenase, Sci. Rep. 6 (2016) 35169. doi:10.1038/srep35169.

[62] V.N. Dobrovolsky, J.F. Bowyer, M.K. Pabarcus, R.H. Heflich, L.D. Williams, D.R. Doerge, B. Rn Arvidsson, J. Bergquist, J.E. Casida, Effect of arylformamidase (kynurenine formamidase) gene inactivation in mice on enzymatic activity, kynurenine pathway metabolites and phenotype, (2005). doi:10.1016/j.bbagen.2005.03.010.

[63] L.J. Han Q, Cai T, Tagle DA, Structure, expression and function of kynurenine aminotransferases in human and rodent brains, Cell. Mol. Life Sci. 67 (2010) 353-368. doi:10.1021/n1061786n.Core-Shell.

[64] Q. Han, T. Cai, D.A. Tagle, J. Li, Structure, expression, and function of kynurenine aminotransferases in human and rodent brains, Cell. Mol. Life Sci. (2010). 
doi:10.1007/s00018-009-0166-4.

[65] P. Guidetti, E. Okuno, R. Schwarcz, Characterization of rat brain kynurenine aminotransferases I and II, J. Neurosci. Res. 50 (1997) 457-465. doi:10.1002/(SICI)10974547(19971101)50:3<457::AID-JNR12>3.0.CO;2-3.

[66] L.J. Han Q, Cai T, Tagle DA, Robinson H, Substrate specificity and structure of human aminoadipate aminotransferase/kynurenine aminotransferase II, Biosci. Rep. 28 (2008) 205-15. doi:10.1016/j.humov.2008.02.015.Changes.

[67] D. Zádori, P. Klivényi, E. Vámos, F. Fülöp, J. Toldi, L. Vécsei, Kynurenines in chronic neurodegenerative disorders: Future therapeutic strategies, J. Neural Transm. 116 (2009) 1403-1409. doi:10.1007/s00702-009-0263-4.

[68] D. Zádori, P. Klivényi, J. Toldi, F. Fülöp, L. Vécsei, Kynurenines in Parkinson’s disease: therapeutic perspectives., J Neural Transm. 119 (2012) 275-83. doi:10.1007/s00702-011$0697-3$.

[69] J. Füvesi, C. Rajda, K. Bencsik, J. Toldi, L. Vécsei, The role of kynurenines in the pathomechanism of amyotrophic lateral sclerosis and multiple sclerosis: Therapeutic implications, J. Neural Transm. 119 (2012) 225-234. doi:10.1007/s00702-012-0765-3.

[70] P. Yu, Z. Li, L. Zhang, D.A. Tagle, T. Cai, Characterization of kynurenine aminotransferase III, a novel member of a phylogenetically conserved KAT family, Gene. 365 (2006) 111-118. doi:10.1016/j.gene.2005.09.034.

[71] F.R.S. de Souza, F.L. Fontes, T.A. da Silva, L.G. Coutinho, S.L. Leib, L.F. Agnez-Lima, Association of kynurenine aminotransferase II gene C401T polymorphism with immune response in patients with meningitis., BMC Med. Genet. 12 (2011) 51. doi:10.1186/14712350-12-51.

[72] J. Královičová, I. Vořechovský, Global control of aberrant splice-site activation by 
auxiliary splicing sequences: Evidence for a gradient in exon and intron definition, Nucleic Acids Res. 35 (2007) 6399-6413. doi:10.1093/nar/gkm680.

[73] L.G. Coutinho, S. Christen, C.L. Bellac, F.L. Fontes, F.R.S. de Souza, D. Grandgirard, S.L. Leib, L.F. Agnez-Lima, The kynurenine pathway is involved in bacterial meningitis, J. Neuroinflammation. 11 (2014) 169. doi:10.1186/s12974-014-0169-4.

[74] F.L. Fontes, L.F. de Araújo, L.G. Coutinho, S.L. Leib, L.F. Agnez-Lima, Genetic polymorphisms associated with the inflammatory response in bacterial meningitis., BMC Med. Genet. 16 (2015) 70. doi:10.1186/s12881-015-0218-6.

[75] H. Okamoto, O. Hayaishi, Flavin Adenine Dinucleotide Requirement For Kynurenine Hydroxylase Of Rat Liver Mitochondria, Biochem. Biophys. Res. Commun. 29 (1967).

[76] O. Shoki, N. Nobuyoshi, S. Hiroshi, K. Hiroshi, 3-Hydroxykynurenine, an Endogenous Oxidative Stress Generator, Causes Neuronal Cell Death with Apoptotic Features and Region Selectivity, J. Neurochem. 70 (1998) 299-307. doi:10.1046/j.14714159.1998.70010299.x.

[77] D. Krause, H.S. Suh, L. Tarassishin, Q.L. Cui, B.A. Durafourt, N. Choi, A. Bauman, M. Cosenza-Nashat, J.P. Antel, M.L. Zhao, S.C. Lee, The tryptophan metabolite 3hydroxyanthranilic acid plays anti-inflammatory and neuroprotective roles during inflammation: Role of hemeoxygenase-1, Am. J. Pathol. 179 (2011) 1360-1372. doi:10.1016/j.ajpath.2011.05.048.

[78] R. Lugo-Huitrón, P.U. Muñiz, B. Pineda, J. Pedraza-Chaverrí, C. Ríos, V. Pérez-de la Cruz, Quinolinic acid: An endogenous neurotoxin with multiple targets, Oxid. Med. Cell. Longev. (2013). doi:10.1155/2013/104024.

[79] S.-Y. Wang, K.-M. Duan, X.-F. Tan, J.-Y. Yin, X.-Y. Mao, W. Zheng, C.-Y. Wang, M. Yang, C. Peng, H.-H. Zhou, Z.-Q. Liu, Genetic variants of the kynurenine-3- 
monooxygenase and postpartum depressive symptoms after cesarean section in Chinese women, J. Affect. Disord. 215 (2017) 94-101. doi:10.1016/j.jad.2017.03.023.

[80] J. Ekelund, I. Hovatta, A. Parker, T. Paunio, T. Varilo, R. Martin, J. Suhonen, P. Ellonen, G. Chan, J.S. Sinsheimer, E. Sobel, H. Juvonen, R. Arajärvi, T. Partonen, J. Suvisaari, J. Lönnqvist, J. Meyer, L. Peltonen, Chromosome 1 loci in Finnish schizophrenia families, Hum. Mol. Genet. 10 (2001) 1611-1617. doi:10.1093/hmg/10.15.1611.

[81] D.H.R. Blackwood, A. Fordyce, M.T. Walker, D.M. St. Clair, D.J. Porteous, W.J. Muir, Schizophrenia and Affective Disorders-Cosegregation with a Translocation at Chromosome 1q42 That Directly Disrupts Brain-Expressed Genes: Clinical and P300 Findings in a Family, Am. J. Hum. Genet. 69 (2001) 428-433. doi:10.1086/321969.

[82] H.M.D. Gurling, G. Kalsi, J. Brynjolfson, T. Sigmundsson, R. Sherrington, B.S. Mankoo, T. Read, P. Murphy, E. Blaveri, A. McQuillin, H. Petursson, D. Curtis, Genomewide Genetic Linkage Analysis Confirms the Presence of Susceptibility Loci for Schizophrenia, on Chromosomes 1q32.2, 5q33.2, and 8p21-22 and Provides Support for Linkage to Schizophrenia, on Chromosomes 11q23.3-24 and 20q12.1-11.23, Am. J. Hum. Genet. 68 (2001) 661-673. doi:10.1086/318788.

[83] I. Wonodi, O. Stine, K. Sathyasaikumar, R. Roberts, B. Mitchell, L. Hong, Y. Kajii, G. Thaker, R. Schwarcz, Downregulated Kynurenine 3-Monooxygenase Gene Expression and Enzyme Activity in Schizophrenia and Genetic Association With Schizophrenia Endophenotypes, Arch. Gen. Psychiatry. 68 (2011) 665-674. doi:10.1001/archgenpsychiatry.2011.71.

[84] M. Holtze, P. Saetre, S. Erhardt, L. Schwieler, T. Werge, T. Hansen, J. Nielsen, S. Djurovic, I. Melle, O.A. Andreassen, H. Hall, L. Terenius, I. Agartz, G. Engberg, E.G. Jönsson, M. Schalling, Kynurenine 3-monooxygenase (KMO) polymorphisms in 
schizophrenia: An association study, Schizophr. Res. 127 (2011) 270-272. doi:10.1016/j.schres.2010.10.002.

[85] N. Aoyama, N. Takahashi, S. Saito, N. Maeno, R. Ishihara, X. Ji, H. Miura, M. Ikeda, T. Suzuki, T. Kitajima, Y. Yamanouchi, Y. Kinoshita, K. Yoshida, N. Iwata, T. Inada, N. Ozaki, Association study between kynurenine 3-monooxygenase gene and schizophrenia in the Japanese population, Genes, Brain Behav. 5 (2006) 364-368. doi:10.1111/j.1601183X.2006.00231.X.

[86] V.E. Golimbet, T. V. Lezheiko, M. V. Alfimova, L.I. Abramova, N. V. Kondrat'ev, Association of kynurenine-3-monooxygenase gene with schizophrenia, Russ. J. Genet. 50 (2014) 634-637. doi:10.1134/S1022795414060039.

[87] I. Wonodi, R.P. McMahon, N. Krishna, B.D. Mitchell, J. Liu, M. Glassman, L. Elliot Hong, J.M. Gold, Influence of kynurenine 3-monooxygenase (KMO) gene polymorphism on cognitive function in schizophrenia, Schizophr. Res. 160 (2014) 80-87. doi:10.1016/j.schres.2014.10.026.

[88] F. Moroni, Tryptophan metabolism and brain function: Focus on kynurenine and other indole metabolites, Eur. J. Pharmacol. 375 (1999) 87-100. doi:10.1016/S00142999(99)00196-X.

[89] M. Holtze, P. Saetre, G. Engberg, L. Schwieler, T. Werge, O.A. Andreassen, H. Hall, L. Terenius, I. Agartz, E.G. Jönsson, M. Schalling, S. Erhardt, Kynurenine 3-monooxygenase polymorphisms: Relevance for kynurenic acid synthesis in patients with schizophrenia and healthy controls, J. Psychiatry Neurosci. 37 (2012) 53-57. doi:10.1503/jpn.100175.

[90] C. Lavebratt, S. Olsson, L. Backlund, L. Frisén, C. Sellgren, L. Priebe, P. Nikamo, L. Träskman-Bendz, S. Cichon, M.P. Vawter, U. Ösby, G. Engberg, M. Landén, S. Erhardt, M. Schalling, The KMO allele encoding Arg452 is associated with psychotic features in 
bipolar disorder type 1, and with increased CSF KYNA level and reduced KMO expression, Mol. Psychiatry. 19 (2014) 334-341. doi:10.1038/mp.2013.11.

[91] N. Török, R. Török, Z. Szolnoki, F. Somogyvári, P. Klivényi, L. Vécsei, The Genetic Link between Parkinson?s Disease and the Kynurenine Pathway Is Still Missing, Parkinsons. Dis. 2015 (2015) 1-7. doi:10.1155/2015/474135.

[92] J. McCauley, R. Zuvich, Y. Bradford, S. Kenealy, N. Schnetz-Boutaud, S. Gregory, S. Hauser, J. Oksenberg, D. Mortlock, M. Pericak-Vance, J. Haines, Follow-up examination of linkage and association to chromosome 1q43 in multiple sclerosis, Genes Immun. 10 (2009) 624-630. doi:10.1038/gene.2009.53.Follow-up.

[93] R.S. Phillips, Structure and mechanism of kynureninase., Arch. Biochem. Biophys. 544 (2014) 69-74. doi:10.1016/j.abb.2013.10.020.

[94] G. Komrower, R. Westall, Hydroxykynureninuria, Am. J. Dis. Child. 113 (1967) 77-80.

[95] O. Reddi, M. Reddy, K. Reddy, Familial Hydroxykynureninuria, Hum. Hered. 28 (1978) $238-240$.

[96] M. Christensen, M. Duno, A.M. Lund, F. Skovby, E. Christensen, Xanthurenic aciduria due to a mutation in KYNU encoding kynureninase, J. Inherit. Metab. Dis. 30 (2007) 248255. doi:10.1007/s10545-007-0396-2.

[97] S. Ito, K. Komatsu, K. Tsukamoto, A.F. Sved, Excitatory amino acids in the rostral ventrolateral medulla support blood pressure in spontaneously hypertensive rats, Hypertension. 35 (2000) 413-417. file://c/Users/Gustavo/Documents/1. Doutorado/5. Literatura/1. Artigos Hipertens?o/Ito (00) - Excitatory amino acids in the rostral ventrolateral medulla support blood pressure in spontaneously hypertensive rats.pdf.

[98] K. Mizutani, K. Sugimoto, T. Okuda, T. Katsuya, T. Miyata, T. Tanabe, J. Higaki, T. Ogihara, Y. Yamori, Y. Tsujita, N. Tago, N. Iwai, Kynureninase is a novel candidate gene 
for hypertension in spontaneously hypertensive rats., Hypertens. Res. 25 (2002) 135-40. doi:10.1291/hypres.25.135.

[99] Y. Zhang, K. Zhang, X. He, W. Yuan, G. Wang, S. Mao, P. Gao, W. Huang, D. Zhu, A polymorphism of kynureninase gene in a hypertensive candidate chromosomal region is associated with essential hypertension, Chinese J. Cardiol. 33 (2005) 588-591.

[100] Y. Zhang, J. Shen, X. He, K. Zhang, S. Wu, B. Xiao, X. Zhou, R. Phillips, P. Gao, X. Jeunemaitre, D. Zhu, A rare variant at the KYNU gene is associated with kynureninase activity and essential hypertension in the Han Chinese population, Circ. Cardiovasc. Genet. 4 (2011) 687-694. doi:10.1161/CIRCGENETICS.110.959064.

[101] H. Brkić, B. Kovačević, S. Tomić, Human 3-hydroxyanthranilate 3,4-dioxygenase (3HAO) dynamics and reaction, a multilevel computational study, Mol. Biosyst. 11 (2015) 898-907. doi:10.1039/c4mb00668b.

[102] D.M. Dick, J. Meyers, F. Aliev, J.J. Nurnberger, J. Kramer, S. Kuperman, B. Porjesz, J. Tischfield, H.J. Edenberg, T. Foroud, M. Schuckit, A. Goate, V. Hesselbrock, L. Bierut, Evidence for Genes on Chromosome 2 Contributing to Alcohol Dependence With Conduct Disorder and Suicide Attempts, Am J Med Genet B Neuropsychiatr. 153B (2010) 11791188. doi:10.1002/ajmg.b.31089.Evidence.

[103] F. Geller, B. Feenstra, L. Carstensen, T.H. Pers, I.A.L.M. van Rooij, I.B. Körberg, S. Choudhry, J.M. Karjalainen, T.H. Schnack, M. V Hollegaard, W.F.J. Feitz, N. Roeleveld, D.M. Hougaard, J.N. Hirschhorn, L. Franke, L.S. Baskin, A. Nordenskjöld, L.F.M. van der Zanden, M. Melbye, Genome-wide association analyses identify variants in developmental genes associated with hypospadias, Nat. Genet. 46 (2014) 957-963. doi:10.1038/ng.3063.

[104] I.P. Lapin, Kynurenines and Seizures, Epilepsia. 22 (1981) 257-265. doi:10.1111/j.15281157.1981.tb04108.x. 
[105] M. Amaral, T.F. Outeiro, N.S. Scrutton, F. Giorgini, The causative role and therapeutic potential of the kynurenine pathway in neurodegenerative disease, J. Mol. Med. 91 (2013) 705-713. doi:10.1007/s00109-013-1046-9.

[106] J.F. Martí-Massó, A. Bergareche, V. Makarov, J. Ruiz-Martinez, A. Gorostidi, A.L. De Munain, J.J. Poza, P. Striano, J.D. Buxbaum, C. Paisán-Ruiz, The ACMSD gene, involved in tryptophan metabolism, is mutated in a family with cortical myoclonus, epilepsy, and parkinsonism, J. Mol. Med. 91 (2013) 1399-1406. doi:10.1007/s00109-013-1075-4.

[107] S.I. Fukuoka, K. Ishiguro, K. Yanagihara, A. Tanabe, Y. Egashira, H. Sanada, K. Shibata, Identification and expression of a cDNA encoding human alpha-amino-betacarboxymuconate-epsilon-semialdehyde decarboxylase (ACMSD): A key enzyme for the tryptophan-niacine pathway and "quinolinate hypothesis," J. Biol. Chem. 277 (2002) 35162-35167. doi:10.1074/jbc.M200819200.

[108] M.A. Nalls, V. Plagnol, D.G. Hernandez, M. Sharma, U.M. Sheerin, M. Saad, J. SimónSánchez, C. Schulte, S. Lesage, S. Sveinbjörnsdóttir, K. Stefánsson, M. Martinez, J. Hardy, P. Heutink, A. Brice, T. Gasser, A.B. Singleton, N.W. Wood, Imputation of sequence variants for identification of genetic risks for Parkinson's disease: A metaanalysis of genome-wide association studies, Lancet. 377 (2011) 641-649. doi:10.1016/S0140-6736(10)62345-8. 


\section{Figure legends}

Figure 1.

An overview of the KP. The metabolites are indicated with full name. The names of the enzymes are given in abbreviated forms. Diseases for which association of genetic alteration(s) resulting in malfunction of a particular enzyme has been investigated are listed with references. (Bold: association have been found)

Abbreviations: IDO1,2: Indoleamine-2,3-dioxygenase 1,2; TDO2: Tryptophan 2,3-dioxygenase; KAT: Kynurenine aminotransferase; KMO: Kynurenine 3-monooxygenase / Kynurenine 3Hydroxylase; KYNU: Kynureninase/L-Kynurenine Hydrolase; 3-HAO: 3-hydroxyanthranilate 3,4-dioxygenase; ACMSD: Aminocarboxymuconate semialdehyde decarboxylase/Picolinate carboxylase; NAD+: Nicotinamide adenine dinucleotide

\section{Figure 2.}

The role of IDO1 in immune regulation

IDO1 expression can be enhanced by cytokines (IL-1, IL-2, IL-4, IL-13, TNF $\alpha$, TGF $\beta$, IFN $\alpha / \beta / \gamma$ ) and lipopolysaccharides (LPS). IDO1 induction leads to a decrease in tryptophan amount and the formation of kynurenine metabolites. By activating regulatory $\mathrm{T}$ cells, and via the inhibition of effector T cells and natural killer cells, IDO1 plays an important role in the maintenance of immune homeostasis, tumor immunity and in the suppression of fetal rejection and autoimmunity. 

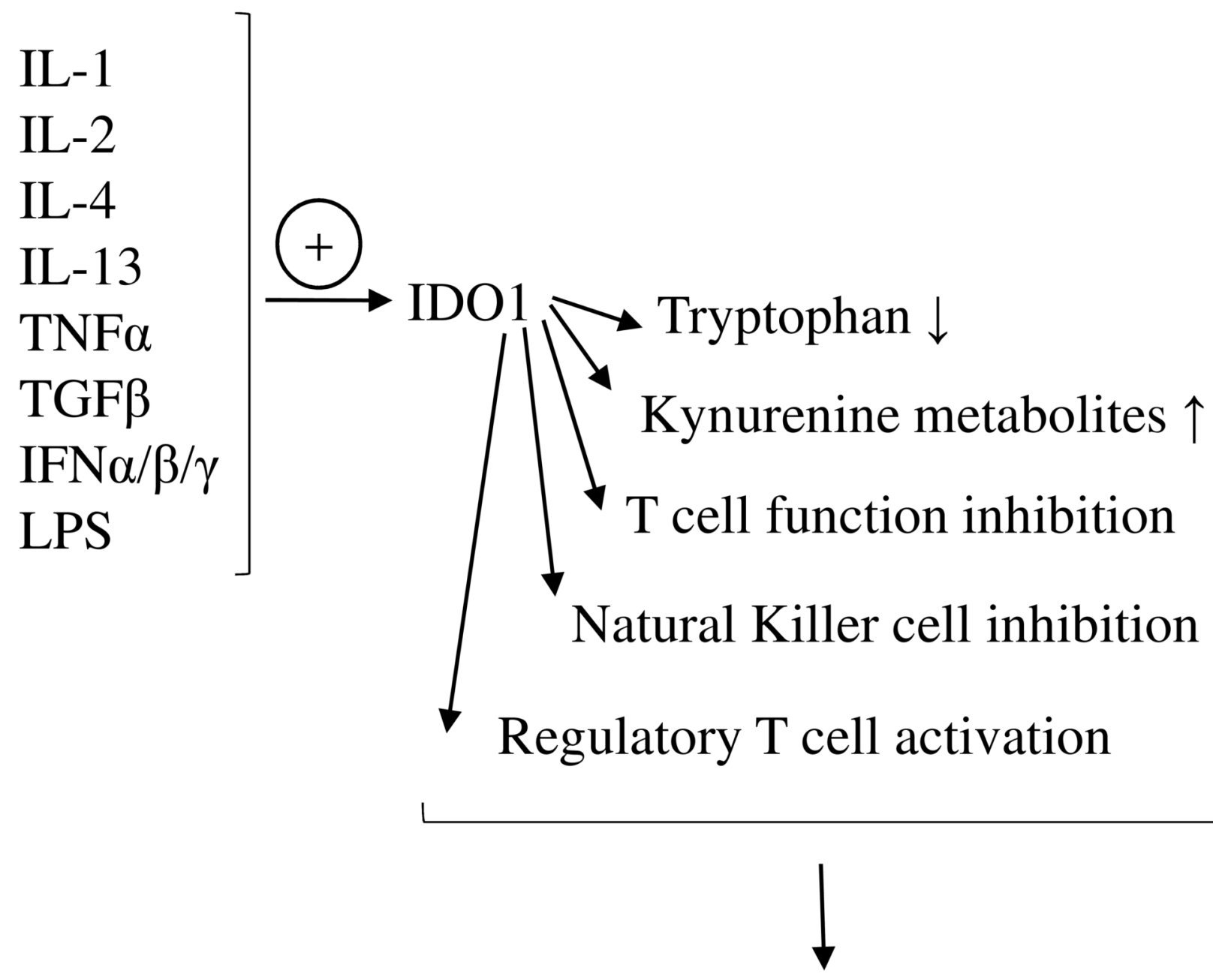

- Immune homeostasis

- Tumor immune escaping

- Fetal rejection suppression

- Autoimmunity suppression 
- IFN- $\alpha$-induced depression $[11,36]$

- Crohn's Disease [37]

- Systemic sclerosis [38]

- Pre-eclampsia [40]

- Recurrent spontaneous abortion [41]

- Pancreatic ductal adenocarcinoma [42]

- Major depressive disorder treatment outcome [45]

$\mid$

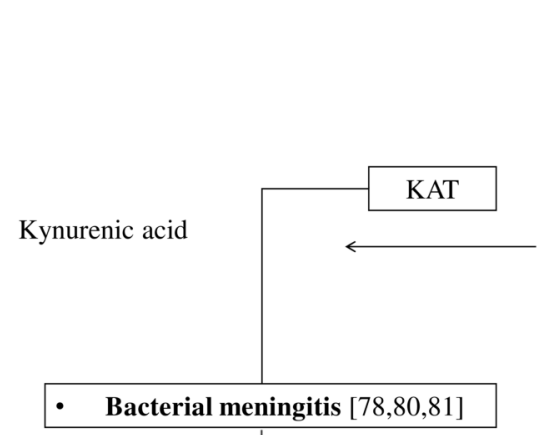

L-formyl-kynurenine

- Tourette syndrome [48]

- Attention deficit hyperactivity disorder [48,50]

- Drug dependence [49,59]

- Autism [67]

- Hypertryptophanemia [68]

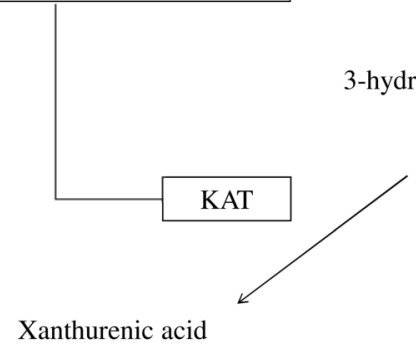

L-kynurenine

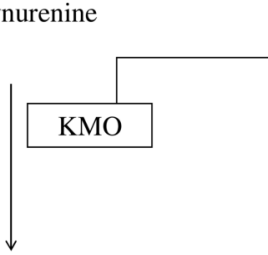

- Schizophrenia $[90,91,92,93,94,96]$

- Bipolar disorder [97]

- Multiple sclerosis [99]

- Parkinson's disease [98]

- Postpartum depressive symptoms [86]

3-hydroxy-L-kynurenine

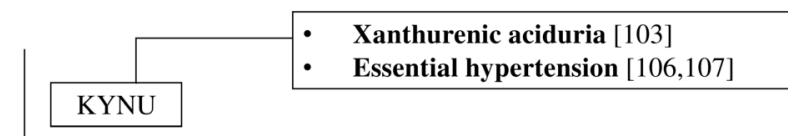

3-hydroxyanthranilic-acid

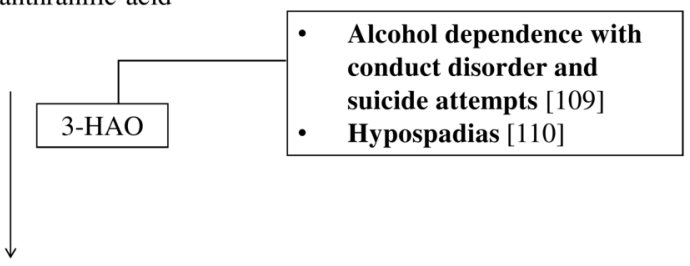

2-amino-3-carboxymuconate-semialdehide

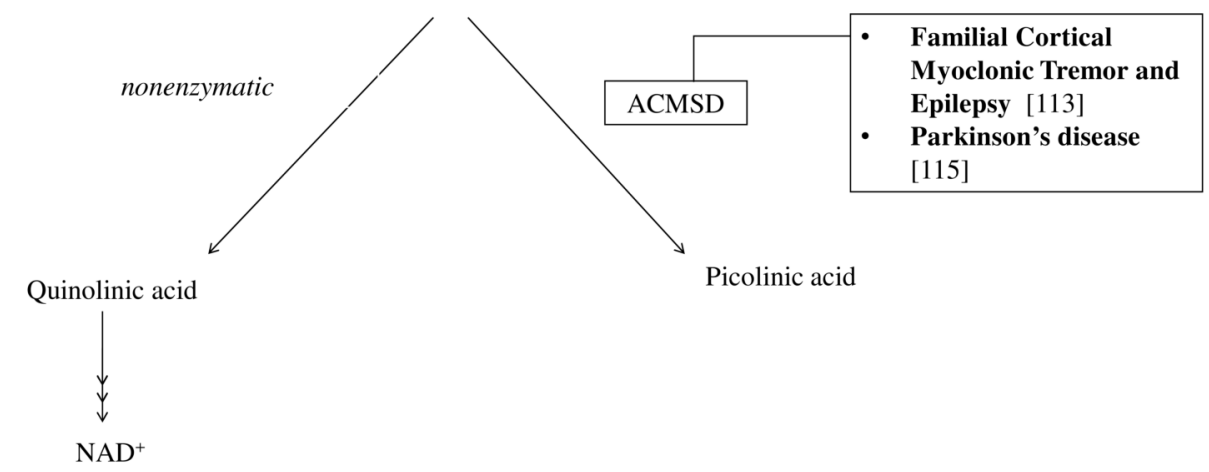

